\title{
WestVirginiaUniversity
}

THE RESEARCH REPOSITORY @ WVU

Graduate Theses, Dissertations, and Problem Reports

2018

\section{Form in the Music of John Adams}

\author{
Michael Ridderbusch \\ West Virginia University, mridder@wvu.edu
}

Follow this and additional works at: https://researchrepository.wvu.edu/etd

\section{Recommended Citation}

Ridderbusch, Michael, "Form in the Music of John Adams" (2018). Graduate Theses, Dissertations, and Problem Reports. 6503.

https://researchrepository.wvu.edu/etd/6503

This Dissertation is protected by copyright and/or related rights. It has been brought to you by the The Research Repository @ WVU with permission from the rights-holder(s). You are free to use this Dissertation in any way that is permitted by the copyright and related rights legislation that applies to your use. For other uses you must obtain permission from the rights-holder(s) directly, unless additional rights are indicated by a Creative Commons license in the record and/ or on the work itself. This Dissertation has been accepted for inclusion in WVU Graduate Theses, Dissertations, and Problem Reports collection by an authorized administrator of The Research Repository @ WVU.

For more information, please contact researchrepository@mail.wvu.edu. 
Form in the Music of John Adams

Michael Ridderbusch

DMA Research Paper submitted

to the College of Creative Arts

at West Virginia University

in partial fulfillment of the requirements for the degree of

Doctor of Musical Arts in

Music Theory and Composition

Andrew Kohn, Ph.D., Chair

Travis D. Stimeling, Ph.D.

Melissa Bingmann, Ph.D.

Cynthia Anderson, MM

Matthew Heap, Ph.D.

School of Music

Morgantown, West Virginia

2017

Keywords: John Adams, Minimalism, Phrygian Gates, Century Rolls, Son of Chamber Symphony, Formalism, Disunity, Moment Form, Block Form Copyright $\odot 2017$ by Michael Ridderbusch 


\section{ABSTRACT \\ Form in the Music of John Adams}

\section{Michael Ridderbusch}

The American composer John Adams, born in 1947, has composed a large body of work that has attracted the attention of many performers and legions of listeners. In addition, this work has drawn the attention of scholars intent on understanding its historical and theoretical context.

Among the theoretical writings are two papers by Catherine Pellegrino: Formalist Analysis in the Context of Postmodern Aesthetics: The Music of John Adams as a Case Study of 1999, and its offshoot article Aspects of Closure in the Music of John Adams of 2002. In these writings she conducts analyses of music by John Adams in order to determine if it is understandable in terms of formalist musical analysis, specifically by the metrics of closure and hierarchy. Closure is attained through pattern-completion. Hierarchy is attained through organic generation of surface content from background content of a single idea; Schenkerian theory and analysis is the classic means of demonstrating this.

Pellegrino ultimately determines that Adams "problematizes closure," and when she attempts to abstract the large scale tonal organization of a number of works by Adams in order to determine if a logical hierarchy is consistently operative, she asserts that the analyses fall short "with regard to the requirement of comprehensiveness."

In addition, music composed by John Adams later in his career can be characterized as disunified as a consequence of an intuitive compositional approach documented by researcher K. Robert Schwarz, and demonstrated through analyses by Pellegrino. For Pellegrino, these disunified works are inaccessible via the methods of formalist analysis, nor is there a good theory of disunified music to apply to them as well.

The purpose of this research paper is to demonstrate that there is music by Adams that is formalist, specifically Phrygian Gates (1977-1978), and that its formalism can be corroborated by testing for closure and hierarchy by analytical means.

The purpose of this paper is also to show how works by Adams that are non-formalist and disunified can be rendered analytically accessible. This will be accomplished by first determining the goals appropriate for analyzing disunified music, and by providing a historical context for disunified music in practice and theory; and secondly by creating a method for analyzing non-formalist music, applying the method to two works by Adams, 
including Century Rolls (1996) and Son of Chamber Symphony (2007), and summarizing the results. 


\section{Acknowledgements}

I extend thanks to my advisor Dr. Andrew Kohn for his patient and astute guidance during the research and writing of this paper on the music of John Adams. Any merit that may be found in the results are in large measure due to him.

I am also thankful for the guidance of Dr. Matthew Heap in matters of composition, and in assisting with the final editing of my paper.

I am grateful for financial assistance from the Dissertation Research Support Program at WVU for helping me with translation work.

I must thank Dr. John Beall for sharing his extensive knowledge of compositional craft; Dr. David Taddie for teaching and demonstrating the possibilities that technology can have for enlarging the scope of musical creativity; and Dr. C. B. Wilson for his engaging course on the history of orchestration, and for the latitude to choose my research projects.

Finally, I must also extend thanks to Dr. Christopher Wilkinson for the high standards he held me to when researching and writing history; and to Dr. John E. Crotty for his insightful lectures on theory that further kindled my interest in the subject. 


\section{Table of Contents}

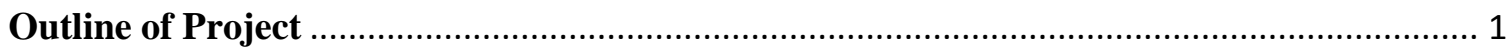

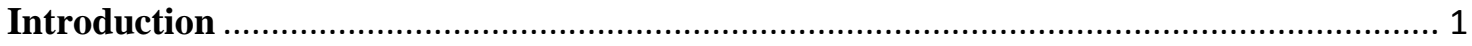

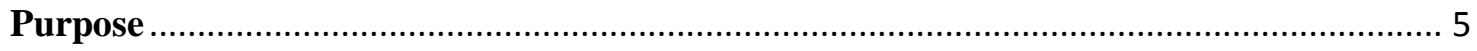

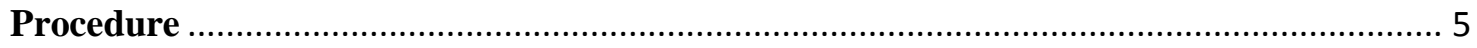

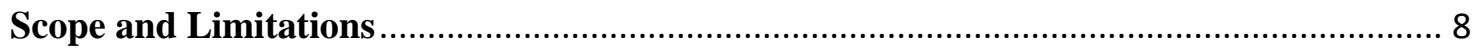

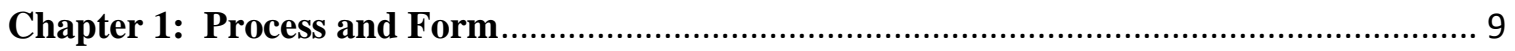

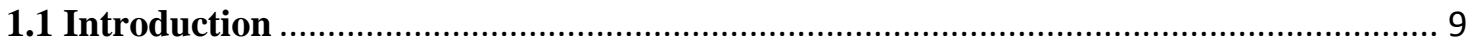

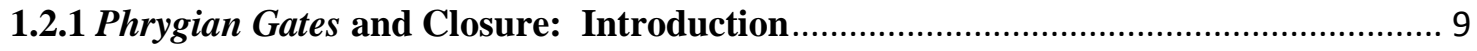

1.2.2 Phrygian Gates and Closure: Classic-Romantic Formal Rhetoric and Minimalist

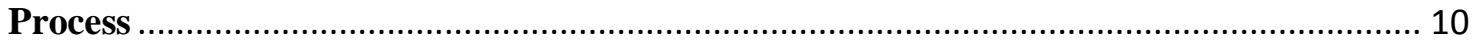

1.2.3 Phrygian Gates and Closure: Tonality as a Problem .............................................. 11

1.2.4 Phrygian Gates and Closure: Tonality as a Solution .............................................. 13

1.2.5 Phrygian Gates and Closure: Modernist Appropriation of Tonality ....................... 16

1.3.1 The Music of Adams and Hierarchy: An Introduction ......................................... 18

1.3.2 Phrygian Gates and Hierarchy: A Post-Tonal Lens.................................................. 19

1.3.3 Phrygian Gates and Hierarchy: A Post-Tonal Lens - Summary ............................ 24

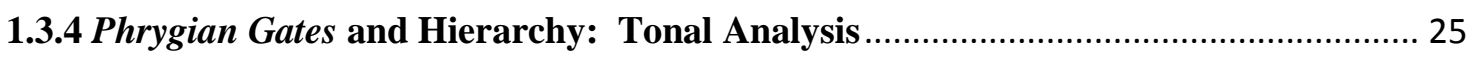

1.3.5 Phrygian Gates and Hierarchy: Formal Analysis .............................................. 28

1.3.6 Phrygian Gates and Hierarchy: Special Considerations ….................................... 31

1.4 Phrygian Gates, Closure and Hierarchy: Summary ................................................. 35

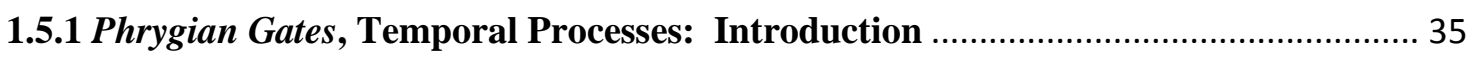

1.5.2 Phrygian Gates, Temporal Processes: Large Scale .................................................. 35

1.5.3 Phrygian Gates, Temporal Processes: Small Scale.................................................. 38

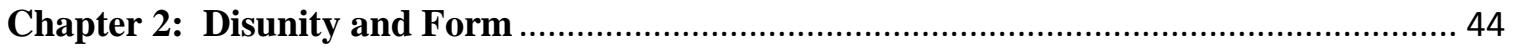

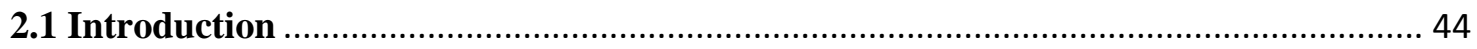

2.2 Formalism in Tonal and Post-Tonal Practice .......................................................... 45

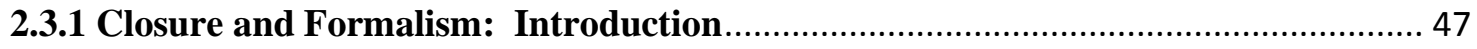

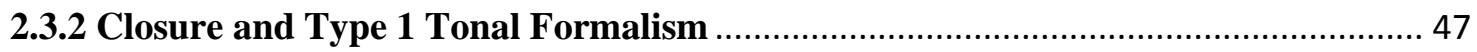

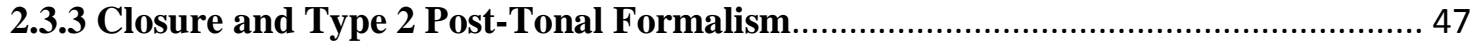

2.3.4 Closure and Type 3 Post-Tonal Non-Formalism .................................................... 48

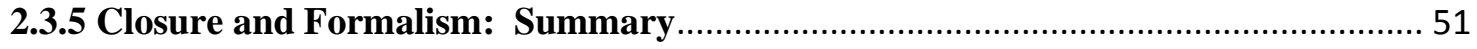

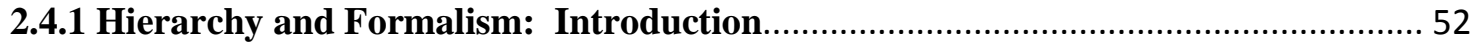

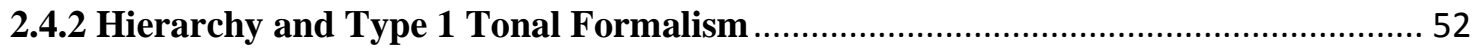

2.4.3 Hierarchy and Type 2 Post-Tonal Formalism ..................................................... 53 
2.4.4 Hierarchy and Type 3 Post-Tonal Non-Formalism ............................................ 66

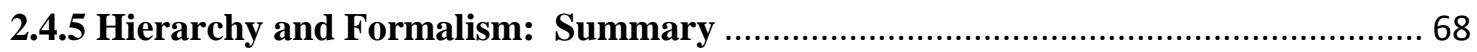

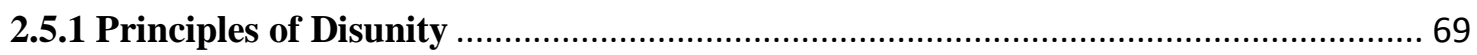

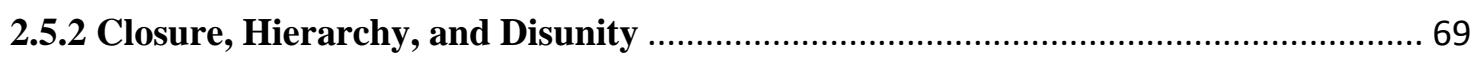

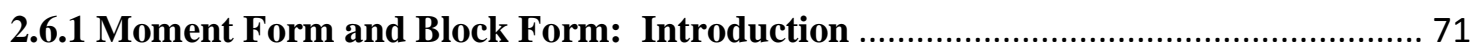

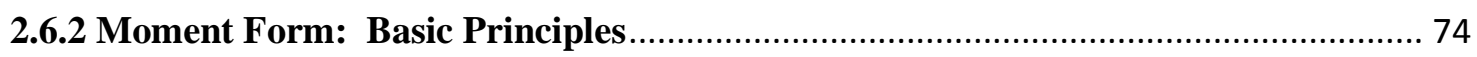

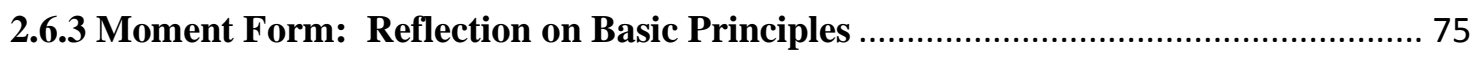

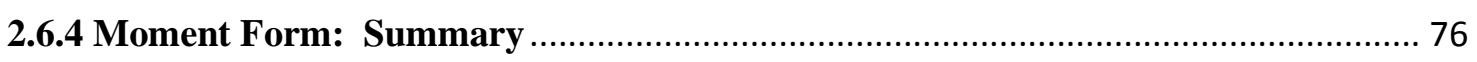

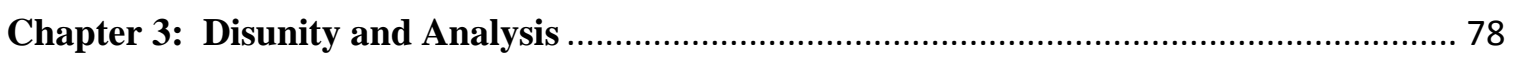

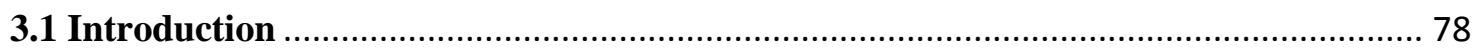

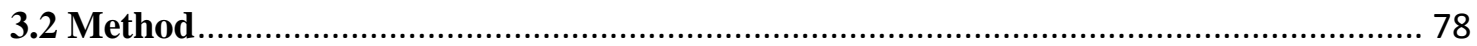

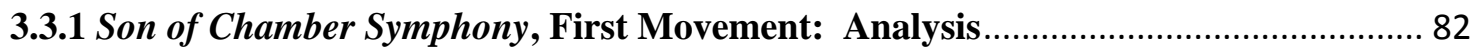

3.3.2 Son of Chamber Symphony, First Movement: Summary ….................................... 92

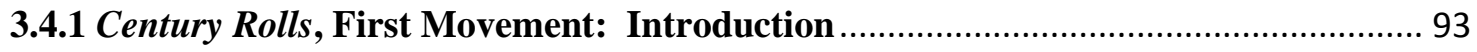

3.4.2 Century Rolls, First Movement: Concerto Form ................................................... 93

3.4.3 Century Rolls, First Movement: Thematic Disunity ............................................. 96

3.4.4 Century Rolls, First Movement: Within and Between Blocks.................................. 98

3.4.5 Century Rolls, First Movement: Stratification ................................................... 101

3.4.6 Century Rolls, First Movement: Additional Considerations .................................. 107

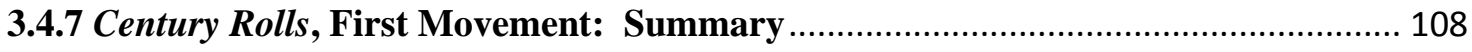

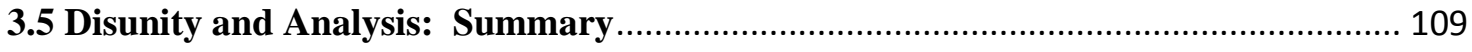

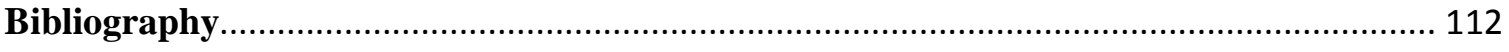




\section{Outline of Project}

\section{Introduction}

\section{Status of Adams}

The American composer John Adams has composed a large body of work that has attracted the attention of many performers and legions of listeners. Its success in the concert hall, in selling recordings, and in drawing journalistic attention signals the music's viability as a significant force in American classical music culture. In addition, this body of work has drawn the attention of scholars intent on understanding its historical and theoretical context. Since 1990, at least 12 substantive journal articles and 20 doctoral dissertations have been written focusing on developing a theoretical understanding of these works.

\section{Formalism, Closure, and Hierarchy}

My project began with reading all of the available theoretical papers regarding the music of John Adams that were accessible to me at that time. Among the writings were two papers by Catherine Pellegrino that were particularly thought provoking for me. This is due to their engagement with the modernist music of Adams with formalist analytical tools designed for understanding either the Classic-Romantic repertoire via Schenkerian analysis, or the motivic or serial repertoire via Forte set theory. I was curious to see where these tools would have utility for explanation, where they would fall short, and if the results could shed light on the music of Adams. These writings include her dissertation, Formalist Analysis in the Context of Postmodern Aesthetics: The Music of John Adams as a Case Study of 1999, and its offshoot article Aspects of Closure in the Music of John Adams of 2002. ${ }^{1}$ In these papers Pellegrino examines the relevance and effectiveness of formalist

\footnotetext{
${ }^{1}$ Catherine Ann Pellegrino, "Formalist Analysis in the Context of Postmodern Aesthetics: The Music of John Adams as a Case Study" (PhD diss., Yale University, 1999).

Catherine Pellegrino, "Aspects of Closure in the Music of John Adams," Perspectives of New Music, vol. 40, no. 1 (January 1, 2002): 147-175.
} 
analysis (also described as "traditional analysis") for providing an explanation of the organization of the music of John Adams. The study was motivated by the apparent conflict between the architecture of formalist modern music and minimalist music, the former premised on hierarchical layers abstracted from the surface of the music, the latter, in its purest sense, based on "a compositional process and a sounding music that are one and the same thing," according to Steve Reich, a leading composer in the minimalist style. ${ }^{2}$ In order to clarify the concept of hierarchical layers in music, Pellegrino quotes theorist Nicholas Cook, who states that formalist analysis is "a belief that any musical form is the expansion of a kernel structure of some kind, an expansion that works hierarchically according to more or less strict rules — so that the analyst's job becomes one of working out just what these rules are in any given case." 3 Since formalist analysis can reveal layers of hierarchy, its application to the early minimalist influenced music of Adams would reveal the extent to which this music still participates in the modernist aesthetic, as measured by the relative success of the analytical method. In this way, the metric of formal hierarchy could be a lens by which to observe the evolution of minimalism, a style that Adams engaged with in the late 1970s, a full decade after its emergence in the 1960s. Application of this metric could also facilitate assessment of the utility of formalist analysis for investigating music influenced by minimalism.

In addition to "hierarchy," Pellegrino also applies the criteria of "closure" to her analyses of the music of Adams. Based on the work of Robert G. Hopkins, she describes closure as "the sense of a satisfactory conclusion that comes with the anticipated arrival at a state of comparative repose following tension or activity." 4 To enable objective evaluation of closure, Pellegrino adopts the analytical method of identifying a musical pattern in a composition, specifically a tonal pattern, ${ }^{5}$ and then assessing whether it reaches

\footnotetext{
2 Steve Reich, "Music as a Gradual Process," In Perceptible Processes: Minimalism and the Baroque, ed. Claudia Swan (New York: Eos Music, 1997), 55-58. This writing was authored in 1968.

${ }^{3}$ Nicholas Cook, A Guide to Musical Analysis (New York: W.W. Norton, 1987), 118-119. Quoted in Pellegrino, "Formalist Analysis," 3.

${ }^{4}$ Robert G. Hopkins, Closure and Mahler's Music: The Role of Secondary Parameters (Philadelphia: University of Pennsylvania Press, 1990), 4.

${ }^{5}$ In her dissertation, Pellegrino cites theorist Joseph Straus as a source for the idea of "patterncompletion": Joseph Straus, "A Principle of Voice Leading in the Music of Stravinsky," Music Theory Spectrum, vol. 4 (Spring 1982): 106-124.
} 
completion. ${ }^{6}$ This implies a strategy premised on the logic that an "anticipated arrival" is understood to be the result of an expectation resulting from a perceived pattern moving toward completion over time.

The experiment she designed is a logical response to a new music in the way that it tests the unknown with the known. By testing for hierarchy and closure, the objects of her study, she is determining the extent to which minimalist music, and specifically the music of Adams, is consistent with the formalist values of the major theoretical methodologies currently in practice, including Schenkerian theory and set theory. ${ }^{7}$

In the conclusion of her dissertation, she describes formalism as an "underlying aesthetic that values hierarchical structure, coherence, closure, and perhaps most of all, unity, and formalism requires of any analysis that it be comprehensive." ${ }^{8}$ Of these values, the ones most specifically addressed by her article and dissertation, as indicated, are closure and hierarchical structure, and the extent to which they provide a comprehensive explanation of the music.

She ultimately determines that Adams "problematizes closure, ${ }^{19}$ and when she attempts to abstract the large scale tonal organization of a number of works by Adams in order to determine if a logical hierarchy is consistently operative, she also asserts that the analyses fall short "with regard to the requirement of comprehensiveness." ${ }^{10}$ More specifically, she says that "where the analytical methods ... work, they work well. The problem with the analytical method ... arises with the amount of music that it is not capable of explaining." 11

\footnotetext{
${ }^{6}$ Pellegrino, "Aspects of Closure," 148.

7 Pellegrino, "Formalist Analysis, " 1.

8 Pellegrino, "Formalist Analysis," 293.

9 Pellegrino, "Formalist Analysis," 291.

10 Pellegrino, "Formalist Analysis," 291.

11 Pellegrino, "Formalist Analysis," 291.
} 
3. Non-Formalism, Disunity, and Analysis

The analyses in chapters 2 and 3 of Pellegrino's dissertation, and the conclusions she derives from those analyses that are outlined in chapter $4,{ }^{12}$ largely indicate that the music of Adams cannot be explained by traditional formalist analysis. A key observation she brings into evidence concerns the increasing role of intuition and the decreasing role of systemization in the compositional process of Adams, as documented by K. Robert Schwarz in his 1990 article Process vs. Intuition in the Recent Works of Steve Reich and John Adams. ${ }^{13}$ This trend began after the rigorous, process oriented architecture of Phrygian Gates, ${ }^{14}$ and the change in compositional procedure this entailed is underscored by words of the composer himself:

I'm not the kind of composer who ... previsages the entire structure of a piece in advance. I like to feel that each composition is a voyage of discovery .... So, in a certain sense, I feel the structure as I'm creating it -- as if an architect were building on an empty site without a blueprint. ${ }^{15}$

For Schwarz, this shift of emphasis from system to intuition is seemingly problematic, in that the "purity of the process is compromised by an approach that 'feels' the structure rather than allowing the structure to 'work itself out'."16 And for Pellegrino, the musical forms engendered by this shift in compositional methodology are characterized by "disunity," thus rendering them inaccessible to the analytical methods of formalist analysis. ${ }^{17}$ These disunified forms could be made accessible through an analytical method tailored to disunity, but at the time she wrote her dissertation in 1999, she claimed that there were no good theories for disunified music. ${ }^{18}$

\footnotetext{
12 Pellegrino, "Formalist Analysis," 268-286.

13 Pellegrino, "Formalist Analysis," 276.

${ }^{14}$ K. Robert Schwarz, "Process vs. Intuition in the Recent Works of Steve Reich and John Adams,"

American Music: A Quarterly Journal Devoted to all Aspects of American Music and Music in America, vol.

8, no. 3 (September 1, 1990): 259.

${ }^{15}$ Schwartz, "Process vs. Intuition," 261.

${ }^{16}$ Schwartz, "Process vs. Intuition," 261.

17 Pellegrino, "Formalist Analysis," 268-277.

18 Pellegrino, "Formalist Analysis," 272.
} 


\section{Purpose}

The purpose of this research paper is to demonstrate that there is music by Adams that is formalist, specifically Phrygian Gates (1977-1978), and that its formalism can be corroborated by testing for closure and hierarchy by analytical means. Adams himself said that his first two mature works influenced by the minimalist style, Phrygian Gates (19771978) and its earlier companion piece China Gates (1977), "were the most strictly organized, rigorously ordered works I ever composed. They also demonstrated the fruits of my initiation to Minimalism." ${ }^{19}$ Although Pellegrino evaluated Phrygian Gates as a work in which "closure is problematized," 20 the composer's profession of strict organization and rigorous order evokes, alternatively, a terminology consistent with formalist values, since strictness and rigor strongly imply comprehensiveness, a feature required of a musical architecture consistent with such values.

This paper will also show how works by Adams that are non-formalist and disunified can be rendered analytically accessible. This will be accomplished by first determining the goals appropriate for analyzing disunified music, and by providing a historical context for disunified music in practice and theory; and secondly by creating a method for analyzing non-formalist disunified music, and applying the method to two works by Adams, including Century Rolls (1996) and Son of Chamber Symphony (2007), and summarizing the results.

\section{Procedure}

Chapter 1 will address formalism in the music of Adams by demonstrating how closure and hierarchy are operative in Phrygian Gates.

The music of Phrygian Gates will first be revealed as formalist in terms of closure. This will be accomplished by distinguishing a cycle of fifths (a pattern that Phrygian Gates does

\footnotetext{
19 John Adams, Hallelujah Junction: Composing an American Life (New York: Farrar, Straus \& Giroux, 2008), 88-89.

${ }^{20}$ Pellegrino, "Aspects of Closure," 169.
} 
not complete) from a diatonic cycle (a pattern that Phrygian Gates does complete). (This is covered in sections 1.2.3 and 1.2.4.)

The music of Phrygian Gates will then be revealed as formalist in terms of hierarchy. This will be accomplished by first reviewing the content of four writings by music theorist Joseph Straus in order to establish analytical concepts that will aid in analyzing the hierarchical structure of Phrygian Gates. (This is covered in sections 1.3.2 and 1.3.3.) These include:

1. "large scale tonal coherence" or symmetry across scale,

2. "pattern-completion",

3. "establishing harmonic areas", and

4. viability of diatonic content in a post-tonal context.

With these concepts in place, an analysis of Phrygian Gates will be conducted to demonstrate its comprehensive "large scale tonal coherence" in the way it deploys a sequence of diatonic sets, or "harmonic areas," that hierarchically express a single diatonic set (in section 1.3.4). In addition, this hierarchy will be shown to be complemented by other musical elements, such as dynamics, textures, and rhythm, etc. (in section 1.3.5).

Finally, detailed research by Kyle Fear regarding the role of rhythm in the form of Phrygian Gates will be presented and commented on to further substantiate the case of formalism in the design of Phrygian Gates (in sections 1.5.1, 1.5.2, and 1.5.3).

Chapter 2 will identify goals appropriate for analyzing disunified music, and provide a historical context for disunified music in practice and theory.

The identification of analytical goals will be accomplished by systematically surveying how closure and hierarchy are operative in each of three tonal practices. (This is covered in sections 2.3 through 2.4.) These practices include: 
1. tonal formalism (informed by Schenkerian theory),

2. post-tonal formalism (informed by the set theory of Forte), and

3. post-tonal non-formalism.

By seeing how closure and hierarchy become inoperable in a post-tonal non-formalist context, we can also see the necessity and utility for what can replace them:

1. instead of closure, we can employ the metric of balance between unity and disunity on a continuum;

2. instead of the prolongation of a hierarchy, we identify sections arranged in a flat, nonhierarchical sequence; and

3. content and its recurrence can be tracked through association and stratification.

These substitutions, or principles of disunity, were derived from my readings of Jonathan Cross and Joseph Straus (discussed in sections 2.3.4 and 2.4.4 respectively, and summarized in 2.5.1).

Providing a historical context for disunified music will be accomplished by engaging with the moment form theory created by Stockhausen in 1960. Since this theory is associated with the radically discontinuous music of the Darmstadt School, it seems like its applicability would therefore be constrained to the repertoire of its time and place. The theory, however, was inspired by the discontinuity of Debussy's late music from fifty years earlier; and its basic principles are flexible, as Stockhausen later admitted. This flexibility is demonstrated by the application of the theory to the analysis of late music by Debussy by Marianne Wheeldon ${ }^{21}$; the discontinuity manifest in at least some of the music of Adams, and the flexibility of the theory, invites a similar analytical approach to his music. (This is covered in sections 2.6.1 through 2.6.4).

Chapter 3 will outline a method for analyzing non-formalist disunified music, apply the method to two works by Adams, including the first movements from Century Rolls (1996) and Son of Chamber Symphony (2007), and summarize the results.

\footnotetext{
${ }^{21}$ Marianne Wheeldon, "Interpreting Discontinuity in the Late Works of Debussy," Current Musicology, no. 77 (Spring 2004): 97-115.
} 
Outlining a method for analyzing non-formalist music will be based on content in chapter 2 , including principles of disunity that resulted from the tonal practice survey (summarized in section 2.5.1, which is partly based on ideas of theorists Jonathan Cross and Joseph Straus), and on the basic principles of moment form theory, flexibly adapted (discussed in section 2.6). The resulting analytical method is organized into a sequence of steps, and includes explanations of basic analytical operations that can be performed (in section 3.2).

The method will then be applied to the first movements of Century Rolls and Son of Chamber Symphony to demonstrate its utility (in sections 3.3 and 3.4). These analyses will privilege thematic over harmonic content.

The summary at the end of chapter 3 (in section 3.5) will encompass the content of both chapters 2 and 3 in order to review the full range of discussion this paper contains on the nature of disunity in music and its implications for analysis.

\section{Scope and Limitations}

This study began with a review of current research featuring a theoretical perspective on the music of John Adams. My investigation into formalism and disunity in music, and their implications for analyzing the music of Adams, emerged from this review. Given the variety of compositional methods employed by Adams over his career, my analyses of Phrygian Gates (1977-1978), Century Rolls (1996), and Son of Chamber Symphony (2007)

in this paper may have a limited applicability to analyzing and understanding other works by him. 


\section{Chapter 1: Process and Form}

\subsection{Introduction}

This chapter will show how closure and a layered formal hierarchy are actually operative in Phrygian Gates, demonstrating the viability of formalist musical analysis for understanding the music of Adams. Close attention will be given to both closure (in section 1.2) and hierarchy (in section 1.3) to demonstrate the comprehensive application of these compositional strategies in the domain of pitch, followed by a summary (in section 1.4). In addition, a final section will show how Adams deployed rhythm to complement the formalist processes of this piece as well (in section 1.5).

\subsubsection{Phrygian Gates and Closure: Introduction}

In "Aspects of Closure in the Music of John Adams," Catherine Pellegrino describes her listening experience of formal closure in various works composed by John Adams as "problematic" in the way they concluded in an "abrupt and unprepared" manner. ${ }^{22}$ She then seeks to objectively identify the reasons for this experience through a systematic analysis of two major works by Adams, including Phrygian Gates (1977-78) and The Chairman Dances (1985). The methodology involves examining how "three categories of musical organization," ${ }^{23}$ namely tonality, form, and rhetoric, are deployed in these works to attempt closure. Tonality is ascribed special significance by Pellegrino because it offers the "most multifaceted perspective on the issue of closure," and because "form, as a closure-generating phenomenon, frequently collapses into tonal structure." 24 This discussion will be confined to her analysis of Phrygian Gates, specifically in its examination of the role of tonality and rhetoric in effecting formal closure, beginning with rhetoric.

\footnotetext{
22 Pellegrino, "Aspects of Closure," 147.

23 Pellegrino, "Aspects of Closure," 148.

${ }^{24}$ Pellegrino, "Aspects of Closure," 149.
} 


\subsubsection{Phrygian Gates and Closure: Classic-Romantic Formal Rhetoric and Minimalist Process}

Pellegrino characterizes the conclusion of Phrygian Gates as one providing "little or no rhetorical indication of closure at the end," and that it ends "loudly and abruptly." Although the concluding chord is held with a fermata to signal closure, arriving on this chord is an abrupt event, since prior to this arrival there is only an uninterrupted stream of block chords articulated by sixteenth note rhythms. ${ }^{25}$

If there is an impression of inconclusiveness when listening to Phrygian Gates, as claimed by Pellegrino, much of it has to do with the aesthetic, or rhetoric, of the Minimalist style. In the Classic-Romantic era, rhetorical gestures often involve a coordination of instrumental, dynamic, and textural elements to signal significant formal events. For example, a recurring trope in this style of music involves concluding a symphony with all instruments deployed, playing at a high dynamic level, and in rhythmic tandem, such as one finds at the end of Beethoven's works. Alternatively, in the "pure" Minimalist style of the 1960s and 1970s, there are no rhetorical gestures, at least as evidenced in the music of some of its major exponents, including Steve Reich (born 1936) and Philip Glass (born 1937) -- a musical work simply ends after compositional determinants involving systematic patterning of pitch and/or rhythm are played out. In the early works of Reich, for example, a system of "phasing" 26 determined musical content once a piece was launched; and in early works of Glass, additive or subtractive processes ${ }^{27}$ were systematically applied. In what can now perhaps be considered a classic manifesto of this aesthetic, "Music as a Gradual Process" 28 from 1968, Steve Reich simply proclaimed that "once the process is set up and loaded it runs by itself." While the music resulting from systematic processes can charm in its preclusion of rhetorical grandstanding, it can also simultaneously convey a logical, machine like severity, especially in the way forms of monumental length can be generated, such as in Music in 12 Parts (1974) by Glass, and Music for Eighteen Musicians

\footnotetext{
${ }^{25}$ Pellegrino, "Aspects of Closure," 168-169.

${ }^{26}$ Keith Potter, Four Musical Minimalists: La Monte Young, Terry Riley, Steve Reich, Philip Glass (New York: Cambridge University Press, 2000), 180-192.

27 Potter, Four Musical Minimalists, 270-273.

${ }^{28}$ Reich, "Music as a Gradual Process," 56.
} 
(1976) by Reich. John Adams has openly admitted to the influence of music by Reich and Glass from the 1970s, ${ }^{29}$ and its legacy of rigorous process dominate his first Minimalist works, China Gates and Phrygian Gates.

Although the endings to these types of works may sound upon first hearing to be abrupt or inconclusive, and thereby lacking appropriate formal rhetoric to signal closure, ${ }^{30}$ they are actually aesthetically consistent with their stylistic provenance, and are simply the result of the conclusion of musical processes. The "problematic" listening experience that Pellegrino describes probably results from having expectations of the music that are incongruent to its style, namely expecting fulfillment of Classic-Romantic rhetorical or formal conventions when the music is Minimalist with a process driven "convention." The evidence she supplies to objectify this claim is similarly incongruent to the object analyzed - her invocation of the writings of Barbara Herrnstein Smith and Robert G. Hopkins as evidence for a normative yardstick by which to evaluate the form of Minimalist music is inappropriate, since the aesthetic or formal goals discussed by Smith and Hopkins are different from those of Minimalism. ${ }^{31}$ According to Pellegrino, they propose that "the simple completion of a formal pattern cannot in and of itself produce closure." 32 This is, of course, precisely the methodology by which the formal goals of process generated Minimalist music are attained.

\subsubsection{Phrygian Gates and Closure: Tonality as a Problem}

Pellegrino's article "Aspects of Closure in the Music of John Adams" (2002) also documents her analysis of Phrygian Gates through the lens of tonal organization. Noting that there is evidence of tonal patterning in this work, her analytical strategy is to identify what patterns exist, and then to "determine whether or not those patterns are completed,

\footnotetext{
${ }^{29}$ Adams, Hallelujah Junction, 89-90.

30 Pellegrino, "Aspects of Closure," 168.

${ }^{31}$ Barbara Herrnstein Smith, Poetic Closure: A Study of How Poems End (Chicago: University of Chicago Press, 1968), 45-46. Hopkins, Closure and Mahler's Music, 15.

32 Pellegrino, "Aspects of Closure," 159.
} 
the completion of a pattern indicating a degree of tonal closure." ${ }^{33}$ One assumes that the absence of such patterning would be objective evidence corroborating her problematic experience of closure in Phrygian Gates.

After describing the tonal plan of the work, i.e. "a series of tonal centers in rising fifths, combined with alternating Lydian and Phrygian Modes"34 (for example, A Lydian and A Phrygian, followed by E Lydian and E Phrygian, etc., leading to a conclusion by the pairing of $\mathrm{E} b$ Lydian and $\mathrm{D} \approx$ Phrygian), she then declares that "this tonal pattern, while perfectly systematic, does not provide tonal closure for the work as a whole."35 Based on her subsequent statements, we learn that this assessment results from the work's failure to complete a tonal pattern within either 1) a system that defines its own endpoint or 2) "a system in which a given endpoint is already defined." ${ }^{36}$ Here she is making the well known distinction between music that is contextual, ${ }^{37}$ with a structure inferable primarily or entirely from within itself, and music that participates within a common practice, such as tonality, with a structure inferable from without, through works by other composers within the same practice. According to Pellegrino, Phrygian Gates fails both of these tests.

Considered from the perspective of contextuality, i.e. from what can be inferred from the music itself, Pellegrino asserts that "the only natural endpoint suggested by the pattern of mode and key center changes is the completion of the cycle of fifths, returning to the beginning point after cycling through the Lydian and Phrygian modes on each of the twelve pitch classes, but this is not where Phrygian Gates ends." 38 If the cycle of fifths is inferred as the system by which pattern-completion is to be gauged, as Pellegrino evidently does, then the tonal patterning of Phrygian Gates is indeed incomplete, since it traverses only seven of the twelve pitch classes in the cycle, including $A, E, B, F \#, C \sharp, G \sharp$, and $D \sharp$.

\footnotetext{
33 Pellegrino, "Aspects of Closure," 149.

34 Pellegrino, "Aspects of Closure," 149.

35 Pellegrino, "Aspects of Closure," 150.

${ }^{36}$ Pellegrino, "Aspects of Closure," 150.

${ }^{37}$ The term "contextual" was of vital importance to Milton Babbitt. See: Milton Babbitt, Milton Babbitt: Words About Music, ed. Stephen Dembski and Joseph N. Straus (Madison: University of Wisconsin Press, 1987), passim.

${ }^{38}$ Pellegrino, "Aspects of Closure," 150.
} 
Considered from the perspective of common practice, i.e. harmonic procedure in the Classic-Romantic era, the tonal plan of Phrygian Gates does not conform to the expectations of monotonality, in that "the overall tonal impression presented by this work is not the traditional 'journey' away from a 'home' key to 'foreign' territory and back again, but instead, a constantly progressing, though predictable, pattern of changing modal centers." ${ }^{39}$ She invokes the theorist Heinrich Schenker when asserting that in a tonal work, the tonic should be the "predefined endpoint" of a tonal journey, an expectation that Phrygian Gates manifestly does not fulfill. ${ }^{40}$

\subsubsection{Phrygian Gates and Closure: Tonality as a Solution}

A second examination of the evidence indicates that the tonal organization of Phrygian Gates does indeed complete a pattern, and therefore achieves closure of the work's harmonic process.

Although Pellegrino believes the tonal pattern to be incomplete based on only a partial rendering of the circle of fifths, as shown in Figure 1, it is actually complete, based on a full rendering of the diatonic sequence or cycle, as shown in Figure 2. Pitch class A, which begins the cycle, will be assumed to be a modal final, in which case the remaining six pitch classes in aggregate with the final spell the content of an A Lydian scale.

This tonal plan of Phrygian Gates is a system that defines its own endpoint, since its sequence of diatonic sets engender the single diatonic set, A Lydian, that governs the path of its tonal journey. Its harmonic process can therefore be viewed as contextual, i.e. inferred from within the music of Phrygian Gates itself.

\footnotetext{
${ }^{39}$ Pellegrino, "Aspects of Closure," 161.

${ }^{40}$ Pellegrino, "Aspects of Closure," 150.
} 
Figure 1. Tonal Organization of Phrygian Gates, by Circle of Fifths.

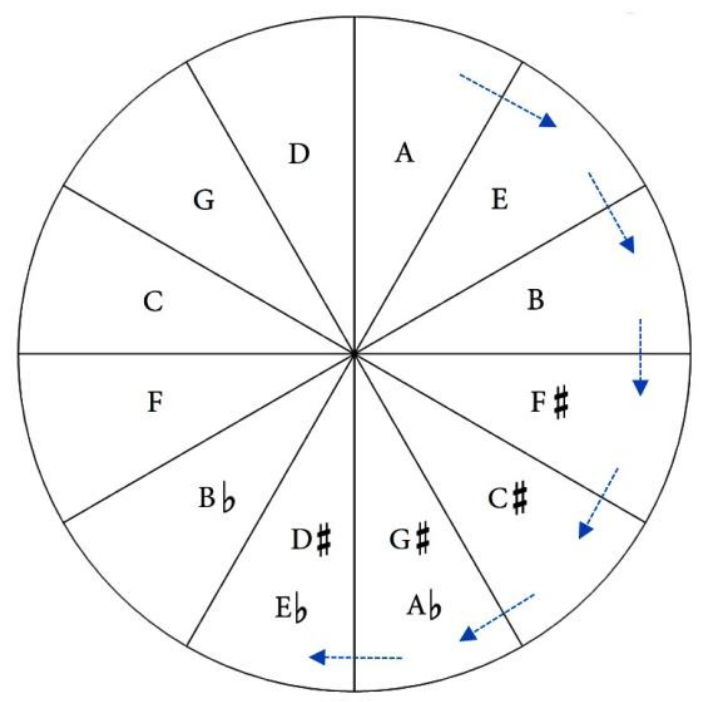

Figure 2. Tonal Organization of Phrygian Gates, by Diatonic Cycle.

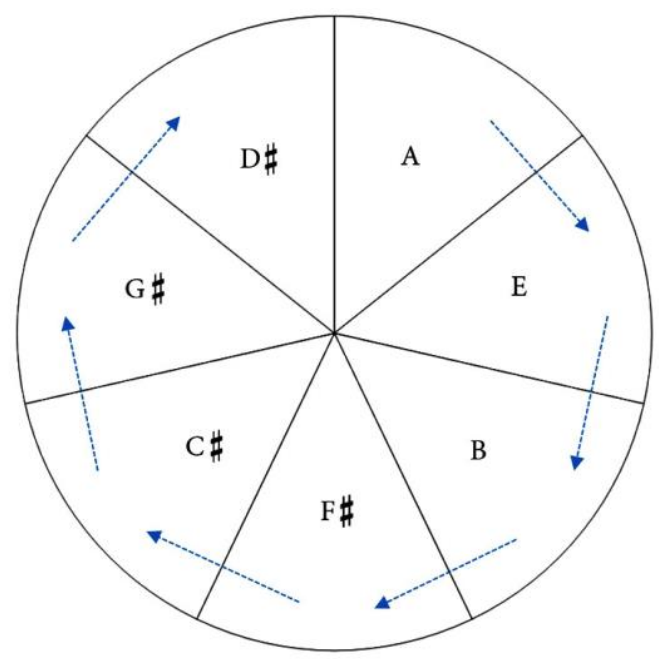

In addition, its harmonic process can also be viewed as inferable from without, in its dialogue, whether intentional or not, with late Classic-Romantic tonal procedures, or with what has been labeled the "second practice," in order to distinguish it from the earlier "common practice." 41 One of the key elements of this second practice is "progressive tonality," a term coined in 1947 by Dika Newlin in her book Bruckner, Mahler,

\footnotetext{
${ }^{41}$ A source that contributed to scholarly awareness of this topic is: William Kinderman and Harald Krebs, eds. The Second Practice of Nineteenth-Century Tonality (Lincoln: University of Nebraska Press, 1996).
} 
Schoenberg ${ }^{42}$ to designate the unusual compositional methodology found in some Mahler symphonies whereby a work concludes in a tonal center different from that with which it began. Such a method challenges the common practice tradition of monotonality as evidenced in the music of the early Classic-Romantic era, and as modeled in the theories of Schenker. Investigation into the compositional procedures of this "second practice" has received renewed emphasis since the 1970s through the work of Robert Bailey on the music of Wagner, who also adopted the terminology of "directional tonality" as an alternative to "progressive tonality," and further enriched the discourse with the related concept of the "double-tonic complex," among other discoveries. ${ }^{43}$ Bailey was an inspirational force, and others have followed his lead, including Bailey's student Christopher O. Lewis in his thorough analysis of Mahler's 9th Symphony, ${ }^{44}$ and Harald Krebs in his lucid and informative essay that surveys some of the tonal procedures operative in Carl Nielsen's symphonies, ${ }^{45}$ to name only two among many who continue to mine this vein of inquiry to the present day. ${ }^{46}$

It is within this "second practice" that the tonal plan of Phrygian Gates can be said to participate, a practice of substantial historical legacy shared by a community of composers with the goal of replacing centripetal monotonality with centrifugal tonal ambiguity or multiplicity.

\footnotetext{
42 Dika Newlin, Bruckner, Mahler, Schoenberg (New York: W. W. Norton, 1978), passim.

${ }^{43}$ Robert Bailey transmitted his influential ideas regarding directional tonality mostly through teaching, rather than publication. His writings include:

Robert Bailey, "The Structure of the 'Ring' and Its Evolution," 19th-Century Music, vol. 1, no. 1 (July 1977): 48-61.

Robert Bailey, ed., Prelude and Transfiguration from Tristan and Isolde (New York: Norton, 1985).

${ }^{44}$ Christopher Lewis, Tonal Coherence in Mahler's Ninth Symphony (Ann Arbor, Michigan: UMI Research Press, 1984).

45 Harald Krebs, "Tonal Structure in Nielsen's Symphonies: Some Addenda to Robert Simpson's Analyses," In The Nielsen Companion, ed. Mina Miller (Portland, Oregon: Amadeus Press, 1994), 208-249.

${ }^{46}$ Recent contributions to the field include, among others:

Boyd Pomeroy, "Tales of Two Tonics: Directional Tonality in Debussy's Orchestral Music," Music Theory Spectrum, vol. 26, no. 1 (2004): 87-118.

Benjamin Kay Wadsworth, "Directional Tonality in Schumann's Early Works," Music Theory Online, vol. 18, no. 4 (December 2012): 1-15, accessed March 24, 2015, http://www.mtosmt.org/issues/mto.12.18.4/mto.12.18.4.wadsworth.php
} 
Therefore when evaluated contextually, i.e. by a system that defines its own endpoint, the tonal organization of Phrygian Gates can be said to complete a tonal pattern, and thereby achieve formal closure through tonal means. When evaluated by standards of communal compositional practice (or "second practice"), i.e. by a system with predefined goals, the tonal organization of Phrygian Gates meets the goal of replacing tonal centricity with tonal plurality, and so by this method too, could be said to complete a tonal pattern. So finally, in contrast to Pellegrino's assessment, this alternative analysis reaches the conclusion that Phrygian Gates passes the test of achieving completion of a tonal pattern, and thereby also achieves tonal closure.

\subsubsection{Phrygian Gates and Closure: Modernist Appropriation of Tonality}

In addition to engaging with methods of tonal patterning characteristic of the "second practice" of the late Classic-Romantic era of music, Phrygian Gates can also be seen engaged with a formulaic tonal construct characteristic of both the Baroque and ClassicRomantic eras, the "sequence," albeit through a distorting lens. This lens, "centralization," is one of many transformational processes identified by author Joseph Straus in his book Remaking the Past.

In his book, Straus lucidly and systematically investigates the ways in which the musical material of the past is recast into new forms by composers of the first half of the 20th century. To that end, in the book's first chapter entitled "Toward a Theory of Musical Influence," he lists and describes an eight facet taxonomy of transformational processes which he claims to be a shared legacy for these composers, in spite of their stylistic differences. They include motivicization, generalization, marginalization, and centralization, among others. ${ }^{47}$

"Centralization," relevant to Phrygian Gates, is a process where "musical elements that are peripheral to the structure of the earlier work ... move to the structural center of the new

\footnotetext{
47 Joseph Straus, Remaking the Past: Musical Modernism and the Influence of the Tonal Tradition (Cambridge: Harvard University Press, 1990), 17.
} 
one." The musical element that undergoes transformation before its compositional application in Phrygian Gates is a diatonic sequence. Normally a foreground element that performs a transitional function, it transforms by process of centralization into a background structure that performs the function of governing the tonal scheme of the entire work - a radical rescaling of the same form from peripheral event to central musical feature.

The magnitude of this rescaling can be conveyed simply by comparing the size of a typical sequence to the transformed version manifested in Phrygian Gates. Example 1 illustrates a typical deployment of a diatonic sequence as foreground element, in descending fifths; Figure 2 illustrates the deployment of a diatonic sequence in Phrygian Gates as background structure, in ascending fifths; the former occupies 5 measures, the latter 1092.

Example 1. Bach, Organ Concerto in A Minor, BWV 593, mm. 5-9. Arrangement of Vivaldi Concerto for Two Violins in A Minor, F.1, n. 177. Typical diatonic sequence, in this instance by descending fifths. ${ }^{48}$
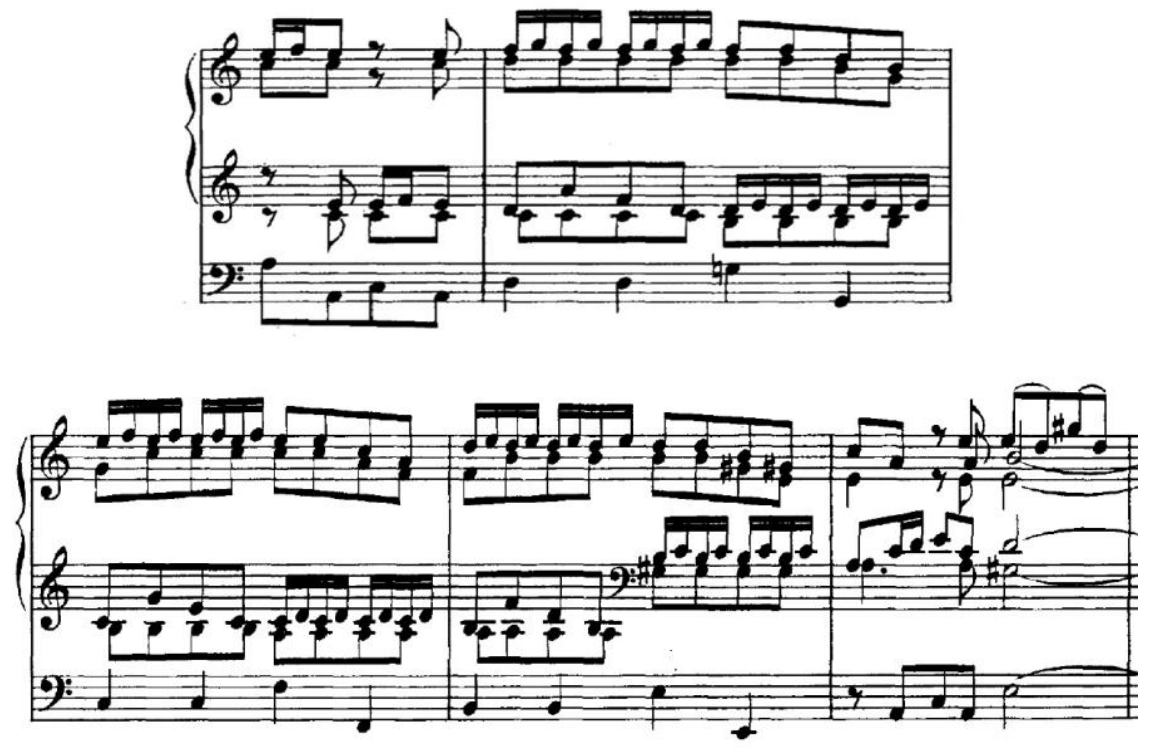

${ }^{48}$ For a systematic discussion of diatonic sequences, see: Edward Aldwell, Allen Cadwallader, and Carl Schachter, "Diatonic Sequences," in Harmony and Voice Leading (Boston: Schirmer, 2011), 301-329. 
Before Phrygian Gates of 1977-78, Steve Reich composed a work involving a similar radical rescaling of a simple tonal process. Like the extended sequence in Phrygian Gates, Reich extends an authentic cadence to a length of over 15 minutes in Four Organs of 1970. When interviewed, Reich described the piece as "the longest V-I cadence in the history of Western music."49 The connection between the two works provides possible evidence of Reich's influence on Adams, ${ }^{50}$ as previously noted, or at least documents their shared adaptation of traditional tonal constructs to new compositional contexts, a method characteristic of composers in the minimalist style at the time. In addition, it can be said that their practice of repurposing tonal artifacts joins them to the larger community of 20th century composers, as documented by Joseph Straus and so many others.

\subsubsection{The Music of Adams and Hierarchy: An Introduction}

In addition to closure, musical architecture consistent with formalist values should also be hierarchical. Pellegrino asserts that "analysis assumes that there are, or ought to be, levels of structure beneath the surface of the music." ${ }^{51}$ In making this point she also quotes theorist Jonathan Bernard in his article "Theory, Analysis, and the 'Problem' of Minimal Music," which addresses the differences between formalist music and minimalist music and the implications those differences have for analysis. Bernard notes that, whereas much of twentieth-century music presents "an intricate surface that can be penetrated only through the application of sophisticated analytical tools," minimalist music can frustrate such an analysis since "instead of richness, one encounters sparseness at the surface." 52 In this article Bernard analyzes music by Philip Glass and Steve Reich in their early "pure" minimalist style, and essentially reaches the conclusion that the forms of these works are

\footnotetext{
${ }^{49}$ Steve Reich, interview by Jonathan Cott, liner notes to Steve Reich: Works 1965-1995, Nonesuch 794512, CD, 1997, 33.

${ }^{50}$ Adams, Hallelujah Junction, 89-90. The openings of The Chairman Dances (1985) and Century Rolls (1996) by Adams, for example, are very similar to the opening of Music for 18 Musicians (1974-1976) by Reich, in that they share the same chord or set, short one pitch class, articulated by a repeating rhythmic value. The chord in Adams is (B-D-F\#-A-C\#-E); the chord in Reich is the same, except for the absence of $C \#$. 51 Pellegrino, "Formalist Analysis," 288.

52 Jonathan W. Bernard, "Theory, Analysis, and the 'Problem' of Minimal Music," In Concert Music, Rock, and Jazz since 1945: Essays and Analytical Studies, eds. Elizabeth West Marvin and Richard Hermann (Rochester: University of Rochester Press, 1995), 259.
} 
modular without depth, i.e. a sequence of logically related formal units without deeper structural layers informing the deployment of content onto the surface. ${ }^{53}$ Bernard also notes that to assume the tertian harmonic basis of later minimalist music also has the "hierarchical nature of common-practice tonality (if not its specific structures) may be assuming far too much." ${ }^{54}$ Since John Adams, a composer ten years younger than Glass and Reich, adopted the minimalist style after its evolution into a harmonically based music, his compositions invite an investigation like that conducted by Bernard, to determine the extent to which they can be understood hierarchically.

Where formal closure was validated through identifying a tonal pattern and then verifying its completion, hierarchy will be validated through identifying the layers of a composition and then verifying their comprehensiveness.

\subsubsection{Phrygian Gates and Hierarchy: A Post-Tonal Lens}

Pellegrino in her writings confined her analysis of Phrygian Gates to an investigation as to whether or not closure in a formalist sense is operative in its form, and determined that it wasn't. However, since my alternative analysis has shown closure to be operational in Phrygian Gates, there is merit in taking the additional step of demonstrating how hierarchy comprehensively informs the work's unfolding, and thereby confirm the work's status as a composition consistent with formalist values. In addition, the composer's testimony regarding the work's strict organization and rigorous order invites further scrutiny as well. ${ }^{55}$

The writings of Joseph Straus provide useful tools for conducting this type of analysis, and for facilitating the validation of hierarchy in this work. The aggregate of key ideas in four specific items can logically and effectively form a basis for understanding tonal structure in Phrygian Gates. These include:

\footnotetext{
53 Bernard, "Problem of Minimal Music," 274, 278.

54 Bernard, "Problem of Minimal Music," 284.

55 John Adams, Hallelujah Junction, 88-89. "Phrygian Gates and its smaller companion piece, China Gates ... were the most strictly organized, rigorously ordered works I ever composed."
} 
1. "A Principle of Voice Leading in the Music of Stravinsky" (1982), ${ }^{56}$

2. "The Problem of Prolongation in Post-Tonal Music" (1987), ${ }^{57}$

3. "Middleground Misreadings" in Remaking the Past: Musical Modernism and the

Influence of the Tonal Tradition (1990) ${ }^{58}$, and

4. "Centricity, Referential Collections, and Triadic Post-Tonality," in Introduction to Post-Tonal Theory (2005). ${ }^{59}$

In "A Principle of Voice Leading in the Music of Stravinsky," Straus demonstrates how pitch class sets, or motives, not only inform horizontal and vertical groupings at the surface, but also how those same sets govern content in what could be called the background, establishing a hierarchy that he describes as "large-scale tonal coherence." ${ }^{60}$ This suggests the possibility of structural hierarchy being rendered by a symmetry across scale, whereby content is replicated, or nested, between structural levels. Exemplars from the article clearly show this compositional method in operation on both the foreground and background, as shown in Examples 2 and 3.

Example 2. Stravinsky, Symphonies of Wind Instruments, $5 \mathrm{~mm}$ after Rehearsal $1 .{ }^{61}$

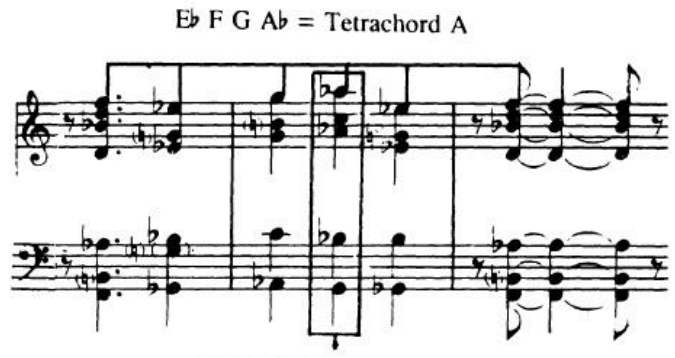

$\mathrm{G} A b \mathrm{~B} b \mathrm{C}=$ Tetrachord $\mathrm{A}$

56 Joseph Straus, "A Principle of Voice Leading," 106-124.

57 Joseph Straus, "The Problem of Prolongation in Post-Tonal Music," Journal of Music Theory, vol. 31, no. 1 (Spring 1987): 1-21.

58 Joseph Straus, "Middleground Misreadings," in Remaking the Past: Musical Modernism and the Influence of the Tonal Tradition (Cambridge: Harvard University Press, 1990), 169-185.

59 Joseph Straus, "Centricity, Referential Collections, and Triadic Post-Tonality," in Introduction to Post-

Tonal Theory (Upper Saddle River, New Jersey: Pearson Education, 2005), 130-181.

60 Joseph Straus, "A Principle," 110.

61 Joseph Straus, "A Principle," 107. 


\section{Example 3. Stravinsky, Symphonies of Wind Instruments. ${ }^{62}$}

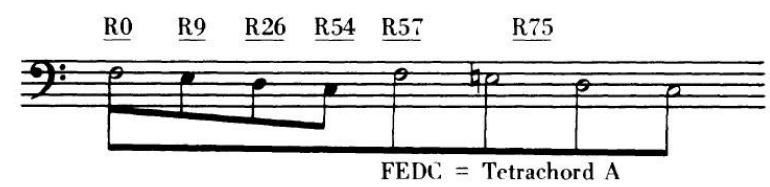

Example 2 demonstration how a tetrachord generates melody and harmony at the foreground level.

Example 3 demonstrates how the same tetrachord generates the background of an entire work. (This example includes rehearsal letters. Although the pitch classes in Example 3 show how the large scale unfolding of the bass line is based on the referential tetrachord, it should also be understood that the foreground is also permeated with the same set.)

In addition, "A Principle of Voice Leading," proposes "pattern-completion" as a means for projecting teleology into a post-tonal work; this involves the establishment of a normative pitch class set so that the absence of a component member of the set engenders expectation in a listener, thus providing a compelling logic for the connection of tones. "Patterncompletion" is the primary focus of the article, the "principle" that informs voice leading in the music of Stravinsky.

The analytical ideas in this article enable identification of musical works that solve the problems of projecting hierarchy (through symmetry across scale, between foreground and background) and effecting closure (through pattern-completion) in post-tonal music, allowing for forms congruent with key formalist values.

In "The Problem of Prolongation in Post-Tonal Music," Straus deems the prospect of prolongation in post-tonal music as limited; this would therefore largely preclude the possibility of compositional renderings or analytical discoveries of comprehensive hierarchies that are compatible with formalist values. To describe the problem, Straus says

\footnotetext{
62 Joseph Straus, "A Principle," 112.
} 
that "just because event $\mathrm{Y}$ falls between two occurrences of event $\mathrm{X}$ does not mean that $\mathrm{Y}$ prolongs X."63 Furthermore, "identification of such departures and returns may help in clarifying the principal goals in some musical foreground, but they will not provide a reliable guide to the deeper structural levels. ${ }^{64}$ One of the main reasons for this problem, he says, is the absence of a clear definition of consonance and dissonance, since "we need a way based on pitch of distinguishing between structural and nonstructural tones." ${ }^{65}$ This implies that, due to the contextual nature of much post-tonal music, it is difficult to create a clear distinction between consonance and dissonance. Finally, he concludes that "if we wish to discuss middleground structure in post-tonal music, we will have to retreat to a less comprehensive but more defensible model of voice leading, one based on association rather than prolongation. Association claims differ significantly from prolongational claims." 66

In the chapter "Middleground Misreadings" in the book Remaking the Past: Musical Modernism and the Influence of the Tonal Tradition, Straus expands on the ideas presented in "A Principle of Voice Leading in the Music of Stravinsky." Where "A Principle of Voice Leading" describes only a motivically based coherence between foreground and background in post-tonal music, the chapter "Middleground Misreadings" includes both "composing out motives" and "establishing harmonic areas" as methodologies for achieving the same type of coherence. ${ }^{67}$ The method of "Composing out motives" has already been described (in "A Principle of Voice Leading). "Establishing harmonic areas" refers to the method of rendering deep level architecture through successive transpositions of a referential pitch class set. Straus notes that there can be two types of harmonic areas, one comprising twelve pitch classes, or the aggregate, and the other consisting of less than twelve, such as the diatonic set. Since transpositions of the aggregate have identical content, thus negating the teleology of "modulation" between harmonic areas, methodologies such as combinatoriality, partitioning, etc. are necessary to distinguish

\footnotetext{
63 Straus, "The Problem of Prolongation," 7.

64 Straus, "The Problem of Prolongation," 7.

65 Straus, "The Problem of Prolongation," 7.

${ }^{66}$ Straus, "The Problem of Prolongation," 13.

${ }^{67}$ Straus, Remaking the Past, 169.
} 
successive aggregates. Such orderings are unnecessary for non-aggregates, like the diatonic set, since successive harmonic areas would be distinguished by content alone. ${ }^{68}$

Although "Middleground Misreadings," provides only one clear example of the technique of establishing harmonic areas, it is one that demonstrates by implication how an analogue to prolongation can be achieved in a post-tonal context. The analysis of Piano Piece Op. 33a by Schoenberg demonstrates a transpositional scheme of successive harmonic areas that are intervallically congruent to the referential twelve-note set. More specifically, the initial (0-2-7) trichord of the series that forms the basis of the work engenders a succession of harmonic areas transposed to levels $\mathrm{T}_{0}, \mathrm{~T}_{2}, \mathrm{~T}_{7}$, and $\mathrm{T}_{0}{ }^{69}$ Furthermore, partitions of content at the surface project (0-2-7), reinforcing the symmetry across scale. Straus also informs us that similar procedures are operational in the Piano Concerto, Op. 42 as outlined by theorist William Rothstein, whom he cites, ${ }^{70}$ although this isn't the only method by which Schoenberg achieves large-scale coherence in serial music. ${ }^{71}$

Finally, in the chapter "Centricity, Referential Collections, and Triadic Post-Tonality," in the book Introduction to Post-Tonal Theory, Straus introduces the diatonic scale (in addition to the octatonic, whole-tone, and hexatonic collections) as a configuration that can be repurposed to function as a referential set in a post-tonal context. In serving this function, "it acts in a new way, as primarily a referential source collection from which surface motifs are drawn."72 Harmonies partitioned from the diatonic set are of course unconstrained by considerations of tertian construction, since such considerations are in the domain of the tonal, rather than the operative one of the post-tonal.

\footnotetext{
68 Straus, "Middleground Misreadings," 169.

69 Straus, "Middleground Misreadings," 182.

${ }^{70}$ William Rothstein and Donald Martino, "Linear Structure in the Twelve-Tone System: An Analysis of Donald Martino's 'Pianississimo'," Journal of Music Theory, vol. 24, no. 2 (Autumn 1980): 129-165.

${ }^{71}$ For example, see: Andrew Mead, "Large-Scale Strategy in Arnold Schoenberg's Twelve-Tone Music," Perspectives of New Music, vol. 24, no. 1 (Autumn-Winter, 1985): 120-157.

72 Joseph Straus, "Centricity," 141.
} 


\subsubsection{Phrygian Gates and Hierarchy: A Post-Tonal Lens - Summary}

In sum, ideas from these four writings by Straus provide means and exemplars for understanding some principles of form in post-tonal music, and for identifying those forms that are congruent with formalist values of hierarchy and closure.

These ideas include "large-scale tonal coherence," a structural logic projected by tonal hierarchy through symmetry across scale (thus correlating foreground to background), and "pattern-completion," a teleology projected by a normative referential set that engenders listener expectations (a process which enables tonal closure). In addition to the utility these concepts have for analysis, they also provide for an efficient method for determining whether a musical work is consistent with the key formalist values of comprehensive hierarchy (through symmetry across scale or "large-scale tonal coherence") and closure (through "pattern-completion").

Projection of hierarchy can be effected through two methods, including 1) motivic composition (described by Straus as a process of "composing-out motives"), or 2) mapping of surface content into what Straus calls "harmonic areas". ${ }^{73}$ Of the two methods, mapping into harmonic areas is best suited for a comprehensive hierarchy.

When Straus analyzed music based on motivic construction, including music by Stravinsky, he was able to demonstrate the explanatory power of motivic analysis for understanding connections between surface and depth. The examples also show that its power falls short of rendering a comprehensive explanation for a musical work, at least in terms of the examples provided. ${ }^{74}$

Alternatively, the harmonic area analysis conducted by Straus of music by Schoenberg demonstrates a comprehensive hierarchy, in the way a transpositional scheme of successive harmonic areas is intervallically congruent to the first segment of a referential twelve-note

\footnotetext{
73 Joseph Straus, "Middleground Misreadings," 169.

74 Joseph Straus, "Middleground Misreadings," 170-171.
} 
set, and how partitions at the surface reinforce the congruence. Such a construction meets the requirements of formalism in its comprehensiveness. Since Straus indicated that diatonic content can be operative in a post-tonal context, it can therefore be inferred that diatonic sets, repurposed as referential collections in a post-tonal context, could similarly render comprehensive hierarchies. (Straus did not, however, provide an example of this in the writings examined.)

With these principles of form in place, it becomes possible to demonstrate how Phrygian Gates similarly participates in a post-tonal tradition, and how its structure is comprehensively hierarchical.

\subsubsection{Phrygian Gates and Hierarchy: Tonal Analysis}

Phrygian Gates projects a comprehensive tonal hierarchy through a succession of 7 tonal centers (or harmonic areas) that form a referential set that is intervallically congruent to each component harmonic area. More specifically, the 7 tonal centers (each expressed by paired Lydian and Phrygian modes) that comprise the background of the entire work form

a diatonic set, and this set is congruent to each of the component 14 diatonic sets at the surface. Since its content is deployed through harmonic areas, instead of a motivic network, the architecture of Phrygian Gates can be easily understood as comprehensively hierarchical. These structural features are denoted by Figure 3. 
Figure 3. Phrygian Gates, Modal Deployment: Symmetry Across Scale.

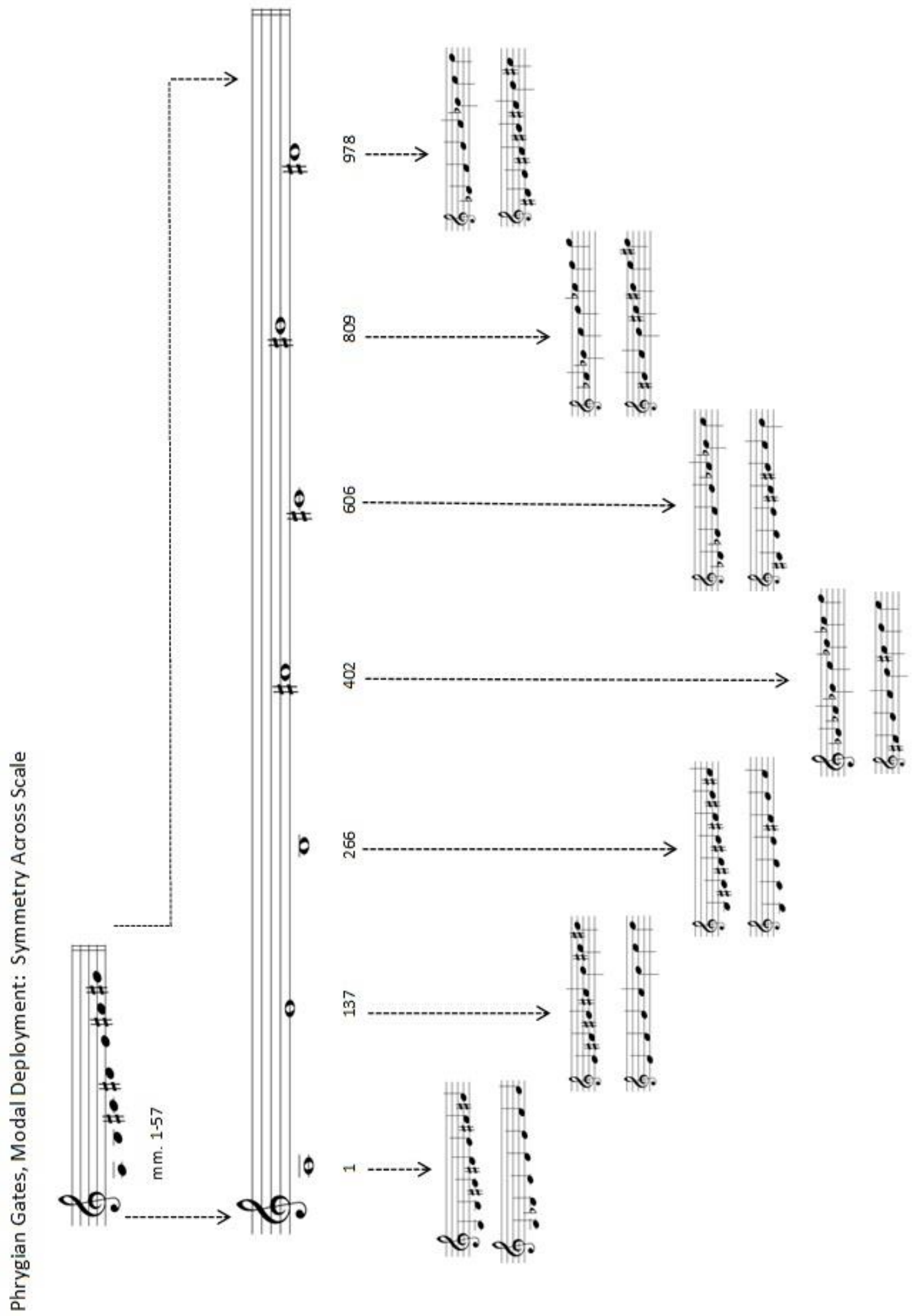


This analysis features a demonstration of Straus's concept of "large-scale tonal coherence" in action, showing symmetry across scale between the foreground and background of Phrygian Gates, a symmetry upon which the work's hierarchical structure hinges. It also demonstrates Straus's concept of "establishing harmonic areas" in the way the tonal hierarchy is projected comprehensively, since all foreground content is mapped from the background to foreground by transposition, therefore leaving no harmonic content unexplained (in distinction from the other means identified by Straus for projecting hierarchy, "composing-out motives," which he notes to be a problematic method for attaining comprehensiveness).

Figure 3 also shows an additional formalist, hierarchical feature of Phrygian Gates. Measures 1-57 additively deploy, one by one, the seven pitch classes of the set comprising the Lydian mode in A. The arrival of pitch class A at m. 57 completes the set. This foreground event is equivalent, in its content, to the background unfolding of the Lydian mode in A, expressed as a cycle of ascending diatonic fifths. The germinational symmetry across scale in evidence here was specifically mentioned by Pellegrino as a hallmark of musical formalism, i.e. that it is "the expansion of a kernel structure of some kind." ${ }^{75}$ To uncover hierarchies of this type in the music of Adams, as suggested by the analysis in Figure 3, is actually not surprising since it's consistent with what Adams has said about his compositional strategy, which includes identification of a work's "DNA;"76 or with his thinking about musical form when, in reference to Beethoven and Wagner, he claims that "often the 'code' of a movement, if not an entire symphony or opera, is encapsulated within the first page or two, albeit in fractal form."77 He further claims that this encoded "information" has "exceptional potential to generate large and complex expressive structures."

\footnotetext{
${ }^{75}$ Nicholas Cook, A Guide, 118-119. Quoted in Pellegrino, "Formalist Analysis," 3.

${ }^{76}$ Adams, Hallelujah Junction, 191.

${ }^{77}$ Adams, Hallelujah Junction, 191.
} 


\subsubsection{Phrygian Gates and Hierarchy: Formal Analysis}

The demonstrated recursive tonal hierarchy of Phrygian Gates is complemented by a form consisting of three nested structural levels from background to foreground; each level is a ternary form; Table 1 charts these levels.

Level 1 spans the entire piece, and is in three sections of $\mathrm{A}, \mathrm{B}, \mathrm{A}^{\prime}$;

Level 2, nested within A' of Level 1, is in three sections of A', C, A"; and

Level 3, nested within C of Level 2, is in three sections of C, D, C'.

As documented by Table 1, these ternary forms are projected by the symmetrical properties of their beginnings and endings; and the reciprocal, contrasting properties of their middle sections. For example, sections $\mathrm{A}$ and $\mathrm{A}^{\prime}$ of level 1 share similar features of multiple modes, contrasting dynamics, durational processes, and active texture; section B is reciprocal in its single mode, lack of dynamic contrast, and static texture. Similar observations can be made regarding levels 2 and 3 .

The symmetry across scale of both the modal structure (shown in Figure 3) and ternary forms (shown in Table 1) are complementary, so when the modal background of Figure 3 is correlated with a formal abstract derived from Table 1, as shown in Figure 4, their relationship emerges clearly. When pattern-completion of the background Lydian diatonic cycle of fifths of level 1 (mm. 1-1092) is completed with the arrival of $D \#$ at m. 947, it also coincides with the center of the durational palindrome of level 2 (mm. 809-1092), and the durational and pitch class palindrome of level 3 (mm. 923-977). By means of this structural nexus, the seemingly independent tonal and formal hierarchies can be seen to be in alignment, in mutual support. 
Table 1. Phrygian Gates, Ternary Form: Symmetry Across Scale.

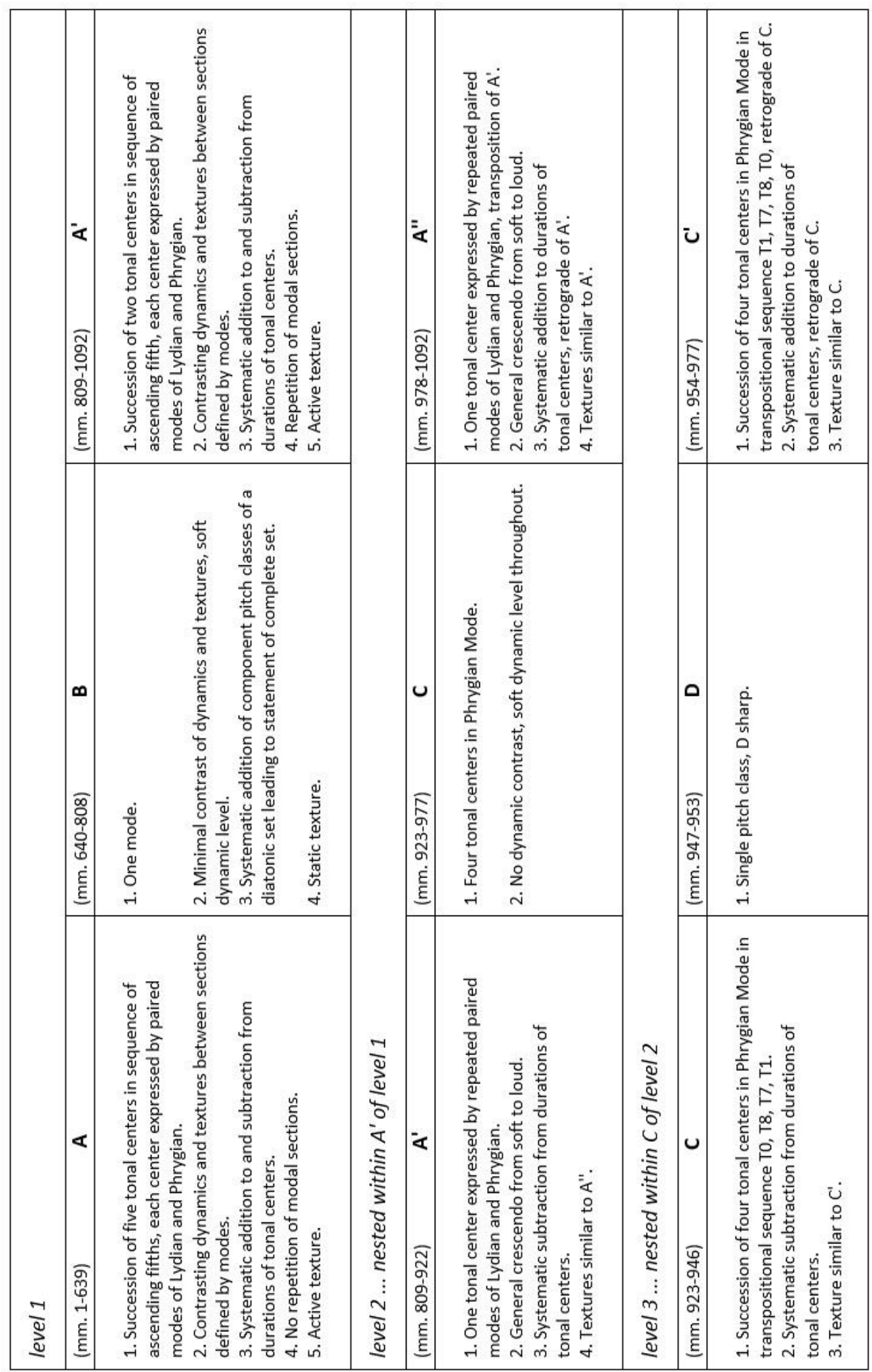


Figure 4. Phrygian Gates, Modal Deployment and Ternary Form: Complementarity.

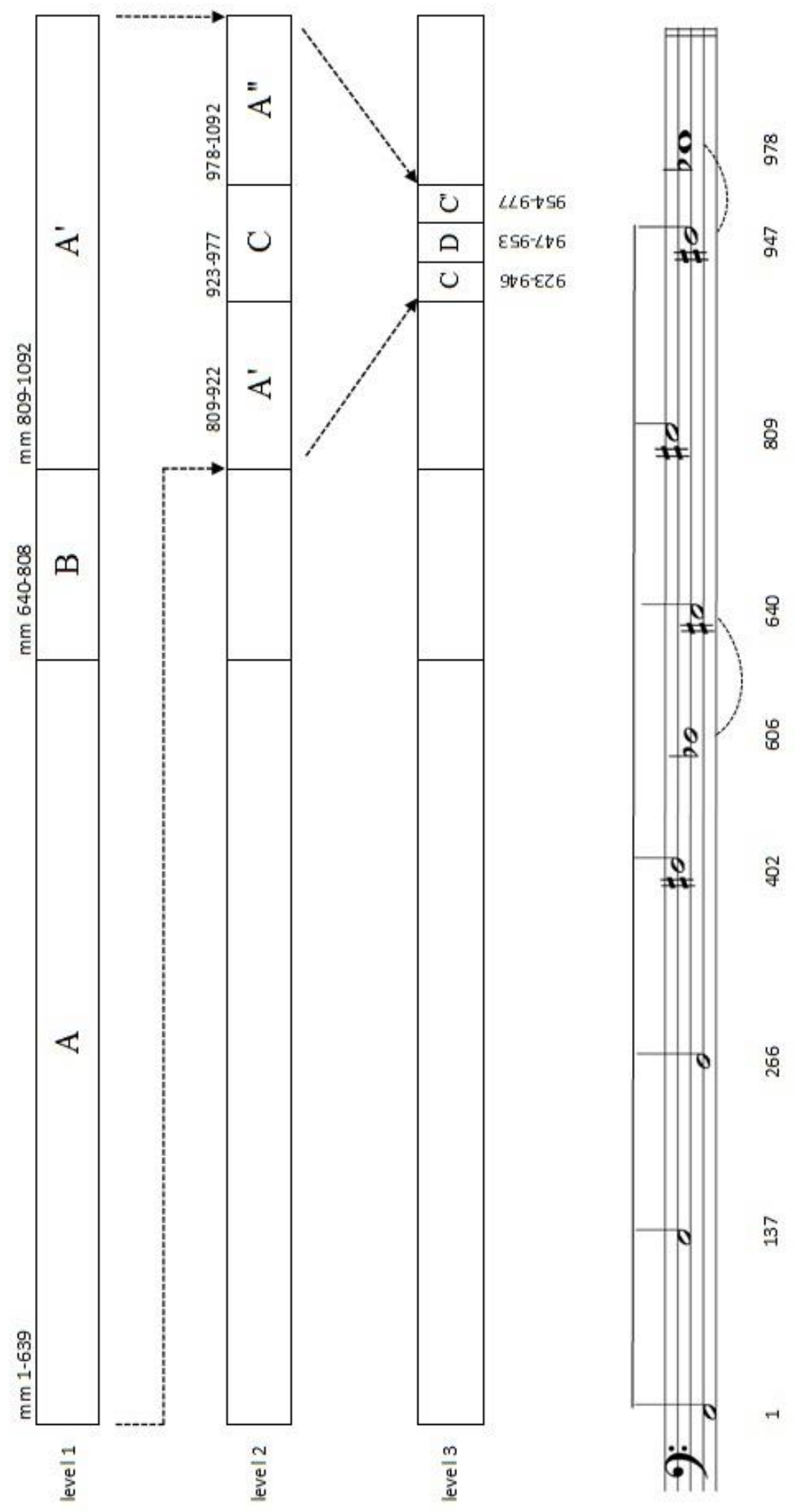




\subsubsection{Phrygian Gates and Hierarchy: Special Considerations}

The systematic transposition of a referential collection that forms the hierarchical tonal structure of Phrygian Gates is challenged by three exceptions that require explanation, located at m. 265, mm. 63-73, and mm. 923-977; the latter two are related.

At $\mathrm{m} .265$, the juncture between modules rendering E Phrygian and B Lydian, there is an "overlap." See Example 4. Since the foreground tonal process has been well established by this point in the piece (mm. 1-265 feature the sequence A Lydian, A Phrygian, E Lydian, and E Phrygian), this exception to the process, does not threaten the prevailing and established tonal logic. It isn't clear what motivates this compositional decision for this transitional passage, other than perhaps the goal of introducing variety into the surface of the piece by means of contrasting white and black piano keys within a single sonority -- an opportunity afforded by the move from E Phrygian to B Lydian. The white keys render set class (0-1-5-6), a set class that can only occur in the Phrygian and Locrian modes where 0 is the final; the context strongly implies Phrygian. The black key "set" is missing D\#, which by means of pattern-completion creates an expectation that is fulfilled at $\mathrm{m}$. 266 .

Example 4. Adams, Phrygian Gates, m. 265.

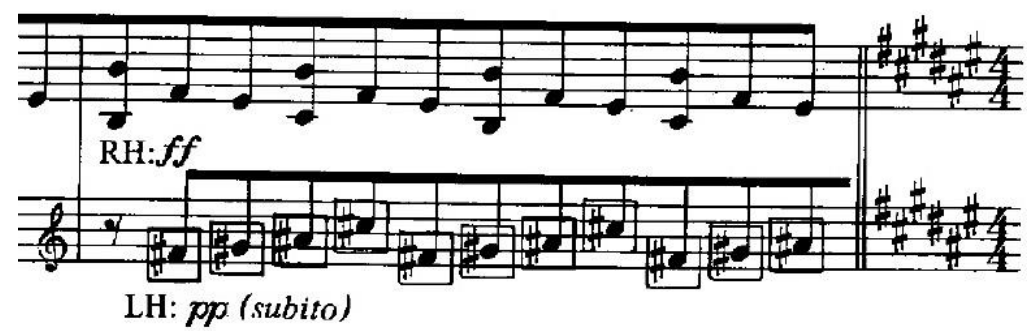

The second exception occurs within the first module of the work in A Lydian (mm. 1-113) where there is a pitch class that is outside its referential diatonic collection, namely $\mathrm{B} b$ (mm. 63-73). See Example 5 for an excerpt. This is the first time in Phrygian Gates that such an event occurs. This can be explained as a prefiguration of the work's oscillations between Lydian and Phrygian, since the $\mathrm{B} b$ in conjunction with A (as confirmed by the voice leading from m. 64 to $\mathrm{m}$. 73) suggests A Phrygian. In this way, the presence of both 
Lydian and Phrygian elements in the opening module function like musical DNA, engendering a tonal gesture characteristic of the entire work. Again, the words of Adams are apposite here when, speculating on how Beethoven or Wagner created their works, he asks whether these composers "didn't revisit the opening and tweak it to more perfectly mirror the course of later events?"78 One can plausibly speculate that this $\mathrm{B} b$ was inserted by Adams for a similar purpose, to mirror later events.

Example 5. Adams, Phrygian Gates, mm. 69-76.
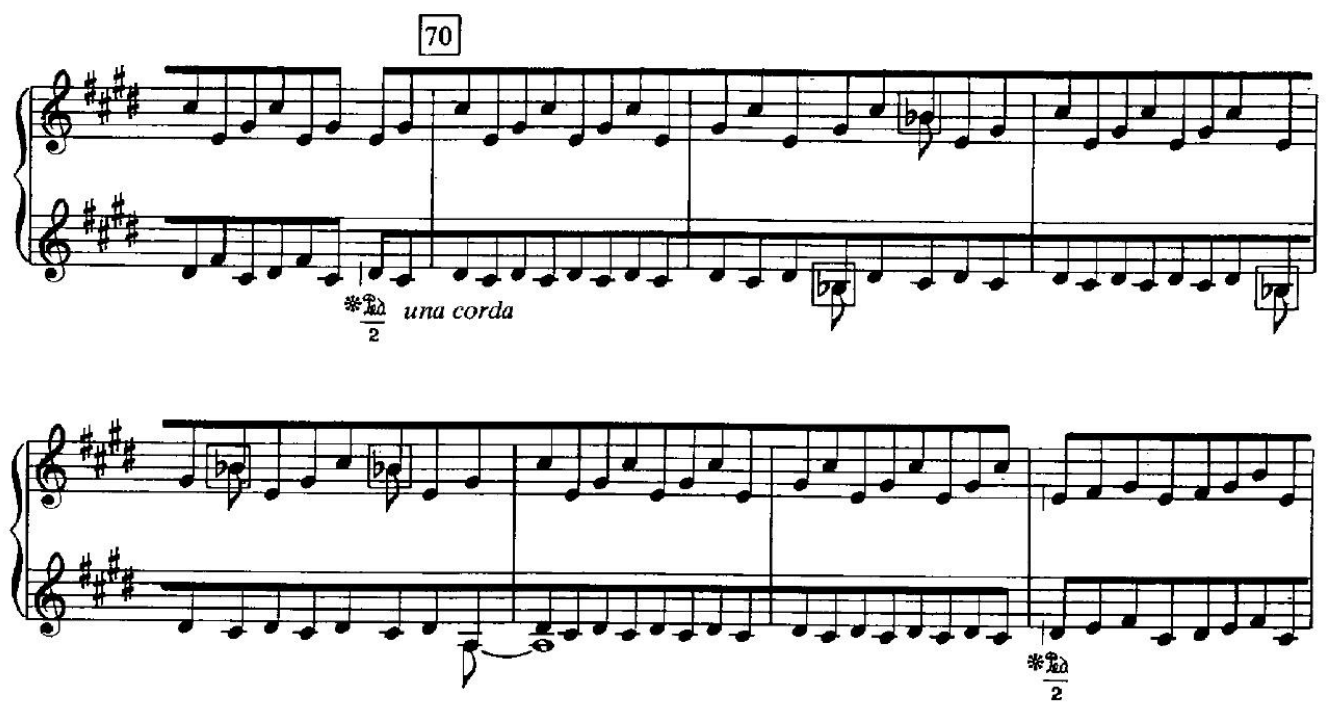

Finally, the third exception to the prevailing tonal logic of Phrygian Gates occurs at section C, level 2, mm. 923-977. This section is treated as an embellishing, structural dissonance to section A', level 1, mm. 809-1092, and so therefore does not intrude into the course of the tonal scheme that generates the content of the entire work, thus preserving the hierarchy. Figure 5, extracted from Figure 4, shows this tonal relationship. How is it possible to make this prolongational claim in a post-tonal context?

\footnotetext{
${ }^{78}$ Adams, Hallelujah Junction, 192.
} 
Figure 5. Phrygian Gates, Detail from Figure 4, mm. 809-1092.

Section $\mathrm{C}$, level 2 is shown subordinate to section $\mathrm{A}^{\prime}$, level 1, since its contrasting tonal content does not impinge on the $\mathrm{G} \sharp$ and $\mathrm{D} \sharp$ modal centers of $\mathrm{A}^{\prime}$.

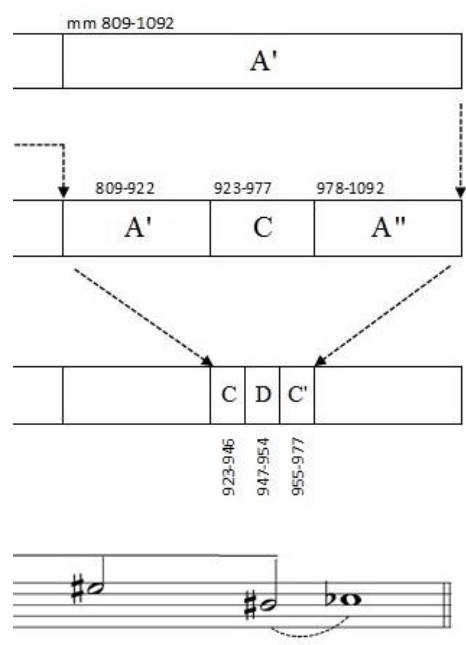

$809 \quad 947 \quad 978$

To project pitch hierarchies in post-tonal music requires a contextual approach, whereby the compositional protocol of a particular piece of music defines consonance and dissonance for that piece, rather than a common practice. In order for this to work there has to be substantial consistency in the method of pitch class deployment in order to clearly imply a normative "yardstick," so that events in non-conformance are understood as "dissonant." This is precisely what occurs in Phrygian Gates.

Section C occurs late in the piece, at m. 923 in a work of 1092 measures. Since up to this moment there have been numerous occurrences, without deviation, of its two major tonal processes (including a background unfolding of a diatonic cycle of fifths in A Phrygian, and foreground oscillations between the Lydian and Phrygian modes), a tonal norm has been established contextually for the piece, so the contrasting tonal content of section $\mathrm{C}$ will therefore be heard as structurally dissonant. 
The divergent content of section C (mm. 923-977) is engendered by similarly divergent content within the first module of A Lydian (mm. 63-73), as previously described. Both of these intrusions feature Phrygian content inserted into a Lydian context, the first in the foreground, the latter in the middleground.

The first intrusion is rendered as pitch class $\mathrm{B} b(\mathrm{~mm} .63-73)$ within the foreground of module one in A Lydian (mm. 1-113). Since A Phrygian content is consistently deployed up to $\mathrm{m}$. 63 , and from $\mathrm{m}$. 74 to $\mathrm{m}$. 113 , the $\mathrm{B} b$ is heard as divergent content, or as dissonant.

The second intrusion is rendered as a middleground Phrygian transpositional schema operating on successive Phrygian sets (section C, mm. 923-977), thus invading the work's background transpositional schema based on a Lydian set. Since this background schema, as indicated earlier, is consistently deployed up to $\mathrm{m}$. 923, the content of section C is heard as divergent and therefore dissonant.

Reciprocals properties inform these two events, including polarities of foreground to background, Phrygian to Lydian, and beginning to end. This method of deriving contrasting content both sustains the unity of the work, and yet mutates content sufficiently to create the differentiation and contrast necessary for embellishing, structural dissonance while still preserving prolongation. ${ }^{79}$

The climax of section C, and the structural climax of the entire work, involves the single pitch class of $E b / D \#$ at mm. 947-953, an event informed by the background Lydian diatonic transpositional cycle, signaling the cycle's completion, and thus affirming the prevailing Lydian background of Phrygian Gates over the exceptional, divergent, and irregular Phrygian content in the first module (mm. 1-113) and within section C (mm. 923977).

\footnotetext{
${ }^{79}$ Compositional methodology informed by reciprocal logic, under the label "logical complementarity," is discussed in Jacob Opper, "Musical Classicism Reflected in Enlightenment Mentality," in Science and the Arts: A Study in Relationships from 1600-1900 (Cranbury, New Jersey: Associated University Presses, 1973), 88-125.
} 


\subsection{Phrygian Gates, Closure and Hierarchy: Summary}

It has been demonstrated that the form of Phrygian Gates is consistent with formalist values of closure and hierarchy. More specifically, section 1.2.4 shows how tonal closure is achieved through pattern-completion, i.e. through a complete statement of a diatonic cycle; and sections 1.3.4 and 1.3.5 show how that tonal pattern forms the background of a hierarchy that is rendered comprehensively. A key strategy involved in rendering this form is the utilization of musical processes. Since its harmonic organization is post-tonal and outside a common practice, Phrygian Gates defines its harmony contextually through rigorous tonal processes. The consistency of the processes enable identification of how and where tonal closure occurs, and also define a normative standard of consonance and dissonance for the piece, thus facilitating the projection of a comprehensive hierarchy that allows for prolongation.

\subsubsection{Phrygian Gates, Temporal Processes: Introduction}

In addition to pitch, the organization of time within Phrygian Gates also demonstrates formalism in its comprehensive patterning of rhythm, as shown by Kyle Fyr in his dissertation "Proportion, Temporality, and Performance Issues in Piano Works of John Adams" (2011) $)^{80}$ The following will summarize some of the key ideas in this writing in order to enlarge and support the formalist perspective on Phrygian Gates.

\subsubsection{Phrygian Gates, Temporal Processes: Large Scale}

Before analyzing Phrygian Gates in terms of systematic organization of time, Kyle Fyr first establishes his analytical methodology for understanding temporal architecture and the rationale behind it. The main problem to be solved in order to build musical form on the basis of time, and to analyze it, is that of understanding the difference between time as subjectively experienced, which is normal for listening, and time as objectively measured by a device, such as a clock, and the implications of this difference for music. If the

\footnotetext{
${ }^{80}$ Kyle Fyr, "Proportion, Temporality, and Performance Issues in Piano Works of John Adams" (PhD diss., Indiana University, 2011).
} 
listening experience is largely subjective, and distorts perceptions of duration, then precise compositional calibration of musical events in time isn't practical as a method for rendering form, or for analyzing it.

Fyr found a solution to this problem through writings by the scholars Edward Cone and Jonathan Kramer which engaged with the music of Stravinsky. In particular, he draws attention to a key passage by Cone in connection with the Symphony in $C$ :

The typical Classical balance, even when apparently rigid, controlled contrasting events moving at varying speeds, so that the listener's experience usually belied the exact parallel of the time-spans and defeated most attempts to measure one against the other. Stravinsky's sections - rhythmically persistent, harmonically static, melodically circular-not only invite the hearer to make the comparisons leading to just such measurement, but also reward him for doing so. Far from exploiting the sonata form as the traditional vehicle for realizing the musical or dramatic potentialities of tonal conflict and progression, he adapts it to his own perennial purpose: the articulated division of a uniform temporal flow. ${ }^{81}$

In other words, Stravinsky's music, in its activity within stasis, generates a "uniform temporal flow" where perceived time and objective clock time are merged, thus allowing for the compositional manipulation of durations to build form, and where the experience of listening and the act of analysis can be centered in time as well.

Fyr also cites the supporting commentary of Jonathan Kramer from his book The Time of Music. When discussing the perception of time and its relation to analysis, Kramer concedes that "the whole question of proportions as perceived, particularly in tonal music, seems too complex to be dealt with by quantitative measurement." 82 But he, like Cone, believes that quantification of time in Stravinsky's music can lead to analytical insights, since there are "none of the attributes of tonal motion ... that might distort our sense of

\footnotetext{
${ }^{81}$ Edward T. Cone, "The Uses of Convention: Stravinsky and His Models," The Musical Quarterly, vol. 48 (July, 1962): 287-299.

82 Jonathan Kramer, The Time of Music: New Meanings, New Temporalities, New Listening Strategies (New York: Schirmer Books, 1988), 53-54.
} 
absolute duration." 83 In addition, he opines that "the more static a passage, the more its perceived length agrees with its clock-time duration." ${ }^{84}$

These observations by Cone and Kramer regarding the music of Stravinsky, as well as the rhythmically consistent textures of China Gates and Phrygian Gates which invite temporal analysis, form a significant part of the rationale invoked by Fyr for analyzing the structure of these works as time-based forms, since he views their organization to be analogous to Stravinsky's methods. ${ }^{85}$ Harmonic motion as a distorting element in these piano pieces is effectively neutralized, since it's in alignment with the component time-based modules of which the work is comprised.

Adopting the unit of the eighth note as a metric for measuring time, Fyr outlined the global temporal organization of Phrygian Gates as seen in Table 2.

Table 2. Global Proportional Temporal Design in Phrygian Gates. ${ }^{86}$

\begin{tabular}{|c|c|c|c|c|}
\hline Measures & Tempo & \# of 8ths & Time span & Mode \\
\hline $1-113$ & $d=90$ & 900 & 2' $30^{\prime \prime}$ & A Lydian \\
\hline $114-136$ & & 180 & $0^{\prime} 30^{\prime \prime}$ & A Phrygian \\
\hline $137-235$ & & 720 & $2^{\prime} 00^{\prime \prime}$ & E Lydian \\
\hline $236-265$ & & 360 & $1^{\prime} 00^{\prime \prime}$ & E Phrygian \\
\hline $266-333$ & & 540 & $1^{\prime} 30^{\prime \prime}$ & B Lydian \\
\hline $334-401$ & & 540 & 1 ' $30 "$ & B Phrygian \\
\hline $402-469$ & $d=135$ & 540 & 1'00" & Gb Lydian \\
\hline $470-605$ & & 1080 & 2'00" & F\# Phrygian \\
\hline $606-639$ & & 270 & $0^{\prime} 30^{\prime \prime}$ & Db Lydian \\
\hline $640-808$ & & 1350 & 2' $30^{\prime \prime}$ & C\# Phrygian \\
\hline $809-922$ & $\cdot=180$ & 900 & $22^{\prime} 30^{\prime \prime}$ & Ab Lydian / G $\bar{F}$ Phrygian \\
\hline $923-977$ & & 360 & $1^{\prime} 00 "$ & Ab Lyd. / D\# Phr. / Eb Lyd. / G\# Phr. \\
\hline $978-1092$ & & 900 & $2^{\prime} 30^{\prime \prime}$ & Eb Lydian / D\# Phrygian \\
\hline
\end{tabular}

\footnotetext{
83 Jonathan Kramer, The Time of Music, 54.

84 Jonathan Kramer, The Time of Music, 54.

${ }^{85}$ Kyle Fyr, "Proportion," 84.

${ }^{86}$ Kyle Fyr, "Proportion," 160.

It should be noted that the modal sequence outlined in Table 2 for $\mathrm{mm}$. 923-977 differs from my reading, which is $G$ Phrygian, $D \#$ Phrygian, D Phrygian, and $G \#$ Phrygian.
} 
The table shows two durational palindromes, extending from mm. 1-808, and from 809 to 1092. The climax is emphasized by framing it within the center of the second palindrome, at $\mathrm{mm}$. 923-977 within $\mathrm{mm}$. 809-1092. It should be noted that the passage at $\mathrm{mm} .137$ to 235 was "adjusted" by Fyr from 792 eighths to 720; it was apparently extended by the composer through prioritizing the compositional foreground over the pre-compositional blueprint, but is here "restored" by Fyr to clarify the global logic. ${ }^{87}$

\subsubsection{Phrygian Gates, Temporal Processes: Small Scale}

Digging deeper, Fyr also reveals a nested proportional framework in the pattern 3-3-2-4, ${ }^{88}$ or its approximate equivalent, in the pattern medium-medium-short-long, as seen in Table 3. The nesting occurs on three levels, including within each phrase, within each submodule, and within the module.

One way this proportional framework is articulated is through textural accents. Phrase 1 of sub-module 1 (mm. 1-7), shown in Example 6, is subdivided into four segments by three single attacks on B. These segments expressed in eighth note values are in lengths of 14, 14,8 , and 20, an approximate equivalent of the proportional pattern 3-3-2-4.

Example 6. Adams, Phrygian Gates, mm. 1-7, Pulse Stream with Textural Accents. ${ }^{89}$

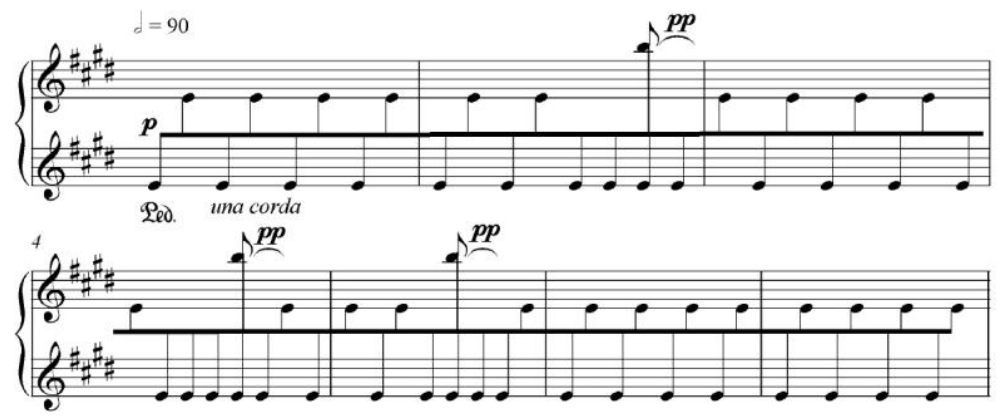

\footnotetext{
${ }^{87}$ For more detail regarding this passage, see also Jeff Lankov, "The Solo Piano Compositions of John Adams: Style, Analysis, and Performance" (PhD diss., New York University, 2014), 163-164. I have reviewed the arguments regarding the adjustment, and believe it to be reasonable. ${ }^{88}$ Adams revealed this patterning; see Adams, Hallelujah Junction, 88.

${ }^{89}$ Kyle Fyr, "Proportion," 120.
} 
Table 3. "Nested Proportional Frameworks in Module 1 of Phrygian Gates."90

Sub-Module 1 (mm. 1-28)

\begin{tabular}{|lccccc|c|}
\cline { 3 - 6 } \multicolumn{1}{c}{} & Beg. - Note 1 & Note 1 - Note 2 & Note 2 - Note 3 & Note 3 - End & Total \# of 8th Notes \\
\hline Phrase 1 & 14 & 14 & 8 & 20 & 56 \\
\hline Phrase 2 & 16 & 14 & 5 & 21 & 56 \\
\hline Phrase 3 & 9 & 7 & 5 & 13 & 34 \\
\hline Phrase 4 & 19 & 19 & 13 & 27 & 78 \\
\hline
\end{tabular}

Sub-Module 2 (mm. 29-56)

\begin{tabular}{|lccccc|c|}
\cline { 3 - 6 } \multicolumn{1}{c}{} & Beg. - Note 1 & Note 1- Note 2 & Note 2 - Note 3 & Note 3 - End & Total \# of 8th Notes \\
\hline Phrase 1 & 19 & 17 & 5 & 24 & 65 \\
\hline Phrase 2 & 14 & 14 & 9 & 19 & 56 \\
\hline Phrase 3 & 5 & 4 & 2 & 8 & 19 \\
\hline Phrase 4 & 24 & 20 & 8 & 32 & 84 \\
\hline
\end{tabular}

Sub-Module 3 (mm. 57-75)

\begin{tabular}{|lccccc|c|}
\cline { 3 - 6 } \multicolumn{1}{l}{} & Beg. - Note 1 & Note 1 - Note 2 & Note 2 - Note 3 & Note 3 - End & Total \# of 8th Notes \\
\hline Phrase 1 & - & - & - & - & 38 \\
\hline Phrase 2 & 11 & 9 & 3 & 15 & 38 \\
\hline Phrase 3 & - & - & - & - & 26 \\
\hline Phrase 4 & 13 & 12 & 8 & 17 & 50 \\
\hline
\end{tabular}

Sub-Module 4 (mm. 76-113)

\begin{tabular}{|lccccc|c|}
\cline { 5 - 6 } \multicolumn{1}{l}{} & Beg. - Note 1 & Note 1 - Note 2 & Note 2 - Note 3 & Note 3 - End & Total \# of 8th Notes \\
\hline Phrase 1 & 19 & 19 & 13 & 25 & 76 \\
\hline Phrase 2 & 22 & 19 & 6 & 29 & 76 \\
\hline Phrase 3 & 12 & 12 & 8 & 16 & 48 \\
\hline Phrase 4 & 29 & 26 & 8 & 37 & 100 \\
\hline
\end{tabular}

TOTAL OF MODULE 1: 900

90 Kyle Fyr, "Proportion," 131. 
The proportional framework is also articulated by a sequence of simultaneous attacks of multiple pulse streams. Phrase 4 of sub-module 2 (mm. 46-56), shown in Example 7, features multiple pulse streams that synchronize at three points by which subdivisions of $24,20,8$, and 32 are delineated, again approximating the 3-3-2-4 proportional scheme.

Example 7. Adams, Phrygian Gates, mm. 46-56, Coordination of Pulse Streams. ${ }^{91}$
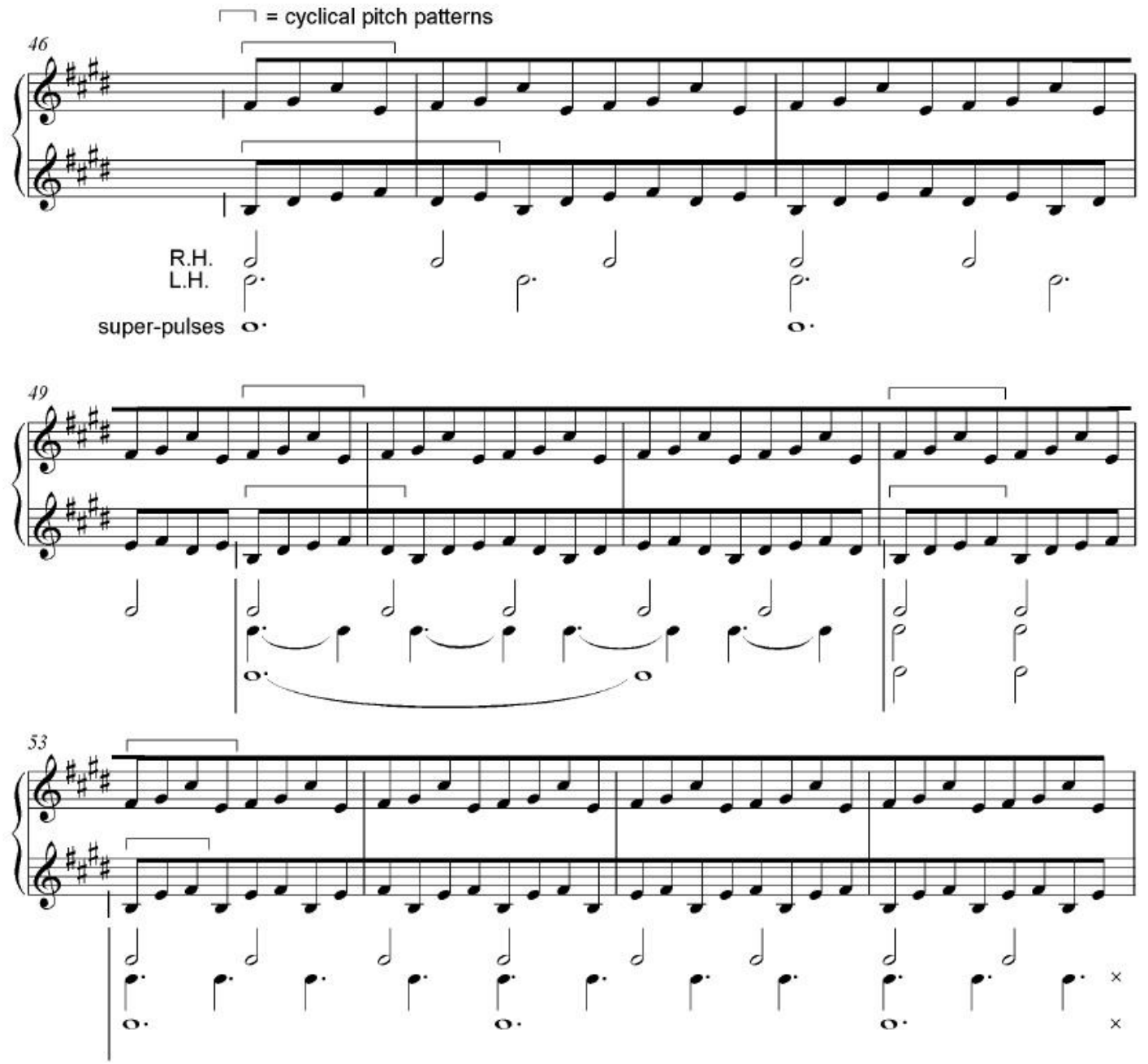

Fyr also outlines in his dissertation a similar nested proportional scheme that informs the contrasting quiescent interior section of Phrygian Gates, "A System of Weights and Measures" (mm. 640-808). ${ }^{92}$

\footnotetext{
${ }^{91}$ Kyle Fyr, "Proportion," 125.

92 Kyle Fyr, "Proportion," 144.
} 
Based on the research of Christopher Shultis and Charles Hamm, Fyr notes that the composer John Cage had already deployed similar nested temporal proportion schemes in his work beginning in the 1930s, including a nested 2-1-3 pattern in his 1951 piece Imaginary Landscape No. $I V .^{93}$ This suggests for Fyr that the ideas of Cage were an influence on Adams. ${ }^{94}$ Such an inference is plausible, given the stimulus that the writings and example of Cage had on Adams for a time, as he later admitted. ${ }^{95}$

The concluding section (mm. 809-1092) organizes time palindromically, as shown in Table 4. As Fyr indicates, this scheme is remarkably similar to that of China Gates, ${ }^{96}$ as shown in Table 5, suggesting that in China Gates (1977), the earlier piece, Adams chose to work within a small form in order to test and develop the compositional implications of the minimalist style before engaging with the demands of an extended form, such as that of Phrygian Gates (1977-1978). Notable similarities indicated by Fyr, and apparent from comparing Tables 4 and 5, include "two outer sections with proportionally contracting/expanding pairs of modules that each alternate between two different pitch collections," and a shared 5-2-5 proportional temporal design (Phrygian Gates, 600-240600; China Gates, 900-360-900). ${ }^{97}$

\footnotetext{
${ }^{93}$ Christopher Shultis, "Silencing the Sounded Self: John Cage and the Intentionality of Nonintention," The Musical Quarterly, vol. 79, no. 2 (Summer 1995): 314. Quoted in Fyr, "Proportion," 82. Charles Hamm, "Privileging the Moment: Cage, Jung, Synchronicity, Postmodernism," The Journal of Musicology, vol. 15, no. 2 (Spring 1997): 283-284. Quoted in Fyr, "Proportion," 82-83.

94 Kyle Fyr, "Proportion," 82-83.

${ }^{95}$ Adams, Hallelujah Junction, 56-59.

${ }^{96}$ Kyle Fyr, "Proportion," 151.

${ }^{97}$ Kyle Fyr, "Proportion," 151.
} 
Table 4. "Formal design in the final section of Phrygian Gates."98

\begin{tabular}{|c|c|c|c|c|c|c|c|c|}
\hline \multicolumn{3}{|c|}{ mm. 809 - 922} & \multicolumn{3}{|c|}{ mm. 923 - 977} & \multicolumn{3}{|c|}{ mm. 978 - 1092} \\
\hline Module & \# of 8 ths & Pitch coll. & Module & \# of 8ths & Pitch colll & Module & \# of 8ths & Pitch coll. \\
\hline 11 & 240 & $3 b$ & 19 & 24 & $(3 b)$ & 51 & 30 & $2 b$ \\
\hline 12 & 240 & 4" & 20 & 24 & (5\%) & 52 & 30 & $5 \%$ \\
\hline 13 & 120 & $3 b$ & 21 & 24 & (2b) & 53 & 60 & $2 b$ \\
\hline 14 & 120 & $4=$ & 22 & 24 & $(4 *)$ & 54 & 60 & $5 \#$ \\
\hline 15 & 60 & $3 b$ & 23 & 12 & (3b) & 55 & 120 & $2 b$ \\
\hline 16 & 60 & 4= & 24 & 12 & (5¥) & 56 & 120 & $5 \#$ \\
\hline 17 & 30 & $3 b$ & 25 & 12 & (2b) & 57 & 240 & $2 b$ \\
\hline \multirow[t]{2}{*}{18} & 30 & $4=$ & 26 & 12 & $(4 \%)$ & 58 & 240 & $5 \#$ \\
\hline & & & 27 & 6 & (3b) & & & \\
\hline \multirow[t]{24}{*}{ Total: } & 900 & & 28 & 6 & (5) & Total: & 900 & \\
\hline & & & 29 & 6 & (2b) & & & \\
\hline & & & 30 & 6 & (4\%) & & & \\
\hline & & & 31 & 3 & $E b$ & & & \\
\hline & & & 32 & 3 & $D \neq$ & & & \\
\hline & & & 33 & 3 & $E b$ & & & \\
\hline & & & 34 & 3 & $D F$ & & & \\
\hline & & & 35 & 3 & DF & & & \\
\hline & & & 36 & 3 & Eb & & & \\
\hline & & & 37 & 3 & $D E$ & & & \\
\hline & & & 38 & 3 & $E b$ & & & \\
\hline & & & 39 & 6 & (4:) & & & \\
\hline & & & 40 & 6 & (2b) & & & \\
\hline & & & 41 & 6 & (5\#) & & & \\
\hline & & & 42 & 6 & (3b) & & & \\
\hline & & & 43 & 12 & (4\#) & & & \\
\hline & & & 44 & 12 & (2b) & & & \\
\hline & & & 45 & 12 & (5\%) & & & \\
\hline & & & 46 & 12 & (3b) & & & \\
\hline & & & 47 & 24 & $(4 \#)$ & & & \\
\hline & & & 48 & 24 & (2b) & & & \\
\hline & & & 49 & 24 & (5\#) & & & \\
\hline & & & 50 & 24 & (3b) & & & \\
\hline & & & Total: & 360 & & & & \\
\hline
\end{tabular}

Table 5. "Global Formal design in China Gates."99

\begin{tabular}{|c|c|c|c|c|c|c|c|c|}
\hline \multicolumn{3}{|c|}{ Section I } & \multicolumn{3}{|c|}{ Section II } & \multicolumn{3}{|c|}{ Section III } \\
\hline Module & \# of 8ths & Pitch coll. & Module & \# of 8ths & Pitch coll. & Module & \# of 8ths & Pitch coll. \\
\hline I & 120 & $5 b$ & IX & 4 & $(0 b)$ & XXVI & 30 & $6 b$ \\
\hline II & 120 & 57 & $x$ & 8 & $(5 F)$ & XXVII & 30 & $o b$ \\
\hline III & 90 & $5 b$ & XI & 16 & (6b) & XXVIII & 60 & $6 b$ \\
\hline IV & 90 & $5 \#$ & XII & 32 & (5b) & XXIX & 60 & $o b$ \\
\hline v & 60 & $5 b$ & XIII & 30 & (ob) & $\mathrm{XXX}$ & 90 & $6 b$ \\
\hline VI & 60 & 57 & XIV & 4 & $(5 \%)$ & XXXI & 90 & $0 b$ \\
\hline VII & 30 & $5 b$ & $x V$ & 8 & (6b) & XXXII & 120 & $6 b$ \\
\hline \multirow[t]{2}{*}{ VIII } & 30 & 57 & XVI & 18 & (5b) & XXXIII & 120 & $o b$ \\
\hline & & & XVII & 32 & (ob) & & & \\
\hline \multirow[t]{9}{*}{ Total: } & 600 & & XVIII & 16 & (5\#) & Total: & 600 & \\
\hline & & & XIX & 8 & (6b) & & & \\
\hline & & & $x x$ & 4 & (5b) & & & \\
\hline & & & XXI & 2 & (5b) & & & \\
\hline & & & XXII & 16 & (ob) & & & \\
\hline & & & XXIII & 8 & $(5 \#)$ & & & \\
\hline & & & XXIV & 4 & (6b) & & & \\
\hline & & & XXV & 30 & (5b) & & & \\
\hline & & & Total: & 240 & & & & \\
\hline
\end{tabular}

${ }^{98}$ Kyle Fyr, "Proportion," 150.

${ }^{99}$ Kyle Fyr, "Proportion," 106. 
The arguments presented in chapter 1 demonstrate that the music of Phrygian Gates by John Adams is formalist in terms of its comprehensiveness in closure and hierarchy in the domain of pitch. This formal rigor is complemented by a similarly comprehensive organization of rhythm. The strict adherence to process by Adams is a characteristic response shared by many composers to the absence of the organizing principles of tonality in the post-tonal context, including both serialists and some minimalists. 


\section{Chapter 2: Disunity and Form}

\subsection{Introduction}

The later work of John Adams, after the early minimalist pieces of the late 1970s, with their thoroughly rationalized, process driven forms, is apparently less rigorously organized, as suggested by the evidence and conclusions presented by Catherine Pellegrino in chapters 2-4 of her dissertation, ${ }^{100}$ and by the composer himself, when he commented that he "feels" the structure of a piece while composing, "as if an architect were building on an empty site without a blueprint." 101

In order to facilitate analysis and understanding of such works that are out of alignment with the values of musical formalism, a theory of non-formalist, disunified music is necessary. This chapter will undertake the task of laying the groundwork for such a theory by:

1. Systematically surveying how closure and hierarchy operate in each of three tonal practices, including tonal formalism (informed by Schenkerian theory), post-tonal formalism (informed by the set theory of Forte), and post-tonal non-formalism. This survey will reveal how closure (in section 2.3) and hierarchy (in section 2.4) become inoperable in a post-tonal non-formalist context, and bring into focus analytical goals appropriate for disunified music (summarized in section 2.5.1).

2. Providing a historical context for disunified music in practice and theory through introducing Stockhausen's moment form theory (in section 2.6).

Accomplishing these goals will provide a foundation for chapter 3 , which will outline a method for analyzing non-formalist disunified music, apply the method to music by John Adams, and summarize the results.

\footnotetext{
100 Pellegrino, "Formalist Analysis."

101 Schwartz, "Process vs. Intuition," 261.
} 


\subsection{Formalism in Tonal and Post-Tonal Practice}

A fundamental conceptual background to the compositional and theoretical issues involving formalism and tonality can be generalized and mapped out as indicated in Table 6 , in broad historical terms.

Table 6. Historical Overview of Formalism and Tonal Practice.

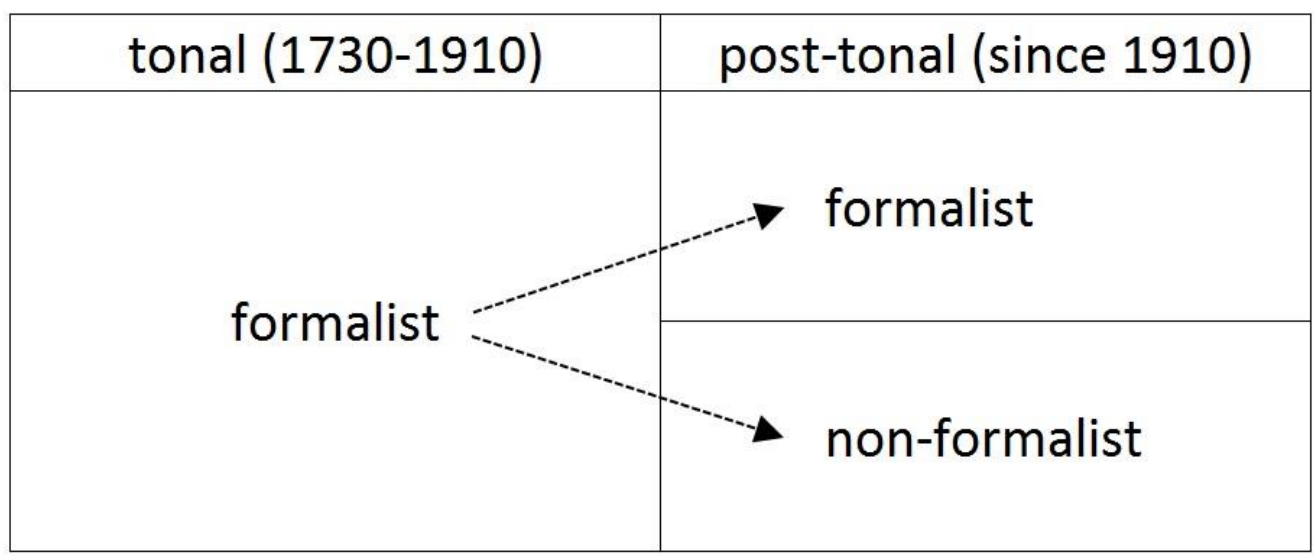

Information presented in this table of course reflects the well-known chronological divide between common practice tonality and the later, pluralistic discourse of post-tonal contextual practice, only here presented through the formalist lens. The distinctions between the three typologies of tonal practice outlined by the table, which I will label tonal formalism, post-tonal formalism, and post-tonal non-formalism, can be rendered by considering how the key elements of formalism, closure and hierarchy, function within each of them. Table 7 is such a rendering. ${ }^{102}$ The contents of the table are elaborated on in the following sections on closure and hierarchy, 2.3 and 2.4 respectively.

\footnotetext{
102 Table 7, as an abstraction or generalization of tonal practice, has the advantage of clarifying the issues at hand in understanding tonality and formalism, which is the intention here; of course it has the disadvantage, like any generalization, of glossing over conflicting detail. I think more is gained than lost, however, with this approach; and the introduction of specific musical examples in this chapter helps to anchor this "map" to the actual musical terrain it represents.
} 
Table 7. Formalism and Tonal Practice in Three Typologies.

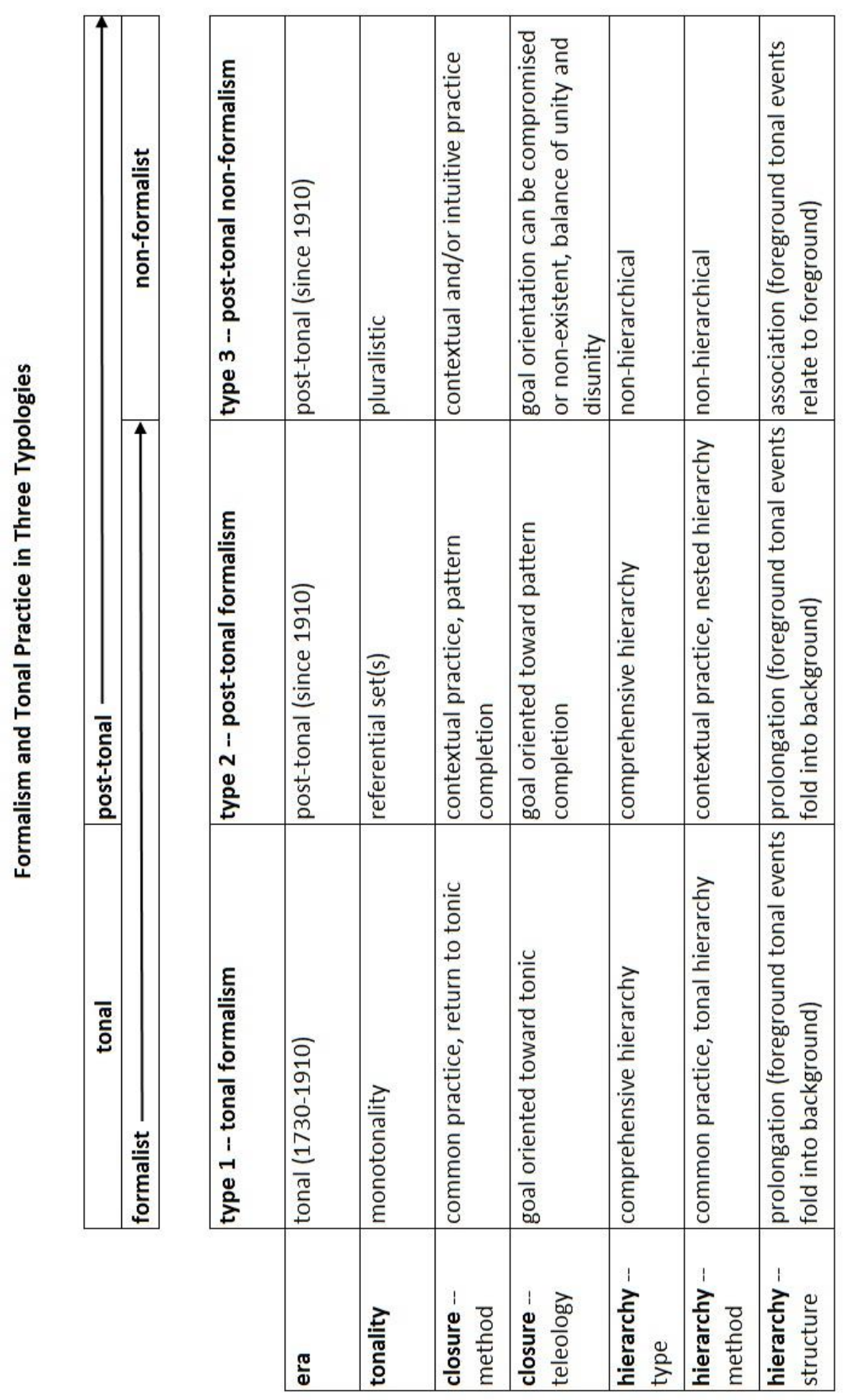




\subsubsection{Closure and Formalism: Introduction}

This section will 1. examine in broad outline three typologies of closure that are operative within tonal formalism, post-tonal formalism, and post-tonal non-formalism (labeled respectively types 1,2, and 3 in Table 7); 2. contextualize the position of Phrygian Gates by Adams among them; and 3. compare the analytical goals appropriate for elucidating music of the three typologies in order to clarify differences and identify challenges. Ultimately, the goal is to develop an analytical method for formal disunity. My template for closure is a strategy based on "pattern-completion."103 It consists of a perceived pattern moving toward completion over time. This strategy is therefore teleological, in that it engenders an "anticipated arrival" as a result of an expectation resulting from the perceived pattern.

\subsubsection{Closure and Type 1 Tonal Formalism}

Monotonality, within the Classic-Romantic era of ca. 1730-1910, is formalist, and the tonal organization of much of the music of this era can be encompassed within the theoretical models of Heinrich Schenker. Closure is effected through completion of the teleology of common practice tonality, which is achieved through return to the home key, or tonic. Schenker's theory emerged through his study of works by Bach, Haydn, Beethoven, and other composers of the Baroque and Classic-Romantic eras.

\subsubsection{Closure and Type 2 Post-Tonal Formalism}

Referential sets, whether diatonic, serial, or of some other construction, are characteristic of the post-tonal era, a period postdating ca. 1910. The organization of much post-tonal formalist music based on referential sets can be encompassed within the theoretical model of set theory as detailed in The Structure of Atonal Music by Allen Forte. For these sets to project musical architecture in a manner congruent with formalism, a composer must deploy their content in a rigorously consistent manner. This enables the possibility of

103 Joseph Straus, "A Principle of Voice Leading," passim. 
constructing a contextual, rather than common practice, teleology that is directed toward the goal of completing a tonal pattern, and thus achieve closure. A classic example of such a compositional methodology is the serial method as practiced by Schoenberg and Webern of the Second Viennese School, and by later adherents, such as Milton Babbitt and others. Phrygian Gates by John Adams is also arguably within this post-tonal formalist practice of closure as well (as demonstrated in section 1.2.4).

\subsubsection{Closure and Type 3 Post-Tonal Non-Formalism}

Post-tonal, non-formalist concert music post-dating 1910 is diverse and pluralistic in its tonal organization. It also challenges closure. Since it doesn't participate in common practice type 1 tonal formalism, and since it doesn't participate in type 2 contextual posttonal formalism that defines its own teleology through a rigorous system, formal closure in type 3 post-tonal non-formalist music is by definition compromised or even non-existent, at least in the sense as its understood in types 1 and 2. Since tonal or motivic features in this type 3 case do not conclusively denote form, our attention turns primarily to the surface or texture of a work for the signaling required to navigate the form, whether as listener or analyst. So instead of a teleology that seeks to attain the goal of closure by confirming a tonic, or completing a motivic pattern, post-tonal non-formalist music demonstrates an alternative aesthetic that seeks to balance the component parts of a form, particularly in the case of forms whose parts emphasize discontinuity. Balance is key.

The research of Jonathan Cross, published in The Stravinsky Legacy, is particularly relevant to this discussion, since it takes as its starting point Symphonies of Wind Instruments (1920) by Stravinsky, a landmark work that has been central to a discourse regarding formal discontinuity. In addition to providing a historical overview of analytical commentary regarding Symphonies, ${ }^{104}$ a commentary that helps to substantiate the work's status as a benchmark in formal innovation, Cross asserts that:

104 Jonathan Cross, The Stravinsky Legacy (New York: Cambridge University Press, 2005), 24-28. 
...the discontinuity of the variously-defined musical blocks, though mitigated in certain ways, remains unresolved to the end; ... and despite the 'morphology of closure' brought about by the concluding chorale, closure is nonetheless resisted: the musical fragments remain 'in play' beyond the end of the work. ${ }^{105}$

In addition to Stravinsky, other composers discussed by Jonathan Cross whose music exhibits similar formal discontinuity include Edgard Varèse, Olivier Messiaen, Karlheinz Stockhausen, Michael Tippett, Harrison Birtwistle, and Brian Ferneyhough. In his survey and analysis of the works of these composes, Cross shows how balance provides a means to achieving formal coherence in these works that engage with discontinuity. For example, he expresses general admiration for Debussy and Stravinsky in the way they impressively "handle the balance between integrative and disintegrative elements," in distinction from Varèse, whose formal oppositions in Amériques are "absolute, and therefore less coherent"; ${ }^{106}$ comments on how the "dynamism" of Michael Tippett's Piano Sonata No. 2 "springs from the way in which widely divergent materials are pitted against each other in a balanced way, without offering the possibility of reconciliation..."; 107 and remarks on how a "balancing is achieved" by Harrison Birtwistle in Carmen arcadiae mechanicae perpetuum in spite of the "diversity of materials and processes." 108

Although a precise metric is not provided by Cross by which to assess relative degrees of success with achieving a balance of component parts in a discontinuous form, Cross does invoke analytical tools devised by Cone, taken from Cone's article "Stravinsky: The Progress of a Method," in order to demonstrate with some specificity compositional features that contribute to integration, including the procedures of stratification, interlock, and synthesis. ${ }^{109}$ (Comments are here confined to the first two terms.) By stratification, he means "the separation in musical space of ideas" or "musical areas," so that ideas are expressed in alternation over time, such as A1, B1, A2, B2, A3, B3. And by interlock, he

\footnotetext{
${ }^{105}$ Cross, The Stravinsky Legacy, 25-26.

${ }^{106}$ Cross, The Stravinsky Legacy, 42.

${ }^{107}$ Cross, The Stravinsky Legacy, 70.

${ }^{108}$ Cross, The Stravinsky Legacy, 77.

${ }^{109}$ Edward T. Cone, "The Progress of a Method," Perspectives of New Music, vol. 1, no. 1 (Autumn 1962): 19-20.
} 
refers to the continuity between ideas, such as between iterations of $\mathrm{A}$ and iterations of $\mathrm{B}$, though interrupted by stratification. ${ }^{110}$

For the analyst, the task is to identify structures of stratification and interlock in a work to help assess the composite degree of balance among all its component parts. Cross shows how this compositional strategy can be engaged with analytically in the context of discontinuous, block-like forms.

For example, while remarking on how Amériques by Varèse is a work "fascinating in its unpredictability," ${ }^{111}$ he also notes that it avoids incoherence through "the way in which cross-block progressions take place (interlock),"112 thus alleviating the discontinuity produced by the work's stratification, which Cross describes as a "rhetoric of colliding sound-masses and shifting planes." ${ }^{113}$ He makes similar observations regarding the fourth movement of Et expecto resurrectionem mortuorum by Messiaen, noting that though "stratification is achieved by abrupt interruption of blocks," there is nevertheless "a degree of interlock across them (suggesting a limited linearity)."114 And Cross characterizes the form of Carmen arcadiae mechanicae perpetuum by Birtwistle as one where a "process of stratification" engenders a "comprehensive disruption of local continuity," and where "nonetheless, a larger-scale connectedness -- interlock -- is apparent..." between blocks. ${ }^{115}$ Musical features performing the function of "interlock" in Carmen between blocks identified by Cross include, among others, rhythmic patterns, harmonic clusters, timbre, pitch rotation, and homorhythmic and polyrhythmic textures. ${ }^{116}$ Many of the works by all of the composers discussed here are elucidated by Cross with similar specific evidence.

\footnotetext{
${ }^{110}$ Cone, "The Progress of a Method," 19.

${ }^{111}$ Cross, The Stravinsky Legacy, 46.

112 Cross, The Stravinsky Legacy, 42.

113 Cross, The Stravinsky Legacy, 42.

${ }^{114}$ Cross, The Stravinsky Legacy, 54.

115 Cross, The Stravinsky Legacy, 75.

${ }^{116}$ Cross, The Stravinsky Legacy, 74. See the book for a complete and systematic listing.
} 


\subsubsection{Closure and Formalism: Summary}

By comparatively examining how closure is operative within tonal formalism, post-tonal formalism, and post-tonal non-formalism (labeled respectively types 1, 2, and 3 in Table 7), we have seen in broad outline how: 1. closure within a system of tonal formalism is achieved through a teleology of return to tonic, 2. closure within a system of post-tonal formalism evolved into a teleology of pattern-completion, and 3. closure in a post-tonal non-formalist music emphasizes a balance between unity and disunity, or integrative and disintegrative elements, thus abandoning a teleology of closure, and therefore inaugurating a new formal paradigm. We have also seen how closure for types 1 and 2 can be theoretically contextualized within the systems of Schenker and Forte respectively, and how type 3 can begin to be elucidated through application of Cone's analytical tools of stratification and interlock. Composers were identified and specific works examined in order to exemplify creative responses to the new formal paradigm of discontinuous block structure described here.

This comparative analysis of three typologies of closure (two of which are formalist) facilitates the contextualization of Phrygian Gates by Adams among them, since its completion of a tonal pattern is clearly congruent to the method and teleology of type 2 (as demonstrated earlier in this paper in section 1.2.4).

Finally, by comparing the analytical goals appropriate for elucidating music of the three typologies, what emerges are the special challenges posed by type 3 post-tonal nonformalist works. Whereas type 1 and type 2 works have relatively objective criteria by which to identify teleology and closure, including return to tonic and pattern-completion respectively, type 3 works are assessed on the basis of balance, which is determined by a relatively subjective process of evaluating the equilibrium among component parts, each of which can be articulating either integration or disintegration. Repetition of content tends toward formal integration; minimal repetition or its absence tends toward disintegration. This assessment can be aided by applying Cone's method of identifying formal stratification and interlock to determine, if musical processes are operative between 
stratified blocks with related content to interlock them. The results of this analytical process can be seen to be operative on a continuum between polarities of unity and disunity. Although somewhat subjective, engagement with this analytical process does not preclude analyses of insight and utility - the ones by Cross sampled in section 2.3.4 are indicative of this.

\subsubsection{Hierarchy and Formalism: Introduction}

Like section 2.3 regarding closure and formalism, this section will 1. examine in broad outline three typologies of hierarchy that are operative within tonal formalism, post-tonal formalism, and post-tonal non-formalism (labeled respectively types 1, 2, and 3 in Table 7); 2. contextualize the position of Phrygian Gates by Adams among them; and 3. compare the analytical goals appropriate for elucidating music of the three typologies in order to clarify differences and identify challenges. Ultimately, the goal is to develop an analytical method for formal disunity.

Figure 6 will be introduced within this section in order to clarify through graphic representation the three typologies of hierarchy.

\subsubsection{Hierarchy and Type 1 Tonal Formalism}

Formalist hierarchy in tonal music (ca. 1730-1910) has been and continues to be primarily identified with and explained by the work of theorist Heinrich Schenker and his followers. Central to his theory is the understanding of music as an elaboration of simple harmonic structures beneath a work's surface, or background, into a complex external tapestry of sound, or foreground. The underlying structure, a simple contrapuntal outline, is labeled the "fundamental structure," or "Ursatz;" and the process of elaboration is described as "composing out" or "auskomponierung." These theoretical principles have been shown to

have considerable explanatory power for much of the repertoire of the Classic-Romantic era (ca. 1730-1910). 
Since Schenker's theory provides for a comprehensive mapping of all surface events to an underlying structure or Ursatz, it meets the condition of comprehensiveness required of musical formalism.

For convenience and simplicity, hierarchy within type 1 tonal formalism is represented in Figure 6 by the traditional harmonic model of Rameau, rather than the contrapuntal one of Schenker, a model which ranks the seven available diatonic chords within a key through privileging the tonic, subdominant, and dominant harmonies on the basis of their utility in defining a tonality, and which further ranks these three chords by recognizing the supporting functions of the subdominant and dominant relative to the tonic, within the common practice of the time. ${ }^{117}$ These harmonies will be represented in the conventional way in Figure 6 by Roman numerals I, IV, and V. Remarkably, the I-IV-V hierarchy discussed by Rameau in his theoretical writings of the 1730s is echoed by Schoenberg in his Harmonielehre of $1910,{ }^{118}$ thus bookending the inception and conclusion of the ClassicRomantic era with published appearances of the era's most significant tonal structures.

\subsubsection{Hierarchy and Type 2 Post-Tonal Formalism}

Formalist hierarchy in post-tonal music (since 1910), in contrast to tonal music, is based on the elaboration of a motive. The theoretical framework for analyzing motivic music was codified by Allen Forte in 1973 with the publication of The Structure of Atonal Music, where the motive is abstracted into a pitch class set that can be realized melodically and/or harmonically. Though appearing in 1973, this theory simply recognizes in a formal way a

\footnotetext{
${ }^{117}$ Thomas Christensen and and Graham Sadler, "Rameau, Jean-Philippe," Grove Music Online, accessed September 15, 2016, http://www.oxfordmusiconline.com

${ }^{118}$ Arnold Schoenberg, Theory of Harmony, trans. Roy E. Carter. (Los Angeles and Berkeley: University of California Press, 1983), passim. See for example the beginning of Chapter IV on "The Major Mode and the Diatonic Chords," or the beginning of Chapter IX on "Modulation."
} 
Figure 6. Hierarchy and Tonal Practice in Three Typologies.
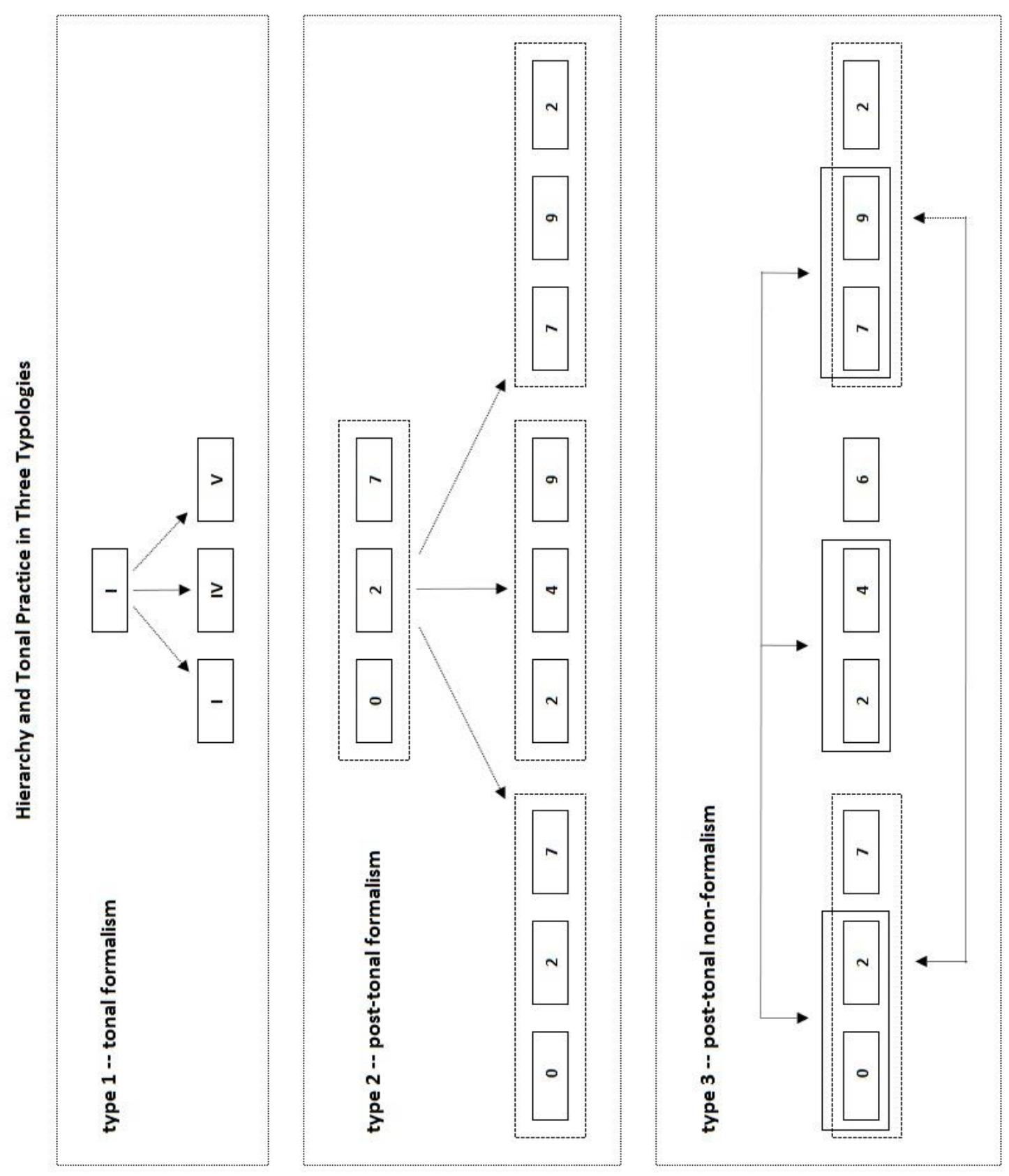
compositional technique that has been operative in much of the music composed since about 1910, and therefore also recognizes the evolutionary (or revolutionary) significance of the introduction of pitch class, or referential, sets as a basis for formal coherence in music, since it challenges the hegemony of tonality, or offers an alternative to it. ${ }^{119}$

Formalist hierarchy in music, or prolongation, requires comprehensiveness, and to meet this requirement in post-tonal music necessitates 1. the deployment of a motive, or referential set, in a rigorously consistent manner, and 2. that iterations of a set be arranged into a nested pattern, from background to foreground.

Prolongation in post-tonal music, involving large-scale projection of a motive from background to foreground, requires the motive's consistent and comprehensive projection in the foreground. Why is this necessary? Because ambiguity in the compositional deployment of motives on the surface introduces the problem of segmentation, requiring the determination or invention of rationale by which one can select partitions from the foreground that are congruent to a main motive. ${ }^{120}$ If such partitioning cannot be made with confidence, then motivic content at the foreground cannot clearly project a motive from the background, and therefore prolongation will be compromised or negated. Repertoire posing such analytical questions involving segmentation includes, for example, the atonal, pre-serial, motivic music of Schoenberg, Berg, and Webern, where the absence of a deterministic set of rules comparable to common practice tonality or serialism sometimes engenders an almost sphinxlike imperviousness to rational explanation. We continue to ask these questions of this music, however, since its enduring capacity to engage the interest of the musical community suggests its almost iconic significance in musical culture.

\footnotetext{
${ }^{119}$ Among the writings that explore the history of the evolution of the basis of musical form, from the tonal to the motivic, see:

Carl Dahlhaus, "Issues in Composition," In Between Romanticism and Modernism, trans. by Mary Whitall (Berkeley and Los Angeles: University of California Press, 1989), 61, 72.

Straus, Remaking the Past, 21-24. This writing also includes many citations for further exploration.

${ }^{120}$ For an outline of issues involving segmentation, and useful citations for additional research, see: Pieter C. Van Den Toorn, Music, Politics, and the Academy (Berkeley and Los Angeles: University of California Press, 1995), 220-223.
} 
More specifically, Schoenberg's post-tonal, pre-seral works from the period 1908-1922 provide a good example of the segmentation problem that results from non-systematic deployment of motivic content. His writings reflect this, since they suggest that his compositional methodology was in flux during this time:

Ever since 1906-1908, when I had started writing compositions which led to the abandonment of tonality, I had been busy finding methods to replace the structural functions of harmony. Nevertheless, my first distinct step toward this goal occurred only in $1915 .{ }^{121}$

He also specifically stated that his methodology was motivically based, though "free," before adopting the serial or twelve tone method:

In my workshop language ... I called this procedure 'working with tones of the motif'. This was obviously an exercise indispensable for the acquisition of a technique to conquer the obstacles which a set of twelve tones opposes to a free production of fluent writing. ${ }^{122}$

Schoenberg's abandonment of tonality while composing with motives in a free manner results in music where it can be difficult to identify a main motif, and therefore also difficult to segment or partition the surface in order to identify its recurrences. This condition problematizes closure or hierarchy in comprehensive formalist terms.

For a more specific example, No. 3 of Three Piano Pieces, Op. 11 (or Drei Klavierstücke) by Schoenberg demonstrates this problem. In addition to the analytical challenge normally involved with segmenting content that is freely and inconsistently deployed, as is the case here, the opening of No. 3 doesn't even clearly isolate a motive in its exposition in order to establish the starting point of a thread (unlike Op. 11, No. 1), confronting the listener instead with multiple strands of content simultaneously deployed, and thus confronting the theorist with an almost baffling multivalence.

\footnotetext{
${ }^{121}$ Arnold Schoenberg, "Composition With Twelve Tones (2)," In Style and Idea, ed. Leonard Stein (Berkeley and Los Angeles: University of California Press, 1984), 247.

122 Schoenberg, "Composition With Twelve Tones (2)," 248
} 
In a survey of theoretical perspectives on this piece, as compiled by theorist Jack Boss in his article "Away with Motivic Working," it is demonstrated that music lacking a comprehensive formalist framework, like Op. 11, No. 3, presents a considerable challenge to theorists who are seeking an explanatory consensus. ${ }^{123}$ In the absence of a post-tonal formalist framework, where a shared set of rules govern the deployment of content, analysis becomes problematic. Boss, for example, notes that theorist Reinhold Brinkmann identified "long and short range motivic and harmonic networks" that provide some coherence. $^{124}$ Example 8 shows Brinkmann's analysis of the first five measures of Op. 11, No.3.

Example 8. Schoenberg, Drei Klavierstücke, Op. 11, No. 3 (1909), First Five Measures Analyzed by Brinkmann. ${ }^{125}$

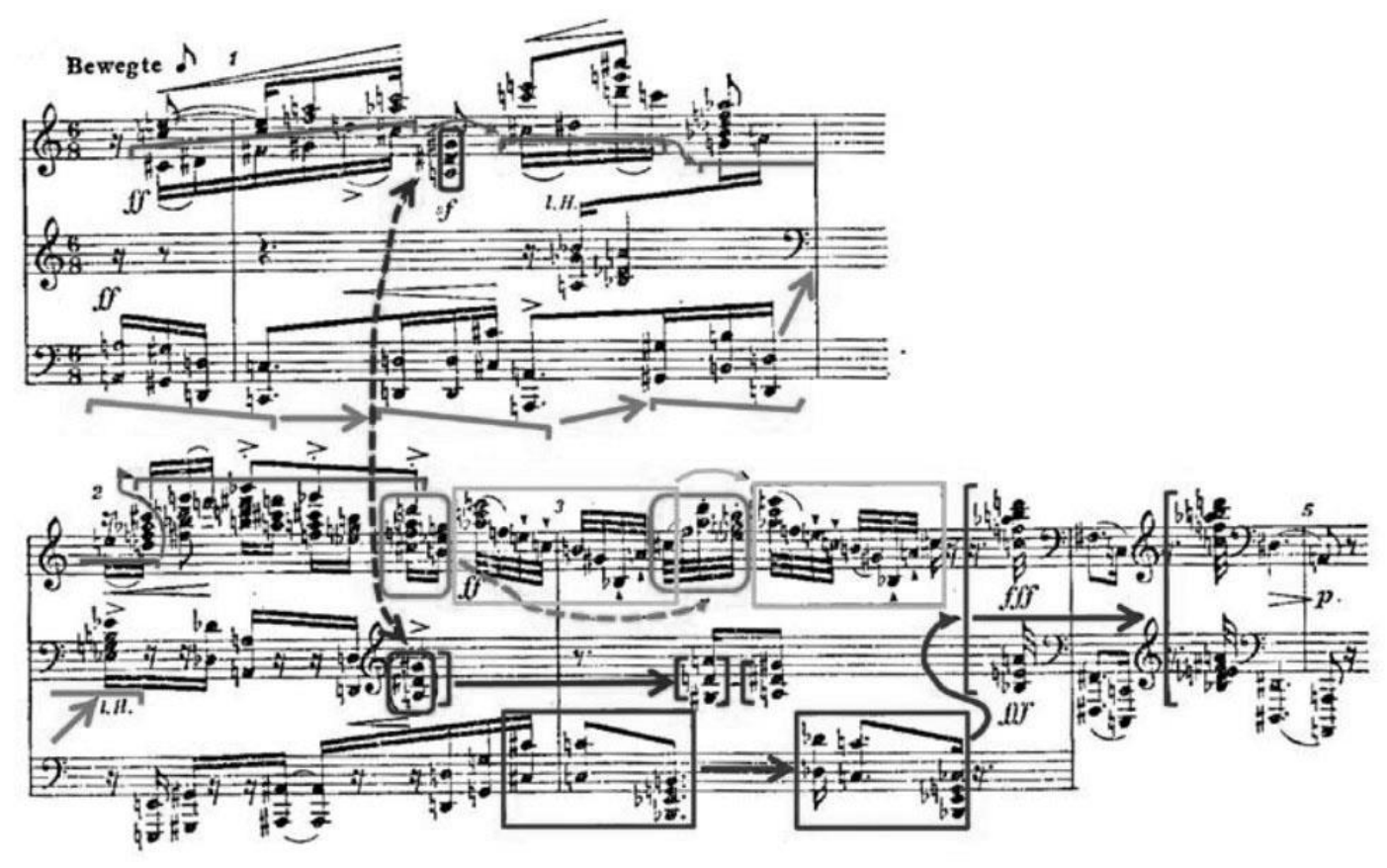

123 Jack F. Boss, "'Away with Motivic Working?' Not So Fast: Motivic Processes in Schoenberg's op. 11, no. 3," Music Theory Online, vol. 21, no. 3 (September 2015).

For the purposes of the argument, I will equate motif and theme to set in the following review of analyses of music by Schoenberg.

124 Boss, "Away with Motivic Working?," 13.

125 Reinhold Brinkmann, Arnold Schönberg: Drei Klavierstücke Op. 11: Studien zur frühen Atonalität bei Schönberg. Beihefte zum Archiv für Musikwissenschaft, vol. 7. (Wiesbaden: Franz Steiner Verlag, 1969), 121. Quoted in Boss, "Away with Motivic Working?," 13. 
Although Brinkman demonstrates coherence in the exemplar, it isn't comprehensive. There is content, for example, in the first system second stave, and in the second system third stave, that is not accounted for by Brinkman's set analysis, where sets are otherwise indicated by brackets, arrows, and squares.

On the other hand, Boss also references the work of theorist Ethan Haimo, who found the work to be athematic: "The opening ideas do not give way temporarily to other ideas; they give way permanently to those ideas, which — in turn - have their own fleeting moment on center stage only to disappear forever." 126

An analysis by Jack Boss identifies yet a third possible explanation of form in the same piano piece, one involving two motivic processes, one of which consists of expanding intervals. ${ }^{127}$ Clearly, the absence of a common practice, or set of rules for deployment of content, results in three completely different analyses of the same music by Brinkman, Haimo, and Boss.

Writings by other theorists make similar conflicting claims over the post-tonal, pre-serial repertoire of Schoenberg, which includes the Op. 11 piano pieces. Philip Friedheim, for example, asserts that the final movements of Drei Klavierstücke, Op. 11, Fünf Orchesterstücke, Op. 16, and all of Erwartung, Op. 17 are athematic. ${ }^{128}$ Alternatively, Herbert Buchanan declares that trichord (0-1-4), a "major-minor third intervallic cell," provides the basis for much of the content in Erwartung, as originally noted by $\mathrm{H}$. $\mathrm{H}$. Stuckenschmidt. ${ }^{129}$

\footnotetext{
${ }^{126}$ Ethan Haimo, Schoenberg's Transformation of Musical Language (New York: Cambridge University Press, 2006), 338. Quoted in Boss, "Away with Motivic Working?," 7.

127 Boss, "Away with Motivic Working?," passim.

128 Philip Friedheim, "Rhythmic Structure in Schoenberg's Atonal Compositions," Journal of the American Musicological Society, 19, no. 1 (1966): 59.

${ }^{129}$ Buchanan, Herbert H. "A Key to Schoenberg's 'Erwartung' (Op. 17)," Journal of the American Musicological Society, 20, no. 3 (1967): 439-440.

H. H. Stuckenschmidt, Arnold Schoenberg, trans. Edith Temple Roberts and Humphrey Searle (New York: J. Calder, 1959), 54. Quoted in Buchanan, "A Key," 439.
} 
This review of various theoretical perspectives on the post-tonal, pre-serial music of Schoenberg begins to demonstrate how music composed with motives without a normative, formalist framework results in music where it can be difficult to identify a main motif. Lack of motivic clarity in turn hinders segmentation of the surface, and therefore problematizes the demonstration of closure or hierarchy in comprehensive formalist terms.

But what if a motive or referential set is deployed comprehensively at the surface, and in transpositions intervallically congruent to itself? Prolongation in a post-tonal context would then become possible. Jonathan Cross considered such an outcome when he speculated on the possibility of a referential sonority becoming a "substitute for the triad," and of its corollary, the "prolongation of a referential sonority," although he still raised the problem of segmentation. ${ }^{130}$ Formalism can solve that problem. It therefore seems plausible to make claims of prolongation in post-tonal music that are analogous to tonal music when the context is formalist.

Figure 6 provides a graphic abstraction of this analogy, showing a correlation between hierarchies expressed in the context of tonal formalism and post-tonal formalism (types 1 and 2). It shows a hierarchy of tonic with a subordinate complex of tonic, subdominant, and dominant (I-IV-V); and immediately below this a hierarchy of referential set 0-2-7 with a subordinate complex of trichords $0-2-7,2-4-9$, and 7-9-2. The transpositional scheme by which the three trichords in the subordinate complex are derived from the referential set is intervallically congruent to the referential set itself, thereby generating three harmonic areas whose composite content can be said to be self-similar with its source. Although this abstraction has utility for clarifying the issues under consideration, it will be useful to provide examples showing how this model of formalist prolongational hierarchy in post-tonal music has a corresponding terrain in actual music.

In his article "Atonal Composing-Out" by theorist Joseph Straus we learn that structures expressing symmetry across scale are a "common solution" to the "central problem" of post-tonal music, which is one of "describing relatively large spans of music in coherent

${ }^{130}$ Cross, The Stravinsky Legacy, 201. 
ways," and that this compositional strategy has been given a variety of names, including "composing-out, concealed repetition, motivic parallelism, nesting, augmentation (enlargement), and self-similarity." ${ }^{131}$ We also learn that there exists a "vast literature on this subject." 132 Exemplars in the article demonstrate application of the method to music by a variety of composers in formal scales ranging from relatively small to large, including Ruth Seeger, Anton Webern, Schoenberg, Alban Berg, Stravinsky, and Milton Babbitt. Although most of the examples are not formalist, in that they do not feature comprehensive processes of closure or hierarchical layering, they still make the point of how pervasive the compositional method of projecting motivic self-similarity has been. Since our concern is with hierarchy expressed comprehensively in a formalist way, we will want to see large scale exemplars that demonstrate how self-similarity can control content for entire movements or even entire works.

The Straus article does include an apposite exemplar of a comprehensive large scale formalist hierarchy. It is the first movement of Schoenberg's Piano Concerto, Op. 42 (1942), where a prolongation of the work's serial theme engenders the entire movement, as demonstrated in Example 9. Here, each note of the row is projected by 12 corresponding harmonic areas consisting of prime and inverted forms of the series related by hexachordal combinatoriality, and their retrogrades. ${ }^{133}$

\footnotetext{
131 Joseph Straus, "Atonal Composing-Out," in Order and Disorder: Music-Theoretical Strategies in 20thCentury Music (Leuven, Flanders: Leuven University Press, 2004), 31.

132 Straus, "Atonal Composing-Out," 31. This writing also includes many citations for further exploration.

133 Straus, "Atonal Composing-Out," 33-34.
} 
Example 9. Schoenberg, Piano Concerto, Op. 42 (1942),

Prolongation of Serial Theme in the First Movement ${ }^{134}$

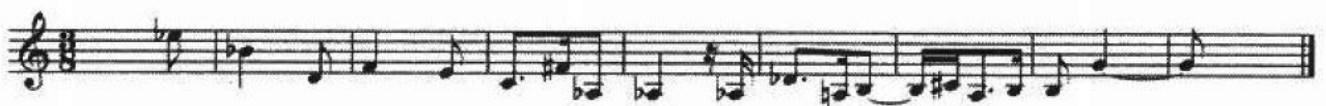

$P_{3}: \quad E b-B b-D-F-E-C-F \#-A b-D b-A-B-G$

pc: $\quad \begin{array}{llllllllllll}3 & 10 & 2 & 5 & 4 & 0 & 6 & 8 & 1 & 9 & 11 & 7\end{array}$

\begin{tabular}{|l|c|c|c|c|c|c|c|c|c|c|c|c|c|}
\hline Meas & 1 & 46 & 54 & 63 & 74 & 86 & 103 & & 107 & 117 & 122 & 126 & 133 \\
\hline Area & $\mathrm{A}_{3}$ & $\mathrm{~A}_{10}$ & $\mathrm{~A}_{2}$ & $\mathrm{~A}_{5}$ & $\mathrm{~A}_{4}$ & $\mathrm{~A}_{0}$ & $\mathrm{~A}_{6}$ & $\mathrm{~A}_{8}$ & $\mathrm{~A}_{1}$ & $\mathrm{~A}_{9}$ & $\mathrm{~A}_{11}$ & $\mathrm{~A}_{7}$ & $\mathrm{~A}_{3}$ \\
\hline Rows & $\mathrm{P}_{3}$ & $\mathrm{P}_{10}$ & $\mathrm{P}_{2}$ & $\mathrm{P}_{5}$ & $\mathrm{P}_{4}$ & $\mathrm{P}_{0}$ & $\mathrm{P}_{6}$ & $\mathrm{P}_{8}$ & $\mathrm{P}_{1}$ & $\mathrm{P}_{9}$ & $\mathrm{P}_{11}$ & $\mathrm{P}_{7}$ & $\mathrm{P}_{3}$ \\
& $\mathrm{R}_{3}$ & $\mathrm{R}_{10}$ & $\mathrm{R}_{2}$ & $\mathrm{R}_{5}$ & $\mathrm{R}_{4}$ & $\mathrm{R}_{0}$ & $\mathrm{R}_{6}$ & $\mathrm{R}_{8}$ & $\mathrm{R}_{1}$ & $\mathrm{R}_{9}$ & $\mathrm{R}_{11}$ & $\mathrm{R}_{7}$ & $\mathrm{R}_{3}$ \\
& $\mathrm{I}_{8}$ & $\mathrm{I}_{3}$ & $\mathrm{I}_{7}$ & $\mathrm{I}_{10}$ & $\mathrm{I}_{9}$ & $\mathrm{I}_{5}$ & $\mathrm{I}_{11}$ & $\mathrm{I}_{1}$ & $\mathrm{I}_{6}$ & $\mathrm{I}_{2}$ & $\mathrm{I}_{4}$ & $\mathrm{I}_{0}$ & $\mathrm{I}_{8}$ \\
& $\mathrm{RI}_{8}$ & $\mathrm{RI}_{3}$ & $\mathrm{RI}_{7}$ & $\mathrm{RI}_{10}$ & $\mathrm{RI}_{9}$ & $\mathrm{RI}_{5}$ & $\mathrm{RI}_{11}$ & $\mathrm{RI}_{1}$ & $\mathrm{RI}_{6}$ & $\mathrm{RI}_{2}$ & $\mathrm{RI}_{4}$ & $\mathrm{RI}_{0}$ & $\mathrm{RI}_{8}$ \\
\hline
\end{tabular}

Another relevant exemplar can be culled from the music of George Crumb. In the movement "Por Qué Nací Entre Espejos?" ("Why was I born surrounded by mirrors") from Madrigals, Book IV (1969), he organizes content both hierarchically and palindromically down to two levels, as shown in Figure 7; axes of symmetry denoting the palindromes are indicated by dotted lines.

${ }^{134}$ Straus, "Atonal Composing-Out," 34. Example 9 is a facsimile from the article. 
Figure 7. Crumb, Madrigals, Book IV: "Por Qué Nací Entre Espejos?" (1969),

Hierarchical and Palindromic Structures ${ }^{135}$

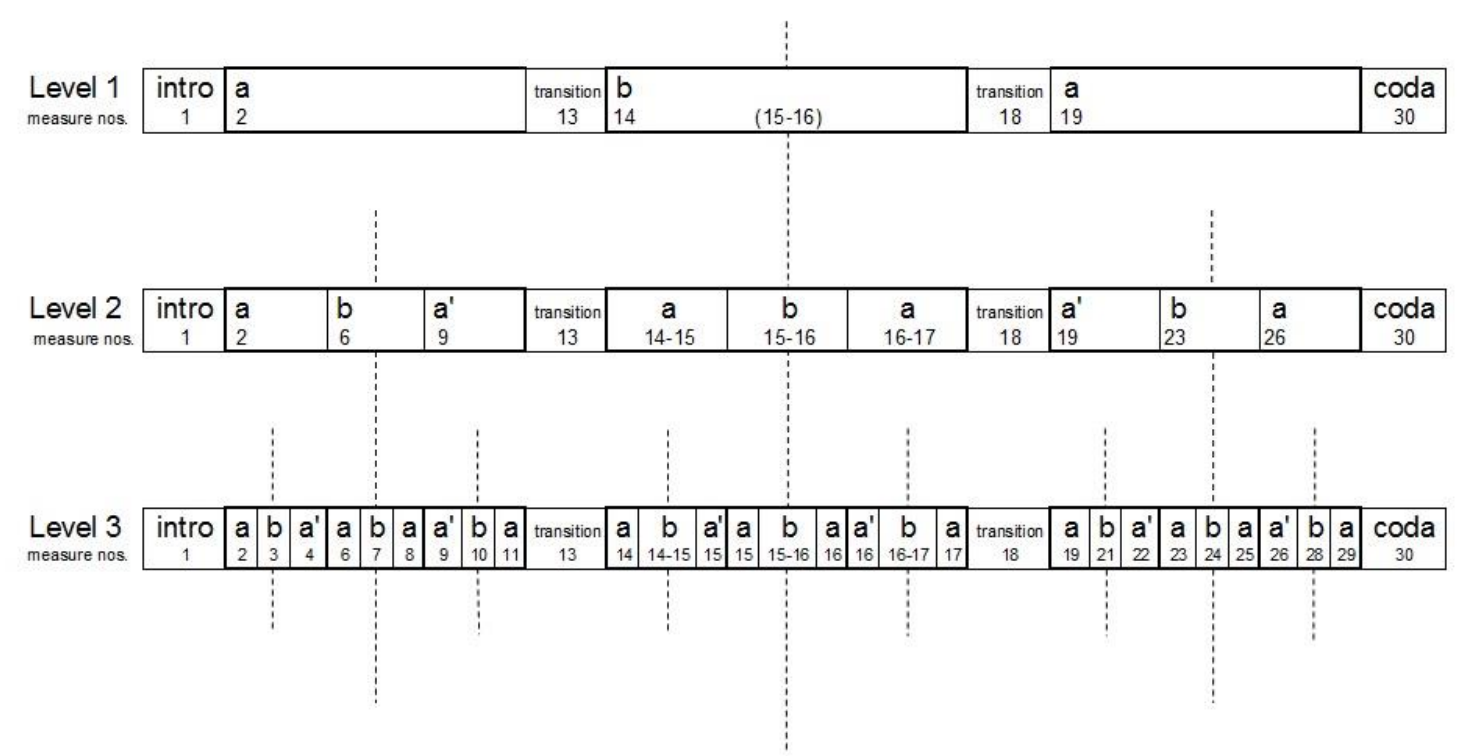

We learn from Brendan McConville that in Cello Variations (1970) by Charles Wuorinen, self-similarity occurs in both pitch and time. ${ }^{136}$

The first two measures of the work, for example, posit a six note referential set $(F, D, E$, $F \sharp, B, G)$ followed by five transpositions of same set based on its ordered intervals $(9,2$, $2,5,8)$, resulting in a symmetry across scale that expresses the set both directly in mm. 12 and in composite, nested form in mm. 1-9, as shown in Example 10. The initial pitch of each transposition of the referential set is circled in the Example, which in aggregate spells a collection isomorphic to the referential set, a nesting that Wuorinen projects through "distinct metric, timbral, agogic, and dynamic accents." 137

\footnotetext{
135 Diagram by author.

${ }^{136}$ Brendan McConville, "A 'Simple Composition' of Charles Wuorinen: Isomorphism, Self-Similarity, and Nesting in Cello Variations," Theory and Practice, vol. 36 (October 2011): 151-177.

137 McConville, "Nesting in Cello Variations," 154.
} 
Example 10. Charles Wuorinen, Cello Variations (1970), mm. 1-9. ${ }^{138}$
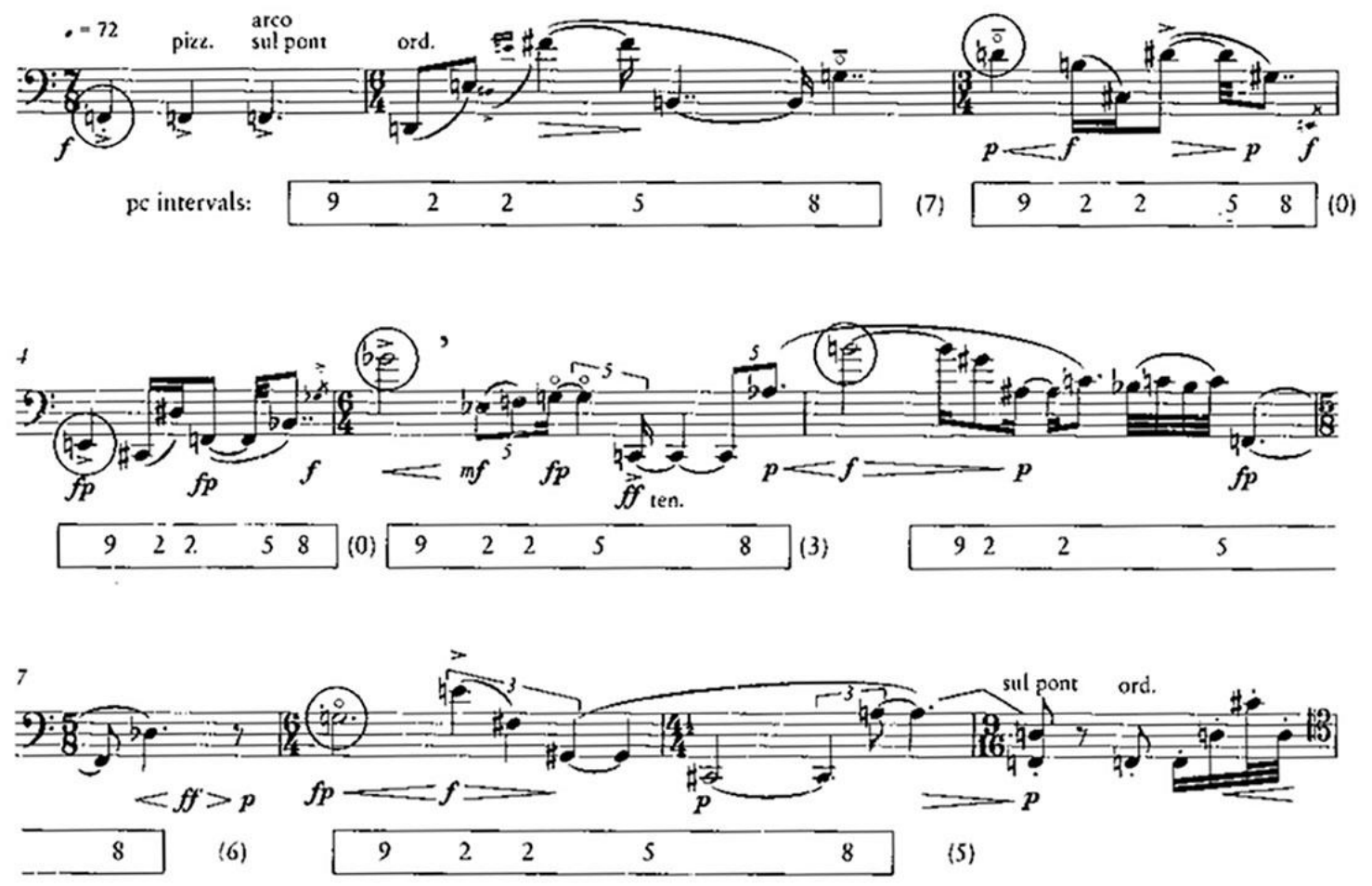

In Table 8 we see evidence from McConville showing how the referential set, or motive, is projected onto the form of Cello Variations as a whole. The pitch centers for each of the work's six sections in aggregate spell the referential motive, ${ }^{139}$ and the ordered intervals of the set $(9,2,2,5,8,10)$ determine the relative lengths in time of the sections, per the timepoint system developed by Milton Babbitt, and adapted by Wuorinen. ${ }^{140}$ Wuorinen's interest in self-similar structures of this kind eventually led him to research the fractal geometry of Mandelbrot in the late 1970s, and to compositionally apply processes inspired by fractals. ${ }^{141}$

\footnotetext{
138 McConville, "Nesting in Cello Variations," 153.

139 McConville, "Nesting in Cello Variations," 166.

140 McConville, "Nesting in Cello Variations," passim.

${ }^{141}$ McConville, "Nesting in Cello Variations," 175-176.
} 
Table 8. Charles Wuorinen, Cello Variations (1970), Formal Overview. ${ }^{142}$

\begin{tabular}{|c|c|c|c|c|c|c|}
\hline Section: & 1 & 2 & 3 & 4 & $s$ & 6 \\
\hline Measures: & $1-43$ & $44-52$ & $53-62$ & $63-80$ & $81-112$ & $113-132$ \\
\hline $\begin{array}{l}\text { duration in } \delta \\
\text { at } \$=144 \text { : }\end{array}$ & $\begin{array}{c}9 \times 36= \\
324 \delta\end{array}$ & $\begin{array}{c}2 \times 36= \\
72 \delta\end{array}$ & $\begin{array}{c}2 \times 36= \\
72 \curvearrowright\end{array}$ & $\begin{array}{l}5 \times 36= \\
180 \$\end{array}$ & $\begin{array}{c}8 \times 36= \\
288 \downarrow\end{array}$ & $\begin{array}{c}10 \times 36= \\
360 \$\end{array}$ \\
\hline Actual tempo: & $\delta=144$ & $\lambda=144$ & $\delta=120$ & $j=96$ & $\lambda=144$ & $\delta=144$ \\
\hline $\begin{array}{l}\text { Real duration } \\
\text { in } \delta:\end{array}$ & $\begin{array}{c}324 \oint^{\prime} \\
\text { (same as row } 3)\end{array}$ & $\begin{array}{c}72 \delta \\
\text { (same as roul } 3 \text { ) }\end{array}$ & $\begin{array}{c}60 \AA \\
(72: \times 5 \%=60.4)\end{array}$ & $\begin{array}{c}120 \oint \\
\left(180: \times 2 / 3=120^{\prime}\right)\end{array}$ & 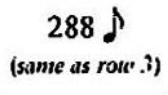 & $\begin{array}{c}360 \text { (same as row 3) } \\
\text { (s) }\end{array}$ \\
\hline Pitch Center: & $\mathbf{F}$ & D & $\mathbf{E}$ & $\mathrm{F}$ & B & G \\
\hline
\end{tabular}

Although the early minimalist style challenged the chromaticism and complex rhythms of serialist composers like Babbitt and Wuorinen through diatonicism and a steady pulse, it still shared, perhaps ironically, a formalist approach in its systematic procedures, such as phasing, and additive and subtractive processes. In Music for Eighteen Musicians (19741976) by Steve Reich, for example, in what is arguably a formalist hierarchy, a series of eleven chords are stated twice at the outset, as shown in Example 11, and then each of the eleven chords are prolonged into what the composer describes as a "small piece," the lengths varying from four to six minutes each. ${ }^{143}$ It may be that the form of this piece served as a model for Adams when composing Phrygian Gates.

\footnotetext{
142 McConville, "Nesting in Cello Variations," 165.

143 Potter, Four Musical Minimalists, 232.
} 
Example 11. Steve Reich, Music for Eighteen Musicians (1974-1976), Chord Pattern. ${ }^{144}$

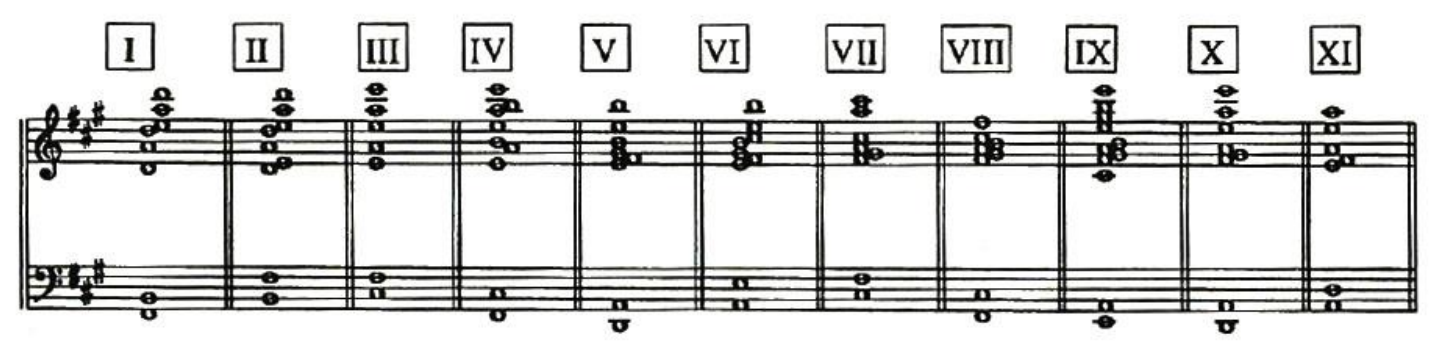

This is the stylistic context for the earliest works of John Adams, including Phrygian Gates (1977-1978), and arguably China Gates (1977) as well, a minimalist context that features formalist processes generating content in a music featuring diatonic pitch collections and regular pulsation. In addition, these early works can also be said to participate in a larger stream of twentieth-century musical thought featuring formalist post-tonal analogues of the formalist tonal hierarchy, where the elaboration of a motive takes the place of the elaboration of harmonic structures. Comments by Adams reveal his awareness of this method of creating symmetry across scale in musical form. For example, like Wuorinen, he sees fractal geometry analogous to hierarchy in music, as is evident when he asserts that the unfolding of an entire Beethoven symphony or Wagner opera can be "encapsulated within the first page or two, albeit in fractal form." ${ }^{145} \mathrm{He}$ also invokes biological metaphors for the same purpose when discussing the form of his Violin Concerto (1993):

The Violin Concerto ... in some ways is the most rigorously worked out piece that I have composed in terms of its internal design, its genetic structure and the way in which the larger structures reiterate. What's the expression we learned in biology, "Phylogeny replicates ontogeny"? Basically, the large organism is a picture of the smallest cellular structure. For example, in the first movement, those rising waves of triads become basic genetic material for the entire movement. ${ }^{146}$

These comments clearly suggest that this concerto merits investigation along formalist lines, especially considering how Adams makes use of the word "rigorously," implying a comprehensiveness that is consistent with formalism. In addition and more generally, these

\footnotetext{
144 Potter, Four Musical Minimalists, 234.

${ }^{145}$ Adams, Hallelujah Junction, 191.

${ }^{146}$ Rebecca Jemian and Anne Marie De Zeeuw. "An Interview With John Adams." Perspectives of New Music, vol. 34, no. 2 (June 1, 1996): 91.
} 
and other comments by Adams suggest that he is a composer who will employ, at least to some degree, processes and symmetry across scale as compositional methodologies, so it may be useful for analysts to be mindful of these possibilities when examining his scores.

\subsubsection{Hierarchy and Type 3 Post-Tonal Non-Formalism}

Whereas formalist hierarchy in tonal music is based on the elaboration of harmonic structures (type 1), and in post-tonal music on the elaboration of a motive in a systematic and comprehensive way (type 2), formalist hierarchy is essentially non-existent when the basis of musical discourse isn't comprehensively systematic (type 3). In the absence of a deterministic set of rules, segmentation of foreground content on the basis of congruence to a generating motive is problematic; and if such congruence cannot be established, then the possibility of a formalist hierarchy isn't possible.

Figure 8, a detail from Figure 6, provides a graphic abstraction of this problem through comparing types 2 and 3.

Figure 8, Detail from "Figure 6. Hierarchy and Tonal Practice in Three Typologies".
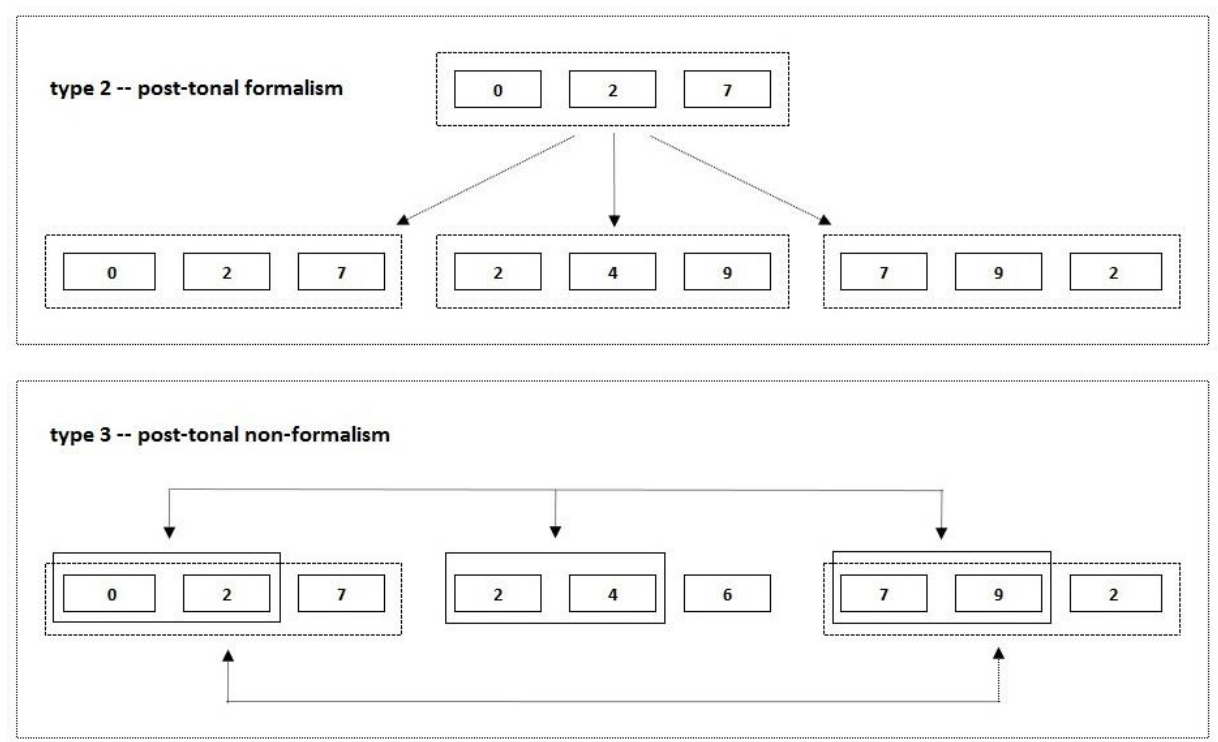
In the type 2 example there is strict control of foreground content, consisting of three transpositions of the main motive at intervals congruent to that motive, thereby rendering prolongation.

In the type 3 example there is a lack of control of foreground content, resulting from the middle trichord diverging from 2-4-9 to 2-4-6, thus disrupting self-similar motivic patterning at the surface. This collapses the hierarchy. In addition, the problem of segmentation arises since the foreground content is inconsistent and non-systematic. For example, in the type 3 case two possible partitionings that incompletely render the main motif are shown (with down and up arrows respectively), but other partitions or segments could be selected based on similar or even differing criteria. The type 3 non-formalist pattern recalls the observations of Jonathan Bernard in connection with the structure of the minimalist music of Philip Glass and Steve Reich, i.e. how it consists of a sequence of formal units without a hierarchy of deeper structural layers (discussed in section 1.3.1). ${ }^{147}$ In this comparative analysis between type 2 and type 3 patterning, we see how the type 2 formalist pattern prolongs a referential motive, and how the type 3 non-formalist pattern can only associate elements at the surface. In the absence of prolongation, we can only make claims of association. In making this distinction between prolongation and association, we are adopting the terminology of Joseph Straus as presented in his article "The Problem of Prolongation in Post-Tonal Music" (discussed in section 1.3.2 above). ${ }^{148}$ In "The Problem" Straus questions Salzer's analysis of Stravinsky's Symphony in Three Movements in which he makes claims of prolongation, ${ }^{149}$ and characterizes the association of motives in Symphonies of Wind Instruments as a "mimicry of the prolongation types of tonal music without their original significance."150 Similar mimicry, or association, is observed by Straus to be operative in Stravinsky's Septet and Les Noces. ${ }^{151}$

\footnotetext{
${ }^{147}$ Bernard, "Problem of Minimal Music," 274, 278.

148 Straus, "The Problem of Prolongation," 13. "If we wish to discuss middleground structure in post-tonal music, we will have to retreat to a less comprehensive but more defensible model of voice leading, one based on association rather than prolongation. Association claims differ significantly from prolongational claims."

149 Straus, "The Problem of Prolongation," 10-13.

150 Straus, "The Problem of Prolongation," 17.

151 Straus, "Atonal Composing-Out," 39-40.

Straus, "Atonal Composing-Out," 48-49.
} 


\subsubsection{Hierarchy and Formalism: Summary}

By comparatively examining how hierarchy is operative within tonal formalism, post-tonal formalism, and post-tonal non-formalism (labeled respectively types 1, 2, and 3 in Table 7), we have seen in broad outline how:

1. hierarchy within a system of tonal formalism is achieved through an underlying structure, a simple contrapuntal outline, labeled the "fundamental structure," or "Ursatz," and through the process of elaborating content from the Ursatz, described as "composing out" or "auskomponierung;"

2. hierarchy within a system of post-tonal formalism is achieved through large-scale projection of a motive from background to foreground, a method requiring the motive's consistent and comprehensive projection in the foreground; and

3. hierarchy in post-tonal non-formalist music is essentially non-existent, since the structural layers possible in formalist music featuring tonality, or featuring systematic deployment of a motif, cannot be achieved by non-formalist, non-systematic procedures, resulting in a single layer of content.

We have also seen how hierarchy for types 1 and 2 can be theoretically contextualized within the systems of Schenker and Forte respectively, and how the single layer of content in type 3 music can be elucidated through application of Straus's analytical concept of association, a concept explicated through contrast with prolongation - the former for describing connections between ideas in a single musical surface without layers, the latter for describing connections between layers.

This comparative analysis of three typologies of hierarchy (two of which are formalist) facilitates the contextualization of Phrygian Gates by Adams among them, since its layered deployment of a motivic pattern is congruent to the method of type 2 (as demonstrated earlier in this paper in section 1.3.3). 
Finally, by confronting the necessity to scale back claims of prolongation to association when analyzing post-tonal non-formalist music, we are also compelled to confront a type of music analysis that engages with musical disunity, since musical unity requires prolongation in order to explain or rationalize how the variety of musical content on the surface of a work is an organic manifestation of a single idea.

\subsubsection{Principles of Disunity}

The summaries in sections 2.3.5 and 2.4.5 have demonstrated how non-formalist compositional procedures can lead to musical structure lacking the teleology of closure and the coherence of organic unity, thus requiring a new analytical paradigm. Based on these findings, analysis of a non-formalist work will therefore identify sections based on content arranged in a flat, non-hierarchical sequence, detect where and how content recurs through association and stratification, and assess the balance between integrative and disintegrative elements. Balance assessment of this kind occurs between reciprocals of unity and disunity on a continuum, rather than in polarity.

\subsubsection{Closure, Hierarchy, and Disunity}

When engaging with disunity in musical analysis, one should consider the significant investment musicologists and theorists have placed in its opposite, organic unity. Alan Walker, for example, in his article "Chopin and Musical Structure: An Analytical Approach" (1973), says that it is the "presence or absence of background unity as a criterion which enables us to distinguish between mastery and mediocrity." 152 Ruth Solie, in her article "The Living Work: Organicism and Musical Analysis" (1980), invokes Heinrich Schenker himself through his pronouncement that "musicians are distinguished into those who create out of the background, who are the geniuses ... and those who move only within the foreground, who are the non-geniuses ..." ${ }^{153}$ Ultimately, Solie comes to the conclusion

\footnotetext{
${ }^{152}$ Alan Walker, "Chopin and Musical Structure: An Analytical Approach," In The Chopin Companion: Profiles of the Man and Musician, ed. Alan Walker (New York: W.W. Norton, 1973), 228.

153 Ruth A. Solie, "The Living Work: Organicism and Musical Analysis," 19th Century Music, vol. 4, no. 2 (Autumn, 1980): 155.
} 
that "organic aesthetic beliefs [i.e. background engendering foreground] have been useful ... insofar as they have helped to steer the course of analysis away from the purely mechanistic and simplistically structural," thus avoiding "morphological, low-level observations." 154

More recently, scholars have been challenging organic unity as the ideal of musical aesthetics, and the goal of analysis. Musicologist Robert Fink, for example, in "Going Flat: Post-Hierarchical Music Theory and the Musical Surface" (2001), explains that he will "present a hyperbolic series of analytical vignettes, from Beethoven to Rochberg, that will attempt to demonstrate that depth models of musical structure become progressively more untenable — or, at least, progressively worse explanations of salient musical experiencesas we approach the contemporary moment."155 Indeed, a related case in point concerns how Schenker's theory or "depth model" of prolongation, when applied to the music of Stravinksy, has delivered dubious results, as observed by theorists Joseph Straus and Gretchen Horlacher. ${ }^{156}$ This of course isn't surprising since much of Stravinsky's music is post-tonal, and therefore operates outside a common practice system with a normative scaling of consonance and dissonance. In the absence of this scaling it isn't possible to comprehensively rank content hierarchically, and project prolongation.

More recently, William van Geest, in "The Concept of Unity in Musical Analysis: Some Ontological Issues" (2012), claims that "the coexistence of unity and disunity is not only possible, it is necessary." And that, "in order for a claim for unity to bear analytical significance, it must be in spite of a disunity of some type." He also likens this insight to

\footnotetext{
154 Solie, "The Living Work," 156.

155 Robert Fink, "Going Flat: Post-Hierarchical Music Theory and the Musical Surface," In Rethinking Music, eds. Nicholas Cook and Mark Everist (New York: Oxford University Press, 2001), 103.

156 Straus, "The Problem of Prolongation," 10-13.

Gretchen G. Horlacher, Building Blocks: Repetition and Continuity in the Music of Stravinsky (New York:

Oxford University Press, 2011), Chapter 2, page 8. She describes these analytical attempts as "uncomfortable adaptations" that "generally suffered from an overextended reliance on Schenker's model."
} 
be congruent with the "ancient doctrine of discordia concors, by which harmony is produced by conflicting elements." 157

This re-examination of unity and disunity in music helps facilitate the consideration of an alternative viewpoint - instead of a totalizing discourse of irreconcilable opposites operative as polarities, one can think of complementary reciprocals operative on a continuum. Or metaphorically, we can trade a switch for a knob. And although increasing the diversity of foreground content, toward disunity, leads to a threshold that, when crossed, renders untenable the possibility of organic unity through prolongation, it also leads to an alternative strategy of non-organic unity through association of non-hierarchical elements. Basically we relinquish hierarchy and go flat. And we carry into the new musical situation a dialectic of balance between unity and disunity. These are, of course, the theoretical conclusions reached earlier in this chapter in section 2.5.1, "Principles of Disunity." These conclusions also have a historical antecedent in the early $20^{\text {th }}$ century, namely "moment form."

\subsubsection{Moment Form and Block Form: Introduction}

The balance between unity and disunity, or between continuity and discontinuity, had been engaged with by German composer Karlheinz Stockhausen (1928-2007), a member of the Darmstadt School, and then incorporated into a theory that describes a musical form emphasizing discontinuity. He labeled it "moment form" and introduced it through his 1960 article "Moment Form - New Relations between Durations of Performance and Work and Moment." ${ }^{158}$ Marianne Wheeldon, in Interpreting Discontinuity in the Late Works of Debussy, has described moment form as "one of the few theoretical attempts to broach musical discontinuity, both theoretically and aesthetically." ${ }^{159}$ Noting the attention given the music of late Debussy in writings by other composers of the Darmstadt School,

\footnotetext{
${ }^{157}$ William van Geest, "The Concept of Unity in Musical Analysis: Some Ontological Issues" (paper presented at the 5th International Conference of Students of Systematic Musicology, Montreal, Canada, May 24-26, 2012). This document reviews the writings of many authors over many years, and includes an extensive list of citations.

${ }^{158}$ The earliest moment form piece by Stockhausen is Kontakte (1958-1960).

${ }^{159}$ Wheeldon, "Interpreting Discontinuity," 98.
} 
including Herbert Eimert (1897-1972) and Pierre Boulez (1925-2016), ${ }^{160}$ and the relevance of moment form to discontinuity in Debussy's late works, she was able to effectively adapt principles of the moment form theory to analyze late Debussy. Although the orchestral work Jeux (1912), which was of particular interest to the Darmstadt School, ${ }^{161}$ and other late works by Debussy predate Stockhausen's creation of moment form, "the latter may be understood as having codified formal practices that had been prevalent for many decades." ${ }^{162}$

Moment form theory can also be adapted for the purpose of analyzing the music of John Adams. This requires demonstrating the correlation between moment form and block form, since the music of Adams exhibits block form structures similar to those in the music of Stravinsky. ${ }^{163}$ Writings of Jonathan Kramer and Jonathan Cross show this connection.

Jonathan Kramer adapted moment form for analyzing the music of Stravinsky, in particular Symphonies of Wind Instruments (1920), a work that has an iconic significance comparable to Jeux in the way it innovated discontinuous deployment of content, ${ }^{164}$ and in its lasting influence. ${ }^{165}$ And like Wheeldon, he notes how the moment form theory rationalized decades of previous compositional practice, ${ }^{166}$ including the work of composers such as Stravinsky, Webern, Varese, and Messiaen. ${ }^{167}$

Kramer's application of moment form to the analysis of Stravinsky's music is unusual, given that his music has typically been described by scholars in terms of "block form," as exemplified by such writers as Gretchen Horlacher in Building Blocks: Repetition and Continuity in the Music of Stravinsky (2011), or Jonathan Cross in The Stravinsky Legacy (2005), in the chapter entitled "Block Forms." But it isn't just Kramer. Cross also sees

\footnotetext{
${ }^{160}$ Wheeldon, "Interpreting Discontinuity," 98-99.

161 Wheeldon, "Interpreting Discontinuity," 97.

162 Wheeldon, "Interpreting Discontinuity," 113.

163 Cross, The Stravinsky Legacy, 176-177.

164 Jonathan D. Kramer, "Moment Form in Twentieth Century Music," The Musical Quarterly, vol. 64, no. 2 (April 1978): 184. "... probably the first moment-form piece ever composed."

165 Cross, The Stravinsky Legacy, 24. "... had a profound impact on subsequent composers."

166 Kramer, "Moment Form," 193.

167 Kramer, "Moment Form," 179.
} 
moment form and block form as related. He asserts that "the music of both Stravinsky and Stockhausen - their shared modernism - appears to be concerned with suggesting continuities while simultaneously maintaining discontinuities." 168 This shared aesthetic legacy also has a related theoretical underpinning, according to Cross, in that Stravinsky's "radical block structures," as exemplified by works such as The Rite of Spring (1913), Les Noces (1917, 1923), and Symphonies of Wind Instruments (1920), parallels "Stockhausen's attempt to build new forms independent of models from the past, devoid of the old kinds of narrativity and connectedness." 169

My initial impression upon hearing the works by Adams entitled Century Rolls (piano concerto, 1996) and Son of Chamber Symphony (2007), the subjects of analyses in this paper, was of their similarity to the block like structures of Stravinsky, as found in works such as Les Noces $(1917,1923)$ and Symphony in Three Movements (1945). Indeed, Adams has even acknowledged "the particular influence of Stravinsky" in connection with his orchestral work Fearful Symmetries (1988). ${ }^{170}$ And Jonathan Cross has documented how Adams borrowed elements from the score of Petrushka (1911) for use in both Tromba Lontana (1986) and Short Ride in a Fast Machine (1986). ${ }^{171}$ Cross has also characterized, with some evidence, the structure of Fearful Symmetries to be as "block-like as anything found in Stravinsky." 172 Given the relevance of block form to the music of Adams, and the correlation between block form and moment form, I will apply the basic principles of moment form to understanding block form in the music of Adams. Finally, since the Adams works I will analyze are apparently non-formalist, and since I haven't found any evidence of consistent and/or comprehensive processes at work, a theory appropriate for non-formalist music is required, like moment form.

\footnotetext{
${ }^{168}$ Cross, The Stravinsky Legacy, 57.

${ }^{169}$ Cross, The Stravinsky Legacy, 56.

${ }^{170}$ Cross, The Stravinsky Legacy, 175.

${ }^{171}$ Cross, The Stravinsky Legacy, 175.

${ }^{172}$ Cross, The Stravinsky Legacy, 176.
} 


\subsubsection{Moment Form: Basic Principles}

When analyzing the music of late Debussy through the lens of moment form, Marianne Wheeldon first condensed an explanation of the theory into "three main issues." ${ }^{173}$ This approach focused her analyses into observing compositional characteristics that are in alignment with these issues, and thus enhance the focus and effectiveness of her argument with respect to advancing Debussy as a modernist.

The first issue concerns the autonomy of the individual moment. Stockhausen characterizes the moment as "something individual, independent, and centered in itself, capable of existing on its own." 174 This means that a musical idea within a moment doesn't require content outside that moment for completion, which in turn also means that a musical idea should reach conclusion within its moment.

The second issue follows from the first. It concerns the requirement for moments not to prepare or follow from neighboring moments. He states that moment forms "do not aim toward a climax, do not prepare the listener to expect a climax, and their structures do not contain the usual stages found in the development curve of the whole duration of a normal composition: the introductory, rising, transitional, and fading stages." 175

Finally, the third issue follows from the second. Endlessness. With the suppression of the usual stages or formal processes in a composition, there is correspondingly the absence of the normally obligatory beginning, middle, and end. In this way a listener's experience of passing time is compromised or non-existent, since he or she will be focused on each autonomous, discontinuous moment, rather than on a succession of dependent, continuous moments. ${ }^{176}$

\footnotetext{
${ }^{173}$ Wheeldon, "Interpreting Discontinuity," 100.

${ }^{174}$ Karlheinz Stockhausen, "Momentform: Neue Zusammenhange zwischen Aufführungsdauer, Werkdauer und Moment," In Texte zur elektronischen und instrumentalen Musik, Vol. 1 (Cologne: DuMont, 1963), 200. Quoted in Wheeldon, "Interpreting Discontinuity," 100.

175 Stockhausen, "Momentform," 198-199. Quoted in Wheeldon, "Interpreting Discontinuity," 100.

176 Stockhausen, "Momentform," 199. Quoted in Wheeldon, "Interpreting Discontinuity," 100-101.
} 


\subsubsection{Moment Form: Reflection on Basic Principles}

There is a rigidity inherent in the basic issues or principles laid out in Stockhausen's "Moment Form" article of 1960. Suggesting the ideological climate of the Darmstadt School, the document presents an aesthetic program of radical musical discontinuity that is typical of the formal systems he had been devising in the 1950s and 1960s. ${ }^{177}$ Later, however, he allowed for flexibility in the degree to which moments are autonomous:

There can be moments which have no common elements, or as few common elements as possible, and there are other moments which have a lot in common. Momentforming simply means that there is also the extreme of no common material, and that every given moment has a certain degree of material that has been used before, and of material that is going to be used next. And I say "a certain degree." And I choose these degrees very carefully from moment to moment, between zero and maximum. So the maximum means there is a moment so full of other influences of the past and the future that it is hard to identify this moment. ${ }^{178}$

He also identified a formal problem that can emerge when shared content between moments is dialed down to zero:

If one wants to be different all the time a monotony occurs, ... because trying to be different from element to element all the time leads again to something ... they all have in common, which means to be different or trying to be different, and it levels out all the organic differences. ${ }^{179}$

Marianne Wheeldon's analysis of Debussy's piano prelude Ondine (1913) includes a diagram, reproduced here as Figure 8, that demonstrates how this formal problem is avoided through a careful calibration by the composer of the distribution of shared content between moments. The semicircles in the diagram that show connection between moments with similar material also show a careful plan that seems designed to both "avoid any one

\footnotetext{
177 Wheeldon, "Interpreting Discontinuity," 114. These systems included pointillistic form, group form, statistical form, etc.

178 Karlheinz Stockhausen and Jerome Kohl, "Stockhausen on Opera," Perspectives of New Music, 23, no. 2 (1985): 25. Quoted in Kramer, The Time of Music, 208. Quoted in Michael D. Albaugh, "Musical Form and Joseph Schwantner's Aftertones of Infinity" (DMA, West Virginia University, 2004), 63.

179 "Lecture 1 [PARTE 1/4] Stockhausen Karlheinz - English Lectures (1972)," YouTube, posted 25 January 2013, accessed 4 February 2016, https://www.youtube.com/watch?v=IYmMXB0e17E.
} 
form appearing too often" to promote discontinuity, and yet places "an old moment in the midst of new moments" to subvert the predictability of constant newness. ${ }^{180}$

Figure 8. Ondine, Network of Repetitions. ${ }^{181}$

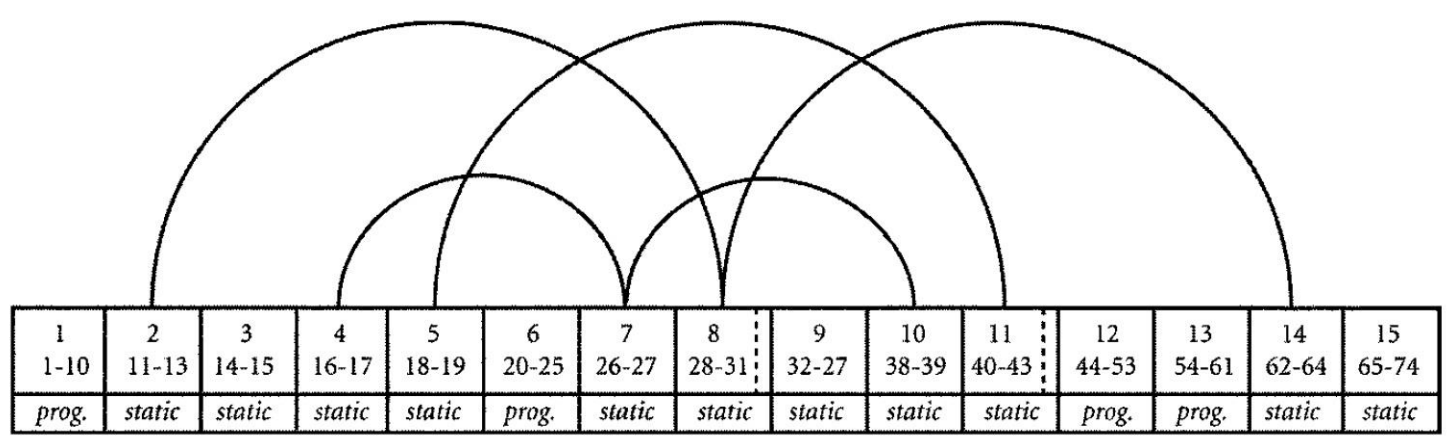

Noting the "highly regulated" recurrence of content, Wheeldon observes that the effect is nevertheless one of formal openess, and draws attention to Jonathan Kramer's observation that formal discontinuity requires a careful ordering of content, since "the truly arbitrary is actually less surprising than the artificially arbitrary." 182

\subsubsection{Moment Form: Summary}

Through a systematic survey, this chapter has clarified the limits of musical formalism as an analytical strategy for non-formalist disunified music, and outlined the results in section 2.5.1, "Principles of Disunity."

This chapter has also provided a historical context for disunity, showing how it emerged as a formal meme in the early 20th century, around 1910, and was given theoretical expression 50 years later by Stockhausen under the label "moment form" in his 1960 article "Moment Form — New Relations between Durations of Performance and Work and Moment."

\footnotetext{
180 Wheeldon, "Interpreting Discontinuity," 111.

${ }^{181}$ Wheeldon, "Interpreting Discontinuity," 111.

182 Jonathan Kramer, The Time of Music, 208. Quoted in Wheeldon, "Interpreting Discontinuity," 111.
} 
Moment form theory was later applied to the analysis of music. Noting the connection between Debussy and the Darmstadt school, Marianne Wheeldon flexibly applied the basic principles of moment form in her analyses of the music of late Debussy. Her writings demonstrate how the moment form theory has wider application as an analytical tool when viewed through the wider lens of 20th century music, rather than through the lens of a post 1950 music congruent to the rigors of Darmstadt School aesthetics.

Disunity or discontinuity was given compositional expression through the work of Stravinsky. Although this practical application of the meme has been labeled "block form," Jonathan Cross notes its similarity to moment form, and how both block form and moment form are expressions of a new paradigm of formal discontinuity.

Taking as an example Wheeldon's flexible application of moment form theory to the music of Debussy, I too will flexibly apply the basic principles of the theory to the music of Adams, since his music features block like structures or moments. The specific method of analysis and results will be discussed in Chapter 3. 


\section{Chapter 3: Disunity and Analysis}

\subsection{Introduction}

This chapter will outline a method for analyzing non-formalist, discontinuous music, including the steps of identification of blocks, assessment of block stasis or development, creation of a diagram, and analysis (in section 3.2). Following this, there will be analyses of two works by John Adams, including Son of Chamber Symphony, first movement (2007), and Century Rolls, first movement (1996) (in sections 3.3 and 3.4 respectively). These analyses will show the practical application of the analytical method outlined at the beginning of this chapter. Finally, there is a summary regarding the discourse on musical disunity covered by this paper (in section 3.5 ).

\subsection{Method}

Block form analysis in this chapter will be conducted by performing the measures outlined in the following steps:

\section{Identification of blocks.}

A block form is non-formalist, so its component parts are assumed to be in a flat, nonhierarchical sequence. Blocks will be identified through privileging the musical surface as the basis for analysis, therefore thematic events and their specific characteristics of contour and rhythm are the main objects of scrutiny; harmonic events are given secondary consideration.

\section{Assessment of block stasis or development.}

Stasis within a block will be assessed through determining if its content exhibits nonprogressive harmony and melodic circularity. Conversely, a non-static developmental block can be identified by its harmonic and melodic teleology, evidenced by methods of chordal succession and patterns of ascent and descent respectively. 
Example 12 shows a block that has been assessed as static. It shows the content of block 9, mm. 82-85, in the first movement of Century Rolls. (Table 12 shows the location of this block relative to others in the movement.) It is characterized by static harmony that consists of an oscillation between two four-note clusters that are a step apart. The melodic content is simply the top note of each chord, and is thus circular. The missing accompanying parts only double the piano part provided in the example.

Example 12. Adams, Century Rolls, First Movement, Block 9, mm. 82-85, Theme E (without accompanying parts).
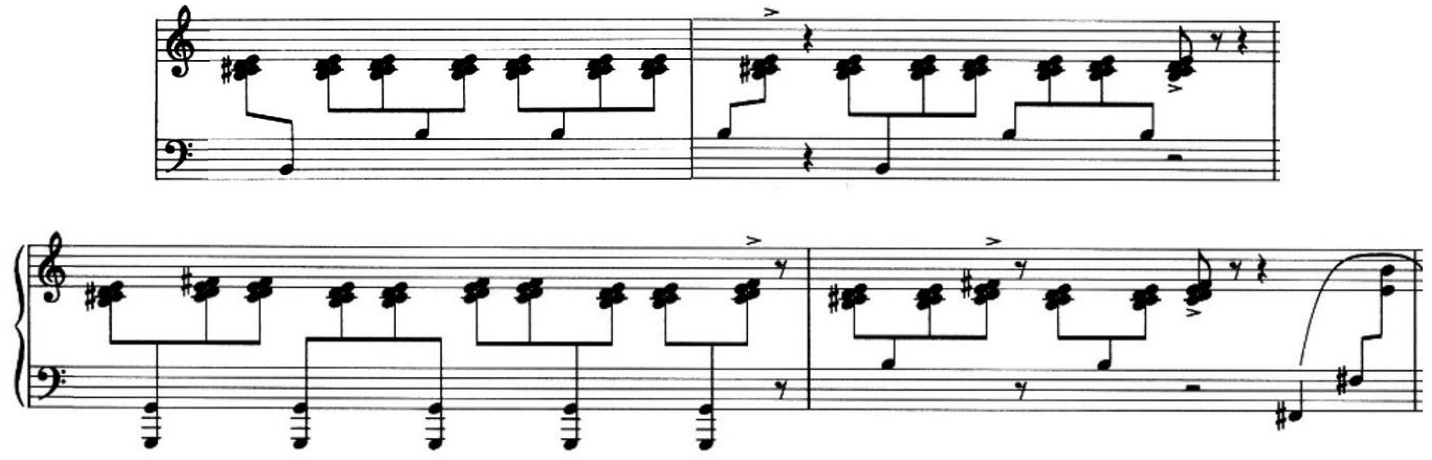

Example 13 shows a block that has been assessed as developmental or dynamic. It shows the content of block 4, mm. 133-137, in the first movement of Son of Chamber Symphony. (Table 9 shows the location of this block relative to others in the movement.) Its harmony is characterized by a chordal succession that is arpeggiated, and its melody unfolds in a pattern of ascent. The missing accompanying parts only double the piano part provided in the example.

Example 13. Adams, Son of Chamber Symphony, First Movement, Block 4, mm. 133-137, Theme D (without accompanying parts).

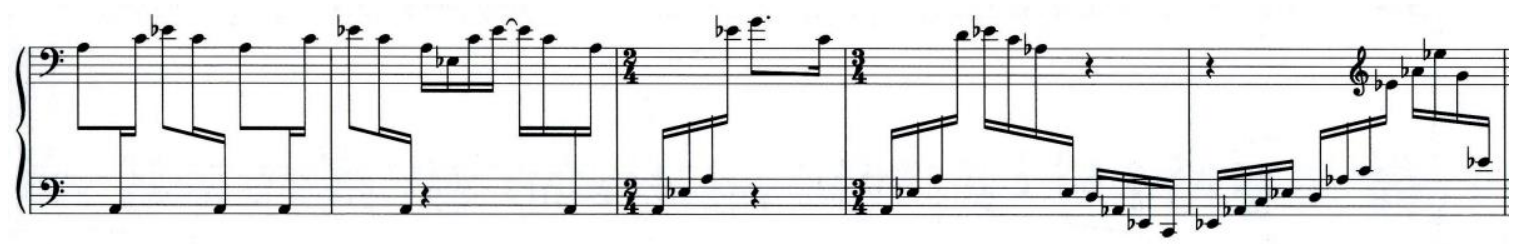


3. Creation of a diagram.

Data collected in steps 1 and 2 will be expressed diagrammatically in order to facilitate analysis.

\section{Conducting an analysis.}

Based on the diagram, the balance between unity and disunity will be assessed through identifying blocks with similar and dissimilar content and describing their relationships.

Unity is a traditional formal value that promotes formal integration of content through similarity. It engenders dependence and therefore continuity between component parts of the form.

Disunity is a value of the moment form aesthetic that challenges integration of content through dissimilarity. It engenders autonomy and therefore discontinuity between component parts of the form.

Formal unity can be assessed through identifying blocks with content that express large scale recurrence or small scale local repetition. For example, if an arrangement of blocks mimics a sonata form, recurrence in the recapitulation promotes formal integration. Large scale recurrence can also by expressed through stratification. Small scale local repetition can change the status of an event from contingent and autonomous to integral and dependent; it also enhances the memorability of an event so that large scale recurrence is more effective.

Formal disunity can be assessed through identifying blocks with content that does not recur on the large scale or repeat at the local level (or where recurrence and repetition are minimal). Although subjective, evaluating the relationship between the aggregate of repeating, dependent blocks and singular, autonomous ones, i.e. between integrative and disintegrative elements, can help scale the degree of disunity in a form. This scaling is 
conducted on a continuum between unity and disunity. While the contrast that autonomous, discontinuous events provide is a normal function of traditional forms, the degree to which discontinuous events are deployed in congruence to the moment form aesthetic can raise the level of contrast beyond traditional or formalist expectations. The latter case raises the analytical question as to whether such levels of contrast simply increase momentum in a unified form, or cross a threshold beyond which emerges a form that is radically discontinuous and disunified.

Data regarding the stasis of content within blocks is also folded into the analytical process. In general, stasis promotes discontinuity between blocks since static elements largely subvert the potential of a musical event to prepare or aim for the next one.

\section{Principles of Disunity}

This method is congruent to basic principles of musical disunity and its analysis as deduced in sections 2.3.5 and 2.4.5, and outlined in section 2.5.1, and include identification of sections based on content arranged in a flat, non-hierarchical sequence, detection of content and its recurrence through association and stratification, and assessment of the balance between integrative and disintegrative elements on a continuum.

\section{Principles of Moment Form}

This method is also congruent to the three basic principles of moment form as outlined in section 2.6.2, and their flexible application as outlined in 2.6.3. It recognizes how component moments of a form, or blocks, can be scaled from autonomous and disunified to dependent and unified (principle 1). It also recognizes how scaling the majority of blocks to autonomous and disunifed in relation to each other can result in a form that in aggregate disrupts traditional, formalist functions of musical narrative, including such functions as introduction, transition, climax, and fading (principle 2). Finally, this method allows for an analysis that would confirm the radical discontinuity of a form, and that would 
also consequently confirm the complete disruption of sequential narrativity, such as a beginning and end (principle 3 ).

\subsubsection{Son of Chamber Symphony, First Movement: Analysis}

In Max Paddison's book Adorno's Aesthetics of Music we are presented with Adorno's idea of how modern culture is conflicted between the traditional and progressive:

The dilemma of modernism as Adorno understands it [is ...] the predicament faced by the artist caught between, on the one hand, the traditional demands of the art work for unity and integration (the harmonious relationship between part and whole) and, on the other hand, the loss of faith in any overarching unity. ${ }^{183}$

In Son of Chamber Symphony by Adams such a dilemma looms large, between the formal expectations entailed by the historically rich tradition of sonata form, extending back to the 1730s and Giovanni Sammartini, and the seeming imperatives of a modernist aesthetics of fragmentation and disunity, as exemplified by Stravinsky, Stockhausen, and others. Adams places himself within this tradition by admitting he drew inspiration from the $O p .9$ Chamber Symphony by Schoenberg, and by borrowing the dotted rhythm featured so prominently in the scherzo of the Ninth Symphony by Beethoven (which also appears in the first movement). ${ }^{184} \mathrm{He}$ also, of course, invoked the genre just by including the word "symphony" in the title of his piece, Son of Chamber Symphony. In the first movement of this work, which will be the subject of the following analysis, this conflict is presented and resolved in the practical realities of musical structure, in a balance between the integrating thematic processes of sonata form and the disintegrating forces of the moment form aesthetic of discontinuity.

As a consequence of introducing discontinuity into the narrative of first movement sonata form, the form's normal outlines are stretched almost to the breaking point, so that what

\footnotetext{
183 Max Paddison, Adorno's Aesthetics of Music (Cambridge: Cambridge University Press, 1993), 3. Quoted in Cross, The Stravinsky Legacy, 26.

184 John Adams, liner notes to John Adams: Son of Chamber Symphony, String Quartet, Nonesuch 523014-

2, CD, 2011, 4-5.
} 
emerges is a vestigial hybrid, when compared to the expectations usually engendered by a sonata process.

Table 9 illustrates these diverging tendencies from a global perspective. The top row denotes block numbers associated with content. Row 2 shows theme group A and theme B; they are deployed according to normal expectations, with their exposition, development, recapitulation, and confirmation in the coda. Conversely, row 3 shows themes C-L; they challenge the unifying effect of A and B with a constant stream of new content, with the exception of large scale recurrences of $\mathrm{D}$ in block 15, and of $\mathrm{K}$ and $\mathrm{L}$ in blocks 23, 25, 27. ("TR" in row 2 represents transitional material.)

Contrast between blocks of differing thematic content creates momentum. Since stasis increases contrast between juxtaposed blocks, as a consequence of the subversion of harmonic and melodic teleology, stasis also consequently increases formal momentum between juxtaposed blocks. This kineticism is apparently consistent with the aesthetic aims of Adams. ${ }^{185}$ Blocks manifesting stasis are outlined in Rows 4 and 5 of Table 9, showing when harmonic or melodic content is either static, labeled "stat", or developmental or dynamic, labeled "d". As can be seen, a majority of the content can be understood as static.

\footnotetext{
185 John Adams, liner notes to John Adams: Son of Chamber Symphony, 4. Adams reveals how it was the "explosive energy" of Schoenberg's Op. 9 Chamber Symphony that captured his interest and inspired his work.
} 
Table 9. Adams, Son of Chamber Symphony, First Movement, Formal Overview.

\begin{tabular}{|c|c|c|c|c|c|c|c|c|c|c|c|}
\hline sonata: & \multicolumn{11}{|c|}{ exposition } \\
\hline block: & 1 & $2 a$ & $2 b$ & 3 & 4 & 5 & 6 & 7 & 8 & 9 & 10 \\
\hline $\begin{array}{c}\text { content -- } \\
\mathrm{a} \text { and } \mathrm{b} \text { : }\end{array}$ & $a 1, a 2, a 3$ & b & & & & & a3 & & a3 & & a1 \\
\hline $\begin{array}{c}\text { content -- } \\
\text { other: }\end{array}$ & & & tr & C & d & e & & e & & $\mathbf{f}$ & $\mathbf{f}$ \\
\hline harmony & stat & stat & d & d & d & stat & stat & stat & stat & stat & d \\
\hline melody & d & stat & d & d & d & stat & stat & stat & stat & d & d \\
\hline $\mathrm{mm} .:$ & $1-54$ & $55-90$ & $\begin{array}{l}91- \\
101\end{array}$ & $102-132$ & $\begin{array}{l}133- \\
137\end{array}$ & $\begin{array}{c}138- \\
147\end{array}$ & $\begin{array}{l}148- \\
149\end{array}$ & $\begin{array}{l}150- \\
151\end{array}$ & $\begin{array}{r}152- \\
153\end{array}$ & $\begin{array}{c}154- \\
165\end{array}$ & $\begin{array}{r}166- \\
180\end{array}$ \\
\hline $\begin{array}{c}\text { length in } \\
\text { measures: }\end{array}$ & 54 & 36 & 11 & 31 & 5 & 16 & 2 & 2 & 2 & 12 & 15 \\
\hline
\end{tabular}

three-part:

\begin{tabular}{|c|c|c|c|c|c|c|c|c|c|c|c|c|c|c|c|c|}
\hline \multicolumn{10}{|c|}{ development } & \multicolumn{2}{|c|}{ recapitulation } & \multicolumn{5}{|c|}{ coda } \\
\hline 11 & 12 & 13 & 14 & 15 & 16 & 17 & 18 & 19 & 20 & 21 & 22 & 23 & 24 & 25 & 26 & 27 \\
\hline a1 & a1 & a1 & & & & a1 & a3 & & a3 & $\begin{array}{c}\text { a1, a2, } \\
\text { a3 }\end{array}$ & b & a1 & a3 & & a3 & a1 \\
\hline & g & $\mathbf{h}$ & i & d & k & $\mathbf{k}$ & & I & & & & $\mathbf{k}$ & & I & & k \\
\hline stat & stat & stat & d & d & d & stat & stat & stat & stat & stat & stat & stat & stat & stat & stat & stat \\
\hline stat & d & stat & d & d & d & stat & stat & stat & stat & d & stat & stat & stat & stat & stat & stat \\
\hline $\begin{array}{c}181- \\
197\end{array}$ & $\begin{array}{l}198- \\
221\end{array}$ & $\begin{array}{l}222- \\
237\end{array}$ & $\begin{array}{r}238- \\
243\end{array}$ & $\begin{array}{c}244- \\
249\end{array}$ & $\begin{array}{l}250- \\
259\end{array}$ & $\begin{array}{l}260- \\
265\end{array}$ & $\begin{array}{r}266- \\
268\end{array}$ & $\begin{array}{l}269- \\
271\end{array}$ & $\begin{array}{c}272- \\
274\end{array}$ & $\begin{array}{c}275- \\
288\end{array}$ & $289-328$ & $\begin{array}{c}329- \\
336\end{array}$ & $\begin{array}{l}337- \\
340\end{array}$ & $\begin{array}{l}341- \\
343\end{array}$ & $\begin{array}{l}344- \\
347\end{array}$ & $\begin{array}{r}348- \\
366\end{array}$ \\
\hline 17 & 24 & 16 & 6 & 6 & 10 & 6 & 3 & 3 & 3 & 14 & 40 & 8 & 4 & 3 & 4 & 19 \\
\hline
\end{tabular}

A B A

The three component themes of theme group A, stated in block 1, are numerically subscripted in my analysis in order of appearance. They include:

A1, a static theme featuring a dotted rhythm (see Example 14),

A2, a developing theme (see Example 15), and

A3, a static theme, again featuring a dotted rhythm (see Example 16). 
Example 14. Adams, Son of Chamber Symphony, First Movement, Block 1, Theme A1 (without accompanying parts).

$$
d=116
$$

2

4

Bass Clarinet

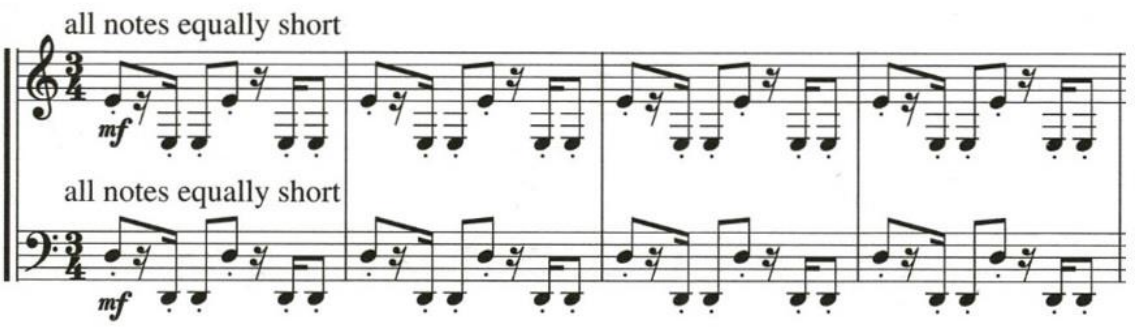

Bassoon

Example 15. Adams, Son of Chamber Symphony, First Movement, Block 1, Theme A2, Quasi-Canonic Passage (without accompanying parts).

Picc.

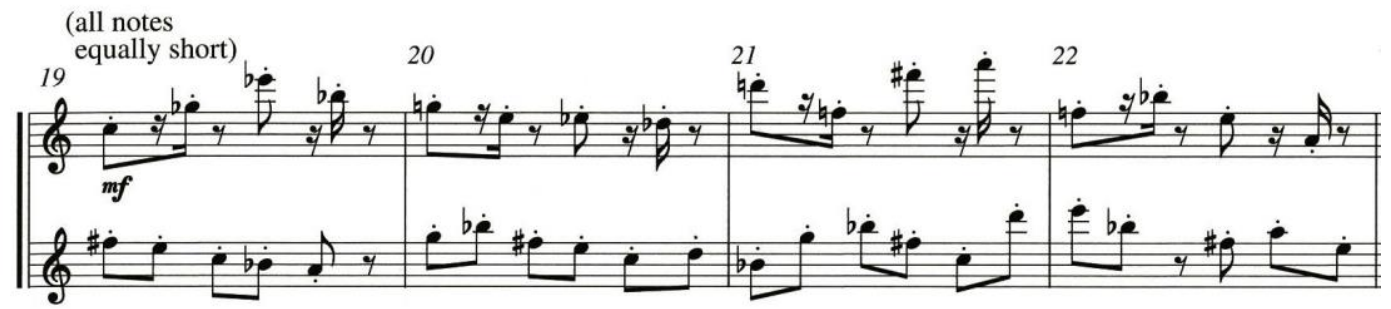

Example 16. Adams, Son of Chamber Symphony, First Movement, Block 1, mm. 36-39, Theme A3 (without accompanying parts).

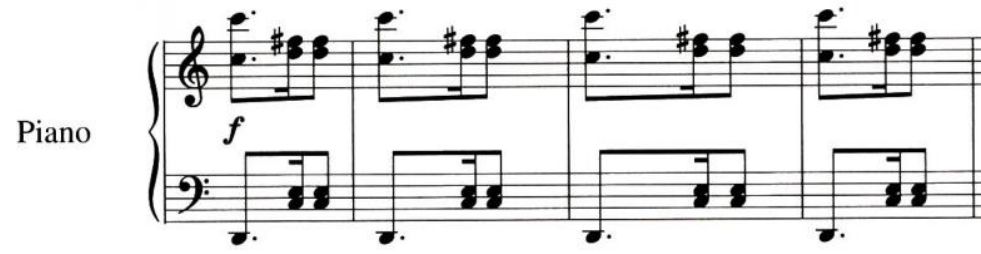

Theme B is presented in block 2 (see Example 17). Its content is static, featuring essentially non-progressive harmony centered in $\mathrm{B} b$ and melodic circularity. As can be seen in the example, the "walking bass" is essentially fixated on $\mathrm{B} b$, and the melody is "circular" in its repetitions, iterations of which are marked in the example with circled pitches. The choice of $\mathrm{B} b$ to follow the $\mathrm{D}$ harmonic center of theme group A suggests another allusion to the Ninth Symphony, which also moves from $\mathrm{D}$ to $\mathrm{B} b$ in its opening. 
Example 17. Adams, Son of Chamber Symphony, First Movement, Block 2A, mm. 54-64, Theme B (without accompanying parts).

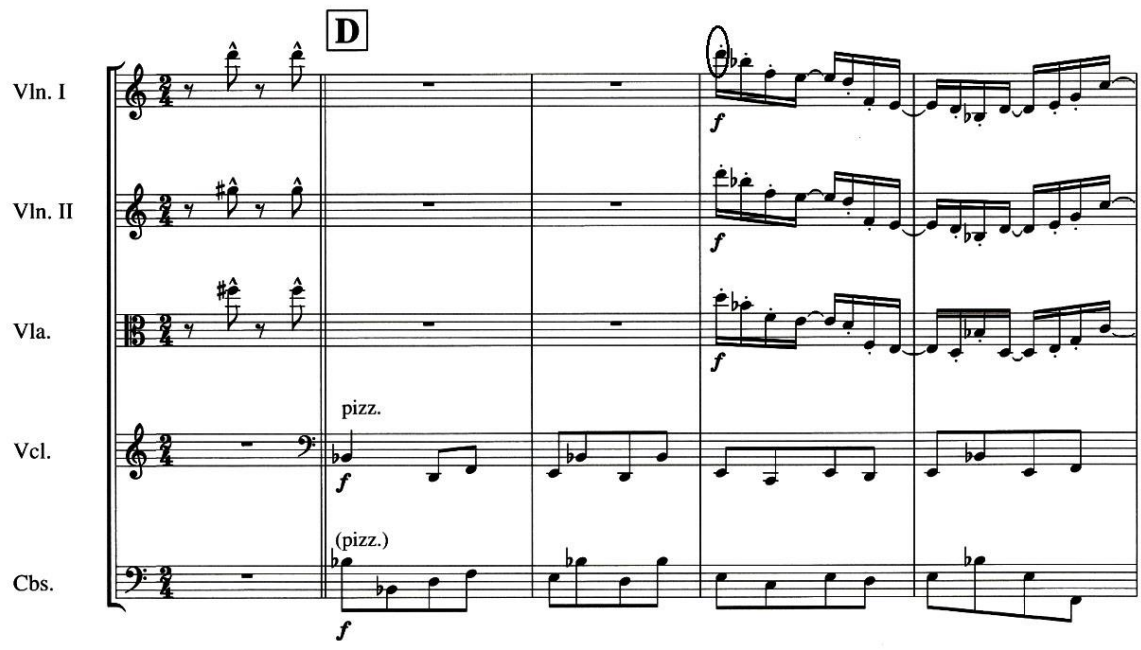

Vln. I

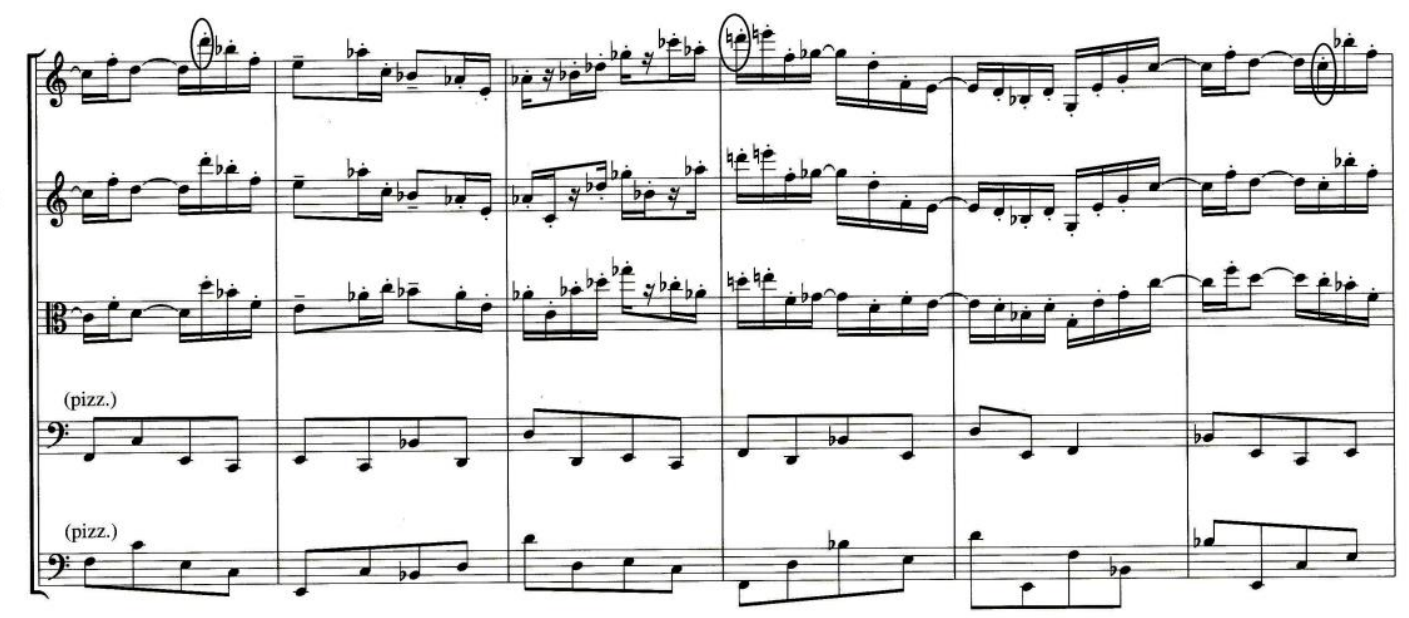

As previously indicated, themes C-L challenge the unifying effect of themes A and B with a constant stream of new content, with the exception of large scale recurrences of $\mathrm{D}, \mathrm{K}$, and $\mathrm{L}$. These themes are in most aspects distinctly different from A and B, and distinctly different from each other. 
Example 18 shows theme $\mathrm{C}$, which is harmonically and melodically developmental, although initially static. Although not shown in the example, the voice leading of the melody and harmony eventually aim for and connect to theme D.

Example 18. Adams, Son of Chamber Symphony, First Movement, Block 3, mm. 102-111, Theme C (without accompanying parts).

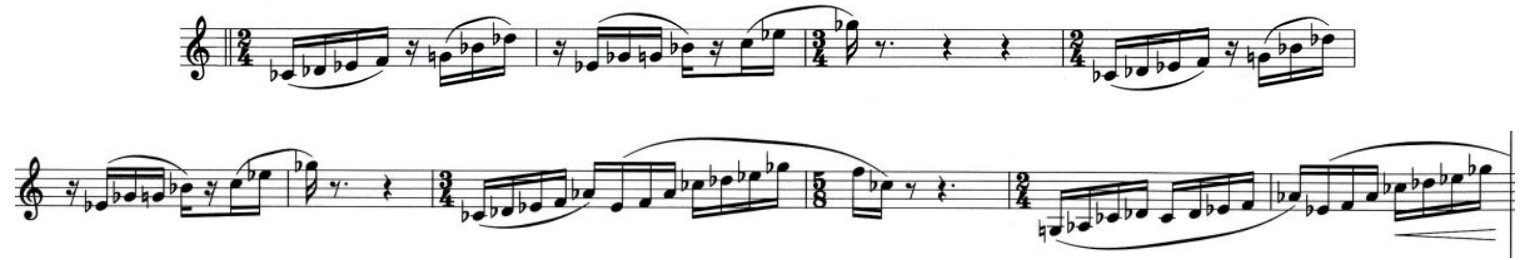

Example 19 shows theme D, which is harmonically and melodically developmental, rendered by an arpeggiated chordal succession and an ascending melody respectively. The missing accompanying parts only double the piano part provided in the example.

Example 19. Adams, Son of Chamber Symphony, First Movement, Block 4, mm. 133-137, Theme D (without accompanying parts).

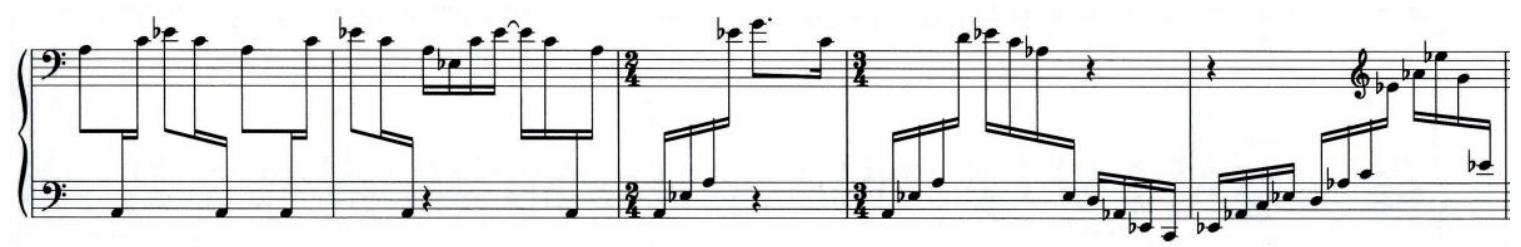

Example 20 shows theme E, which is harmonically and melodically static. The missing wind parts only imitate the piano and strings in stretto. 
Example 20. Adams, Son of Chamber Symphony, First Movement, Block 5, mm. 138-142, Theme E (without accompanying parts).

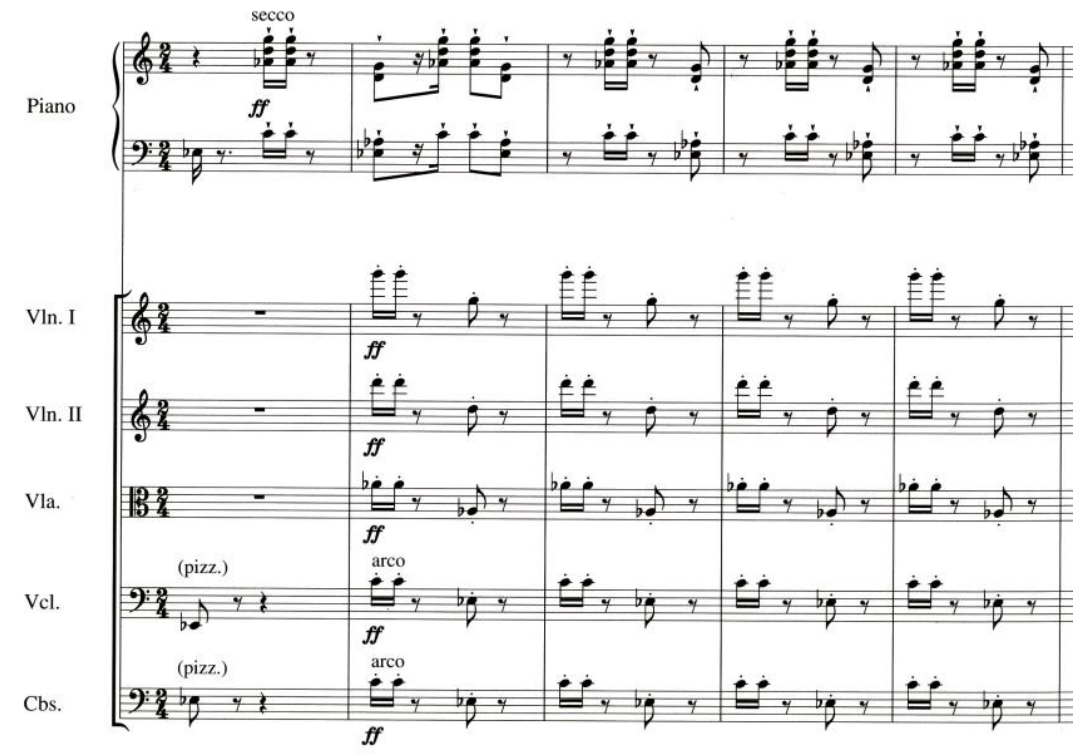

Example 21 shows theme F, which is harmonically static and melodically developmental, rendered by a repeated G-Minor chord in counterpoint with a developing line. The missing parts only double the piano and string parts provided in the example.

Example 21. Adams, Son of Chamber Symphony, First Movement, Block 9, mm. 154-158, Theme F (without accompanying parts).

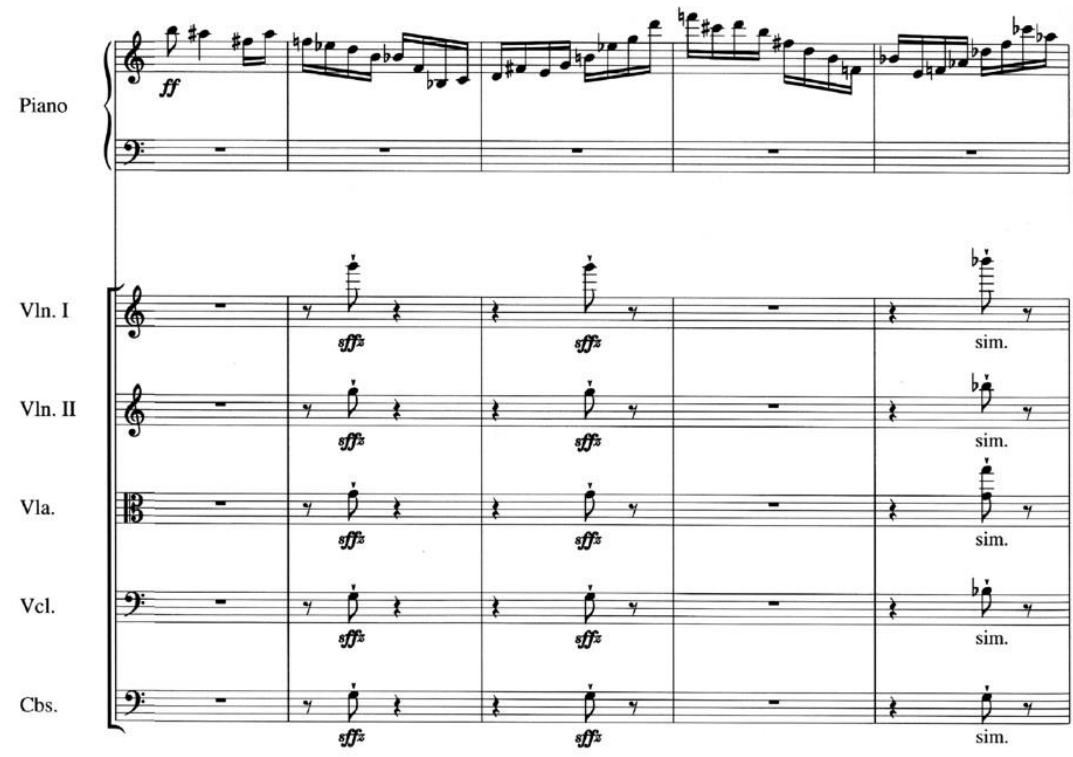


The remaining themes in the $\mathrm{C}-\mathrm{L}$ stream are similarly distinctive. Theme $\mathrm{G}$, shown in Example 24, occurs in block 12; it consists of wide intervals and rapid rhythms. Theme $\mathrm{H}$, found in block 13, consists of a lyrical theme assigned to the violins in octaves in high profile against rhythmically active woodwinds parts. Theme I, in block 14, consists of rising arpeggios. Theme $\mathrm{K}$, in blocks 16 and 17, consists of arpeggios of triads articulated in successive fifths and sixths; and theme L, in block 19, is a short, spiky four note figure. This plethora of distinctive content, most of which does not recur, challenges the unity of this movement.

The ways in which themes $\mathrm{A}$ and $\mathrm{B}$ in blocks 1 and 2 respectively perform a unifying function are fairly predictable in sonata form terms as the movement progresses.

At the end of the exposition is a recurrence of theme A1, the distinctive dotted rhythm that opens the movement. Its appearance here suggests the formal function of a codetta.

The development section announces itself at block 11, m. 181, through clear recurrence of the texture and A1 thematic content that occurred at the beginning of the exposition. This return to the initial theme of the exposition at the beginning of the development is consistent with traditional sonata form practice. ${ }^{186}$ At the end of the development A1 recurs in the treble, and A3 reappears as well.

In addition, theme A2 content from the exposition that is rendered by the oboe (see Example 22), set (0-2-4-5-7-8-10) expressed by pitch classes (D-E-F $\sharp-G-A-B b-C$ ), becomes source material from which much of the content at the beginning of the development (blocks 11-13) is derived, though subject to gradual variation. Example 22 shows this source material from the exposition, and Examples 23 and 24 show its elaboration in the development. These exemplars help demonstrate how the development is performing the normal formal function of reconfiguring content of the exposition.

\footnotetext{
${ }^{186}$ James Hepokoski and Warren Darcy, Elements of Sonata Theory : Norms, Types, and Deformations in the Late-Eighteenth-Century Sonata (New York: Oxford University Press, 2006), 612-613.
} 
Example 22. Adams, Son of Chamber Symphony, First Movement, Block 1, mm. 19-22, Theme A2, Oboe (without accompanying parts).

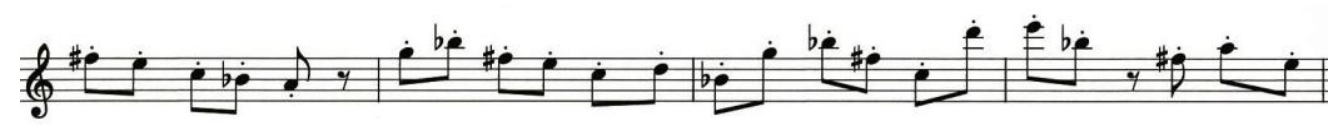

Example 23 shows how the pitch class material of A2 is transformed from melodic content into arpeggiated chordal content; and Example 24 shows how the melodic expression of A2 is transformed by rhythmic diminution and intervallic expansion to render theme $\mathrm{G}$. (Pitch classes $\mathrm{A}$ and $\mathrm{C}$ mutate to $\mathrm{A} \sharp$ and $\mathrm{C} \sharp$ in $\mathrm{m}$. 200.)

Example 23. Adams, Son of Chamber Symphony, First Movement, Block 11, mm. 195-197, Arpeggiation (without accompanying parts).

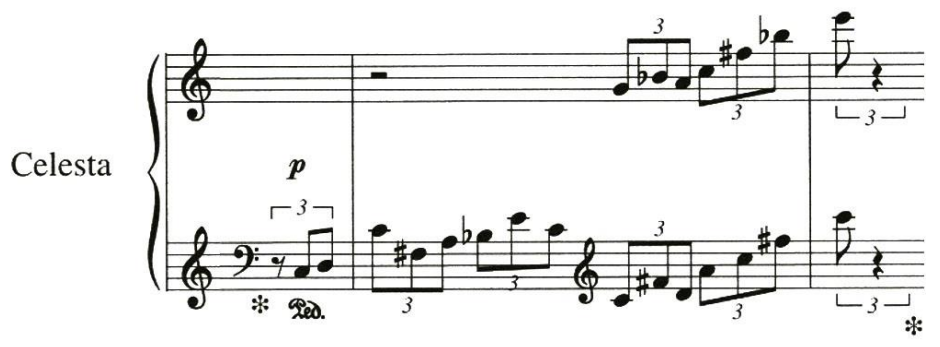

Example 24. Adams, Son of Chamber Symphony, First Movement, Block 12, mm. 198-201, Theme G, Solo Violin (without accompanying parts).

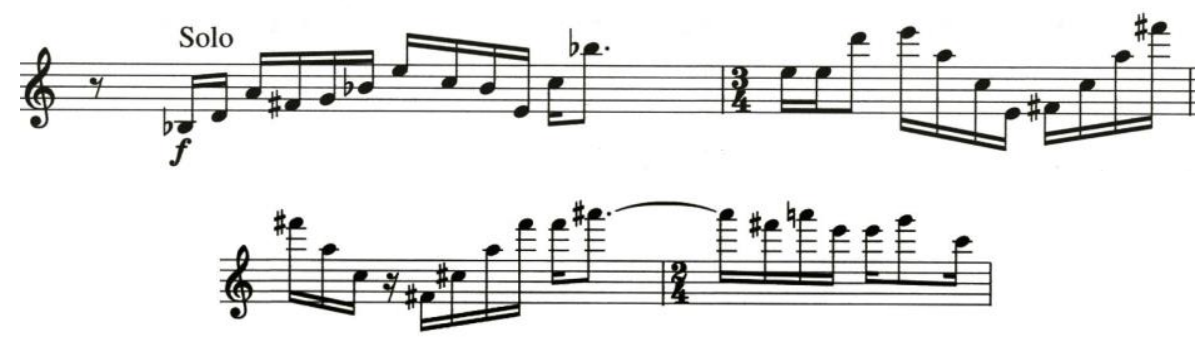

Although theme $\mathrm{G}$ is harmonically related to the exposition, the theme itself is not. Furthermore, themes H, I, K, and L that follow within the development are new, and therefore challenge the traditional function of the development section in sonata form. Although there is precedent for this departure from standard practice in the way Beethoven, for example, similarly expanded the function of the development by introducing a new 
theme, as rendered in the first movement of his Third Symphony, the range of new content introduced by Adams is a radical rescaling of this strategy. The conclusion of the development, at least, brings back with clarity theme A3 from the exposition, helping to balance the new content (in blocks 18 and 20).

The recapitulation features an intersection between global and local unifying narratives, the former in usual sonata form terms for themes A and B, the latter as the center of a symmetrical ternary form for content $\mathrm{K}$ and $\mathrm{L}$, thus "checking" the stream of new content from $\mathrm{C}$ to $\mathrm{L}$.

On a global scale, the recapitulation (of the sonata form) of theme group A is substantially condensed and varied which is probably due to the level of exposure its component motifs have received to this point; conversely, theme B has been held in reserve since its first appearance in the exposition, so its full return has considerable power in its unifying effect, especially since the theme is distinctive and memorable. This event does strongly signal a sonata form recapitulation.

On a local scale, the recapitulation also functions as the central section of a local ternary form that performs the function of establishing recurrence of the last two elements in the content stream of C-L, thus shifting the status of $\mathrm{K}$ and $\mathrm{L}$ from contingent, destabilizing, autonomous events to unifying, dependent ones. This is outlined in Table 10. 
Table 10, Detail from "Table 9. Adams, Son of Chamber Symphony, First Movement."

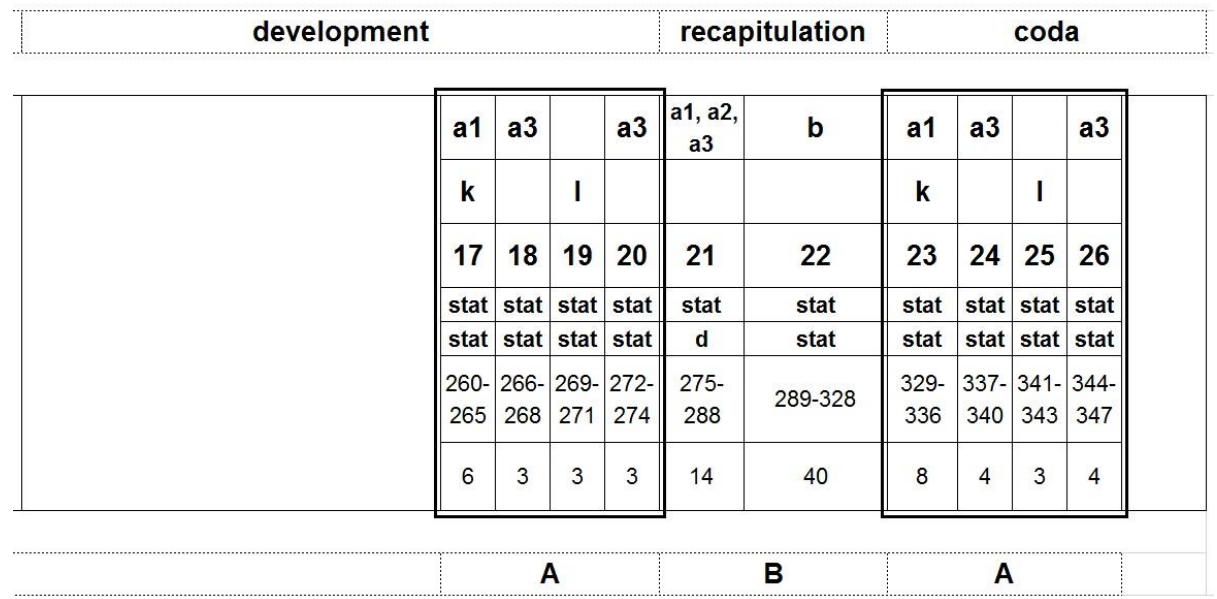

The close proximity of this stabilizing operation that provides local confirmation of $\mathrm{K}$ and $\mathrm{L}$, to the final large scale confirmation of A and B in the recapitulation and coda, helps avert the impression of openness at the conclusion of the moment, since the global unity conveyed by A and B at the end are left unchallenged by new content. In this sense the aesthetic balance in the coda is tipped in favor of the unity of sonata form over discontinuity. ${ }^{187}$

\subsubsection{Son of Chamber Symphony, First Movement: Summary}

The formal balance of this movement is one of equilibrium between two coexisting strata of unified sonata form content and discontinuous content, where the discontinuous stream of content is harnessed to the task of providing formal momentum to the sonata form stream through contrast and disunity. Seen in purely sonata form terms, much content of the discontinuous stream is left stranded without unifying confirmation in the recapitulation and coda, including C, D, E, F, G, H, and I; if viewed as a hybrid however, where the formal values of sonata and moment form are both operative, the stranded material is actually functioning autonomously, in a manner consistent with moment form. Plural

\footnotetext{
${ }^{187}$ Although this impression is somewhat compromised by moving the distinctive motif of A1 from its usual bass deployment, as found at the beginning and elsewhere, to treble at the end, the resulting reciprocal operation is nevertheless analogous to the complementary parts of the form A1 occupies, beginning and end.
} 
logics are therefore in effect in this movement. If the dilemma of modernism involves a choice between between unity and disunity, then there is the possibility of resolving it through invoking the aesthetic value of balance instead, and calibrating the use of both unity and disunity pluralistically when creating musical form, as demonstrated in practical terms by the subject of this analysis.

\subsubsection{Century Rolls, First Movement: Introduction}

The piano concerto Century Rolls was partly inspired by piano roll music of the 1920 s. In listening to such recordings Adams was struck by how the mechanical reproduction transformed the music. So this concerto, according to Adams, "became in part an attempt to recreate that initial response I had received to the sound of the piano as heard via the medium of the piano roll," hence the title. ${ }^{188}$

The first movement of Century Rolls (1996) presents a more conservative example of block form comparative to Son of Chamber Symphony (2007), in that discontinuity is a less salient, though still operative, feature of the musical discourse. The level or degree of discontinuity between these works will be compared and contrasted in the course of the following analysis.

\subsubsection{Century Rolls, First Movement: Concerto Form}

Table 11 will serve as a point of reference for understanding some large scale aspects of the form of the first movement of Century Rolls.

\footnotetext{
188 Sarah Cahill, "Century Rolls," In The John Adams Reader: Essential Writings on an American Composer, ed. Thomas May (Pompton Plains, NJ: Amadeus Press, 2006), 160.
} 
Table 11. Adams, Century Rolls, First Movement, Formal Overview.

\begin{tabular}{|c|c|c|c|c|c|c|c|c|}
\hline section & subsection & themes & $\begin{array}{l}\text { themes not } \\
\text { recapitulated }\end{array}$ & blocks & $\mathrm{mm}$. & $\begin{array}{c}\text { no. of } \\
\mathrm{mm} .\end{array}$ & $\begin{array}{l}\text { block } \\
\text { type }\end{array}$ & notes \\
\hline exposition & $\mathrm{n} / \mathrm{a}$ & $a, b, c, d, e$ & $c, d, e$ & $1-17$ & $1-109$ & 109 & static & $\begin{array}{l}\text { tutti start } \\
\text { a: orchestra } \\
\text { b: piano }\end{array}$ \\
\hline \multirow{5}{*}{$\begin{array}{l}\stackrel{+}{0} \\
\frac{0}{0} \\
\frac{0}{0} \\
\frac{0}{0} \\
\frac{d}{0}\end{array}$} & rotation 1 & $f, g, h, b, c, i, j$ & $f, h, c, i, j$ & $18-29$ & $110-183$ & 74 & \multirow{5}{*}{ 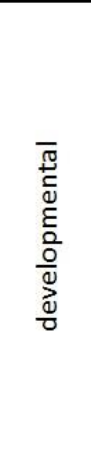 } & tutti start \\
\hline & rotation 2 & $f, g$ & $f$ & $30-32$ & $184-210$ & 27 & & tutti start \\
\hline & rotation 3 & $f, g, k$ & $f, k$ & $33-37$ & $211-249$ & 39 & & $\begin{array}{l}\text { non-tutti start } \\
\text { k similar to g }\end{array}$ \\
\hline & rotation 4 & $f, k$ & $f, k$ & $38-44$ & $250-299$ & 50 & & $\begin{array}{l}\text { non-tutti start } \\
\text { k similar to g }\end{array}$ \\
\hline & rotation 5 & $f, g, l, h$, a & $f, l, h$ & $45-47$ & $300-334$ & 35 & & tutti start \\
\hline recap. & $\mathrm{n} / \mathrm{a}$ & $a, b, g$ & & $48-51$ & $335-414$ & 80 & static & $\begin{array}{l}\text { a: orchestra then piano } \\
\text { b: orchestra then ... }\end{array}$ \\
\hline cadenza & $\mathrm{n} / \mathrm{a}$ & b & & 52 & $415-469$ & 55 & dev. & b: piano \\
\hline transition & $\mathrm{n} / \mathrm{a}$ & scales & & 53 & $470-495$ & 26 & dev. & \\
\hline
\end{tabular}

The large scale formal divisions outlined in Table 11 are established through the conventions of first movement ritornello-sonata concerto form codified by the late 18th and early 19th century. This prototype largely carried over into the 19th and even 20th centuries. $^{189}$

The prototype reserves tutti passages for the function of announcing significant demarcations in the form. This is largely what occurs in the first movement of Century Rolls. Although the exposition is initiated by a small subset of the orchestra, the texture builds until most instruments are participating, fulfilling the requirement of introducing the exposition with a tutti.

There are a number of indicators that denote the formal outlines of the development. It is initiated by the second tutti in the movement at $\mathrm{m}$. 110. Five rotations of content make up

189 Don Randel, ed., The New Harvard Dictionary of Music, Tenth ed. (Cambridge, Massachusetts: Belknap Press of Harvard University Press, 2001), s.v. "Concerto." 
the development, including theme $F$ which begins each rotation, and theme $\mathrm{G}$ (based on theme D from the exposition), which also occurs with regularity in the rotations. Similarly, rotations 1-4 are initiated by a B-Minor sonority, and rotations 1,2 , and 5 are initiated by tutti orchestrations. The rotation of content in the development section, as indicated in Table 11, is a normal compositional methodology within the legacy of sonata form, although the use of some new material is unusual. (This is discussed in section 3.4.3.) ${ }^{190}$ Themes $\mathrm{G}$ and $\mathrm{H}$ in the development are derived from theme $\mathrm{D}$ in the exposition, fulfilling a normative expectation of the sonata form process. (This is discussed in detail in section 3.4.5).

The recapitulation occurs at $\mathrm{m} .335$, and the sense of recurrence is immediately recognizable due to the return of many elements that were present when the exposition began, including the B-Minor sonority, thematic material, and orchestration.

The expected cadenza also appears, its light scoring enhancing the profile of the piano's arabesque figurations before a transitional passage leads to the second movement. The texture of this section is distinctive, and sets it off from the recapitulation.

Drilling down into the exposition, we discover two main thematic areas, including: theme group A consisting of A1 and A2 (mm. 1-33); and theme B (mm. 34-61), introduced by the solo pianist with accompaniment. These themes are represented by Examples 25 and 26 respectively. Since these two thematic areas pervade the exposition and recur in the recapitulation, they conform to important aspects of classic concerto form; their absence in the development section, however challenges the sonata form process upon which the classic concerto form is based.

\footnotetext{
190 Hepokoski and Darcy, Elements of Sonata Theory, 611-614. For examples of rotation theory applied to $19^{\text {th }}$ and $20^{\text {th }}$ century music, see: Warren Darcy, "Die Zeit ist da: Rotational Form and Hexatonic Magic in Act 2 Scene 1," in A Companion to Wagner's Parsifal (Rochester, NY: Camden House, 2005), 215-241. James Hepokoski, "Musical Process and Architecture: A Proposed Overview," in Sibelius: Symphony No. 5 (New York: Cambridge University Press, 1993), 58-84.
} 
Example 25. Adams, Century Rolls, First Movement, Block 1, mm. 1-3, Themes A1 and A2 in Piccolo and Flute 1, Upper and Lower Staves Respectively (without accompanying parts).

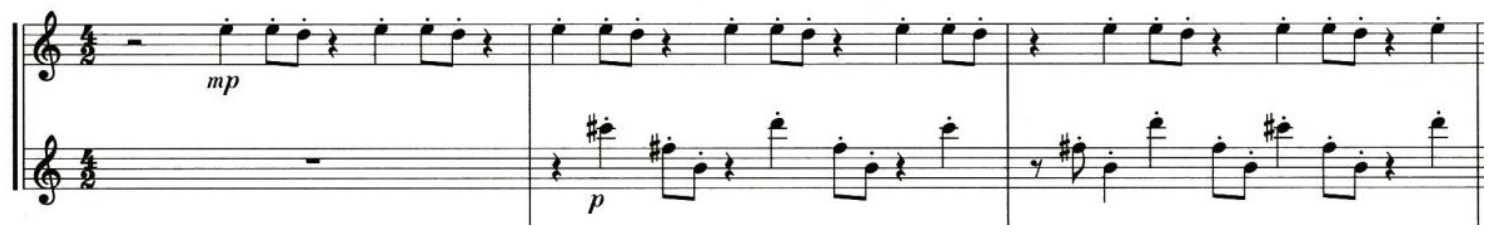

Example 26. Adams, Century Rolls, First Movement, Block 2, m. 34,

Theme B, Solo Piano (without accompanying parts).

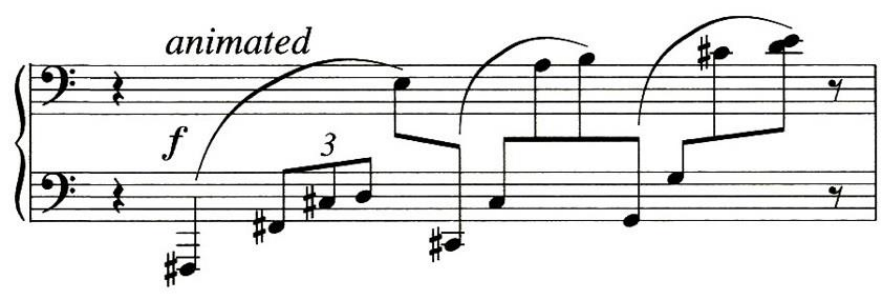

The first movements of Century Rolls (1996) and Son of Chamber Symphony (2007) exhibit similarities and differences in the way they imitate sonata form. They both feature expositions that commence with two comparatively lengthy and contrasting themes or theme groups, a concession to tradition, followed by much shorter and often discontinuous modules, a concession to modernity. While the development of Century Rolls is more conservative in its thematic continuity, as will be seen, Son of Chamber Symphony is radically discontinuous, as previously demonstrated. The way recapitulation is enacted by these works in terms of thematic integration is similarly dichotomous, and will be examined in the next section.

\subsubsection{Century Rolls, First Movement: Thematic Disunity}

Thematic elements that appear subversive to sonata form in this movement are balanced by mitigating factors. 
As indicated in Table 11 in the "themes not recapitulated" column, themes C, D, and E in the exposition do not recur in the recapitulation. However, since it is only themes A and $B$ that receive substantial weight in the exposition in terms of length of statement and recurrence, the absence of $\mathrm{C}, \mathrm{D}$ and $\mathrm{E}$ in the recapitulation isn't missed. Themes $\mathrm{C}$ and $\mathrm{E}$ only make an ephemeral appearance in the exposition, and theme D nearly so.

Normally the development includes content from the exposition. If one, however, compares themes from the exposition and the development in the "themes" column of Table 11, it appears as though there are no common elements (except for B and C, which make very brief appearances). On closer inspection of the score, however, it can be seen that theme $\mathrm{D}$ in the exposition is a progenitor of themes $\mathrm{G}$ and $\mathrm{H}$ in the development. I have chosen to label them differently to reflect a transformation in contour to $\mathrm{G}$, and in length to $\mathrm{H}$. This connection between $\mathrm{D}$ to $\mathrm{G}$ and $\mathrm{H}$ will be thoroughly explored in section 3.4.5.

Then there is the question of new content in the development. How is it deployed for balance? These new themes include F, I, J, K, and L:

1. Since theme F recurs at the beginning of each rotation in the development section its function is linked to the development. Because of its extensive recurrence, additional repetition is unnecessary, especially since it would likely produce monotony.

2. Theme $\mathbf{J}$ is rhetorical, performing the role of transition. It has no distinctive thematic identity.

3. Theme $\mathrm{K}$ is simply theme $\mathrm{G}$, minus the melody. This allows for the piano to switch roles from rendering melody to articulating a dynamic rhetoric of scale and arpeggio patterns that lead to the recapitulation.

4. Theme $\mathrm{L}$ is a one off continuation of theme $\mathrm{F}$ in rotation 5, extending the tutti texture. 
This accounting of the large scale balance of thematic content in Century Rolls highlights the fact that only theme I is left "stranded" through omission of its integration through recurrence or recapitulation. Its colorful content in both its intervals and contour, and in its orchestration featuring the solo piano against celesta and pizzicato strings, makes this formal decision by the composer an interesting one. Perhaps the striking character of this event argues for only one occurrence. Therefore, by the metric of unique, autonomous content, Century Rolls (1996) is a far less radical piece in its disunity than Son of Chamber Symphony (2007), since the former work arguably omits integration of only one theme, and the latter seven.

\subsubsection{Century Rolls, First Movement: Within and Between Blocks}

In aggregate, the content within blocks in the exposition and recapitulation is mostly static in harmonic and melodic content, whereas such content in the development is mostly developmental or dynamic. This is indicated in Table 11 in the column "block type". Although stasis within blocks generates discontinuity since it subverts the potential of a musical event to prepare or aim for the next one, the discontinuity between blocks resulting from such juxtapositions in the first movement of Century Rolls is substantially reduced by harmonic and rhythmic continuity, particularly in the exposition. The exposition (mm. 1-109), for example, unfolds content almost entirely from a diatonic set of two sharps favoring Aeolian (B-C $\sharp-D-E-F \sharp-G-A)$ or Phrygian rotations ( $F \sharp-G-A-B-C \sharp-D-E)$. The recapitulation (mm. 335-414) is a little more complex, featuring $\mathrm{T}_{0}, \mathrm{~T}_{5}$, and $\mathrm{T}_{10}$ iterations of the same set. (The development, in contrast, is harmonically dynamic.) In addition, the rhythm of the content usually confirms the sense of a clear underlying pulse. So even if a block is harmonically and melodically static within, and its thematic content isn't shared between adjacent, juxtaposed blocks, the shared harmonic field between blocks and the uniform pulsation tend to lower by several degrees the level of discontinuity one would normally experience if there had been harmonic contrast and pulse subversion. ${ }^{191}$

\footnotetext{
191 John Adams has employed the expression "harmonic field" when describing a compositional process he has used involving the creation of melodies within an established harmonic framework. See: "BSO Hangout with Marin Alsop, John Adams and Tim McAllister," YouTube, posted 21 September 2013, accessed 18 June 2014, https://www.youtube.com/watch?v=eDIYWjCgq2M.
} 
For a fairly representative exemplar of how this type of block juxtaposition is operative in the exposition, see Example 27. Representing measures 66-69 within blocks 4 and 5, it shows three different thematic ideas $(B, C, D)$ in quick succession in the piano part (accompanying parts omitted). Although structurally discontinuous on the printed page, its rendering in sound seems relatively continuous due to the music's projection of pulse, facilitated by the accompanying parts, and harmonic unity.

Example 27. Adams, Century Rolls, First Movement, Blocks 4 and 5, mm. 66-69, Themes B, C, and D (without accompanying parts).

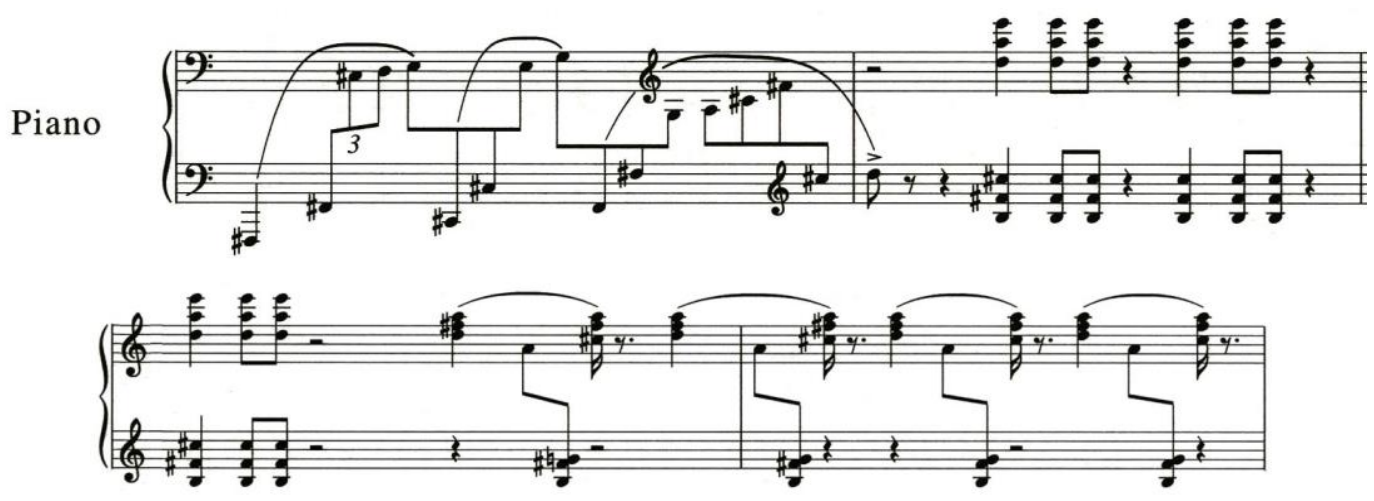

Alternatively, many block juxtapositions in the first movement of Son of Chamber Symphony are starker due to harmonic contrast, changes of meter, and silence, as shown in Examples 28 and 29.

Example 28. Adams, Son of Chamber Symphony, First Movement, Blocks 14 and 15, mm. 242-245 (without accompanying parts).

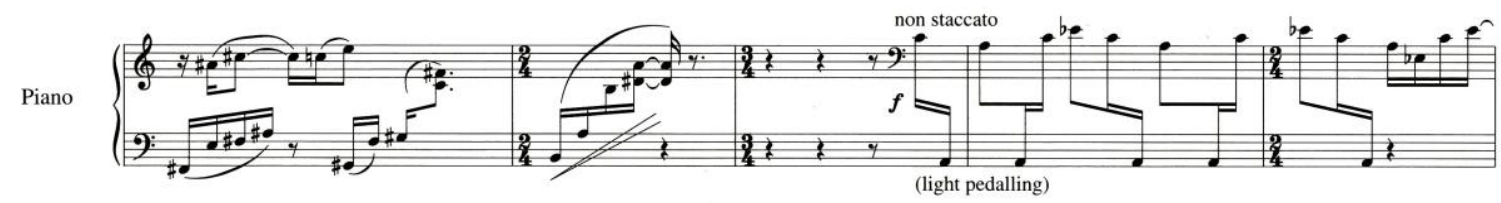


Example 29. Adams, Son of Chamber Symphony, First Movement, Blocks 22 and 23, mm. 326-329 (without accompanying parts).

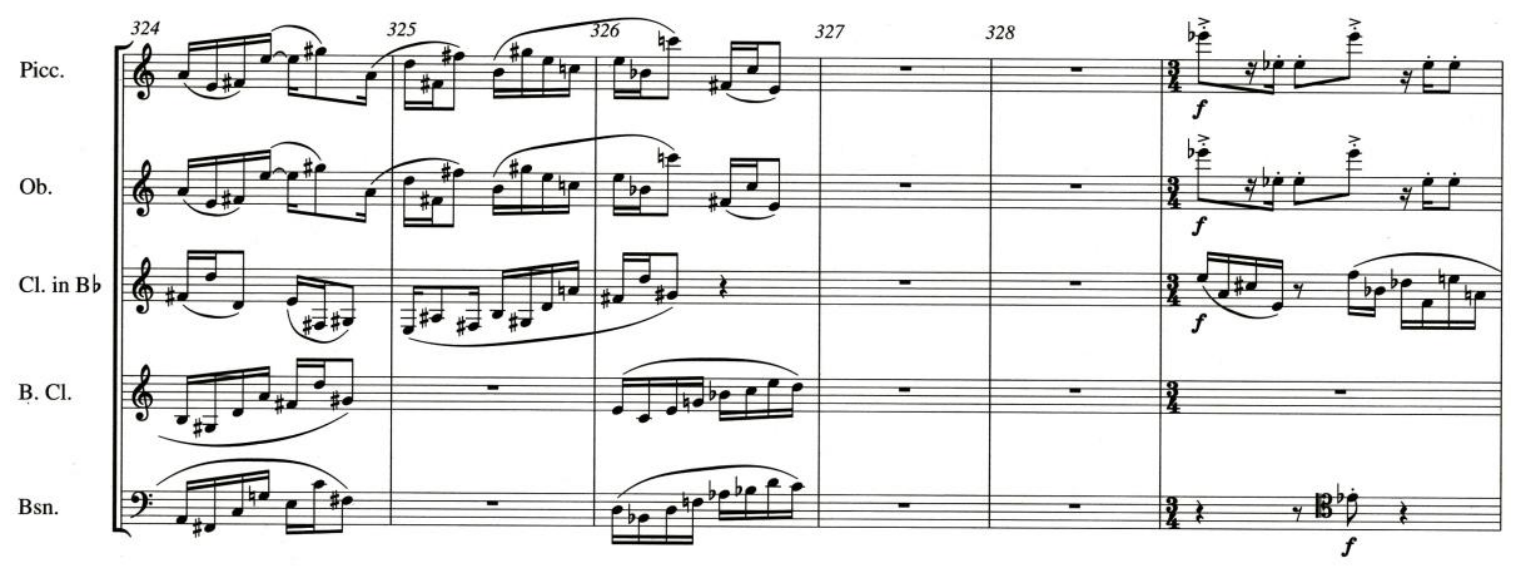

Although the structure of these works is block-like, sometimes discontinuity between blocks is dialed down. The first movement of Century Rolls, for example, includes extended passages of scales and arpeggios that seamlessly connect between blocks in rotations 3 and 4 of the development in the context of theme K. This rhetorical device helps lead the musical discourse to the recapitulation. In addition, these rotations are not initiated by tutti passages, as rotations 1,2 , and 5 are, to further enhance the continuity. (The specific location of $\mathrm{K}$ in rotations 3 and 4 can be discovered in Table 12.)

Son of Chamber Symphony includes a few similar examples where discontinuity between blocks is substantially reduced, such as the transition in block $2 \mathrm{~b}$ between themes $\mathrm{B}$ and $\mathrm{C}$, effected by a descending passage that dovetails into the first note of theme C. (See Table 9.)

Although the first movements of both works feature at times relatively continuous deployment of content between juxtaposed blocks, Son of Chamber Symphony is in aggregate more discontinuous than Century Rolls. 


\subsubsection{Century Rolls, First Movement: Stratification}

In the first movement of Century Rolls, we have seen how thematic disunity and juxtaposition of adjacent blocks only modestly challenge formal integration, as discussed in sections 3.4.3 and 3.4.4, demonstrating a conservative expression of the moment form aesthetic. In contrast, we have also seen how the first movement of Son of Chamber Symphony is radical, featuring a significant amount of disunified, autonomous thematic content, and stark contrast between blocks.

The first movement of Century Rolls also features a compositional device for promoting formal integration of separated blocks, namely "stratification". This term is part of an analytical method devised by theorist Edward T. Cone that appeared in his article "Stravinsky: The Progress of a Method." ${ }^{192}$ As previously discussed in section 2.3.4, it refers to "the separation in musical space of ideas" or "musical areas," so that ideas are expressed in alternation over time, such as A1, B1, A2, B2, A3, B3. The related term of "interlock" refers to the continuity between ideas, such as between iterations of $\mathrm{A}$ and iterations of B, though interrupted by stratification.

To follow the course of stratified content in the first movement of Century Rolls, see Table 12. Content in each block is assigned a letter; later iterations are subscripted with a number (with the exception of A1 and A2, which are separate themes in block 1). In two cases, a stratification chain is expressed by two letters: 1) D1 spawns G1 and H1, after which both $\mathrm{G}$ and $\mathrm{H}$ unfold a series of iterations; 2) $\mathrm{G} 2$ spawns $\mathrm{K} 1$, a label change intended to reflect how $\mathrm{K} 1$ retains the accompaniment pattern of $\mathrm{G} 2$, but replaces the melodic pattern with scales and arpeggios.

${ }^{192}$ Cone, "The Progress of a Method," 19. 
Table 12. Adams, Century Rolls, First Movement, Overview of Blocks.

\begin{tabular}{|c|c|c|c|c|c|c|c|c|c|c|c|c|c|c|c|c|c|}
\hline content: & $a 1, a 2$ & a1, a2, b1 & $\begin{array}{c}\text { b1, } \\
\text { c }\end{array}$ & $\begin{array}{c}\text { b1, } \\
\text { c }\end{array}$ & d1 & c & b1 & b2 & e & b2 & b3 & d1 & d2 & b4 & b1 & d1 & d2 \\
\hline block: & 1 & 2 & 3 & 4 & 5 & 6 & 7 & 8 & 9 & 10 & 11 & 12 & 13 & 14 & 15 & 16 & 17 \\
\hline harmony & stat & stat & stat & stat & stat & stat & stat & stat & stat & stat & stat & \begin{tabular}{|l|} 
stat \\
\end{tabular} & stat & stat & stat & stat & stat \\
\hline melody & $d$ & d & stat & stat & stat & stat & $d$ & stat & stat & stat & stat & stat & \begin{tabular}{|l|} 
stat \\
\end{tabular} & stat & $d$ & stat & stat \\
\hline $\mathrm{mm}:$ & $1-33$ & $34-61$ & $\begin{array}{l}62- \\
64\end{array}$ & $\begin{array}{l}65- \\
67\end{array}$ & $\begin{array}{l}68- \\
69\end{array}$ & $\begin{array}{l}70- \\
71\end{array}$ & $\begin{array}{l}72- \\
79\end{array}$ & $\begin{array}{l}80- \\
81\end{array}$ & $\begin{array}{l}82- \\
85\end{array}$ & $\begin{array}{c}86- \\
87\end{array}$ & $\begin{array}{c}88- \\
91\end{array}$ & $\begin{array}{l}92- \\
93\end{array}$ & $\begin{array}{l}94- \\
97\end{array}$ & $\begin{array}{c}98- \\
101\end{array}$ & $\begin{array}{l}102- \\
103\end{array}$ & $\begin{array}{l}104- \\
105\end{array}$ & $\begin{array}{l}106- \\
109\end{array}$ \\
\hline no. of $\mathrm{mm}$. & 33 & 28 & 3 & 3 & 2 & 2 & 8 & 2 & 4 & 2 & 4 & 2 & 4 & 4 & 2 & 2 & 4 \\
\hline
\end{tabular}

development

rotation 1

\begin{tabular}{|c|c|c|c|c|c|c||c|c|c||c|c|c||}
\hline content: & $\mathbf{f 1}$ & $\mathbf{g} 1$ & $\mathbf{h} 1$ & $\mathbf{h} 2$ & $\mathbf{b 1}$ & $\mathbf{c}$ & $\mathbf{i}$ & $\mathbf{h} 2$ & $\mathbf{i}$ & $\mathbf{j}$ & $\mathbf{h 3}$ & $\mathbf{j}$ \\
\hline block: & 18 & 19 & 20 & 21 & 22 & 23 & 24 & 25 & 26 & 27 & 28 & 29 \\
\hline harmony & stat & stat & d & stat & stat & stat & d & stat & d & stat & d & stat \\
\hline melody & stat & stat & d & stat & stat & stat & d & stat & d & stat & d & stat \\
\hline mm: & $110-117$ & $118-$ & $122-134$ & $135-$ & $138-$ & $140-$ & $145-$ & $152-$ & $154-$ & $161-$ & $163-176$ & $177-183$ \\
& & 121 & & 137 & 139 & 144 & 151 & 153 & 160 & 162 & & \\
\hline no. of $\mathrm{mm}$. & 8 & 4 & 13 & 3 & 2 & 5 & 7 & 2 & 7 & 2 & 14 & 7 \\
\hline
\end{tabular}

rotation 2

\begin{tabular}{|c|c|c|c|}
\hline content: & $\mathbf{f 2}$ & $\mathbf{f 3}$ & $\mathbf{g} \mathbf{}$ \\
\hline block: & 30 & 31 & 32 \\
\hline harmony & d & stat & d \\
\hline melody & d & stat & d \\
\hline $\mathrm{mm}:$ & $184-198$ & $199-$ & $203-210$ \\
\hline no. of $\mathrm{mm}$. & 15 & 4 & 8 \\
\hline
\end{tabular}

rotation 3

rotation 4

\begin{tabular}{|c|c|c|c|c|c|c|c|}
\hline content: & f5 & d3 & k1 & k1 & k1 & k2 & k2 \\
\hline block: & 38 & 39 & 40 & 41 & 42 & 43 & 44 \\
\hline harmony & stat & stat & stat & stat & stat & stat & stat \\
\hline melody & stat & d & d & d & d & d & d \\
\hline $\mathrm{mm}:$ & $250-260$ & $261-$ & $265-$ & $272-$ & $277-284$ & $285-292$ & $293-$ \\
& & 264 & 271 & 276 & & & 299 \\
\hline no. of $\mathrm{mm}$. & 11 & 4 & 7 & 5 & 8 & 8 & 7 \\
\hline
\end{tabular}

recapitulation

\begin{tabular}{|c|c|c|c|c|}
\hline content: & $\mathbf{a 2}$ & $\mathbf{a 2}$ & $\mathbf{a 2 , \mathbf { g 4 }}$ & $\mathbf{b 5}$ \\
\hline block: & 48 & 49 & 50 & 51 \\
\hline harmony & stat & stat & stat & stat \\
\hline melody & stat & stat & stat & stat \\
\hline $\mathrm{mm}:$ & $335-359$ & $\begin{array}{r}360- \\
364\end{array}$ & $365-390$ & $391-414$ \\
\hline no. of $\mathrm{mm}$. & 25 & 5 & 26 & 24 \\
\hline
\end{tabular}

\begin{tabular}{|c|c|c|c|c|}
\hline $\mathbf{f 4}$ & $\mathbf{f 3}$ & $\mathbf{g} \mathbf{2}$ & $\mathbf{k 1}$ & $\mathbf{k 1}$ \\
\hline 33 & 34 & 35 & 36 & 37 \\
\hline d & stat & d & stat & stat \\
\hline d & stat & d & d & d \\
\hline $211-225$ & $226-$ & $230-237$ & $238-$ & $242-249$ \\
& 229 & & 241 & \\
\hline 15 & 4 & 8 & 4 & 8 \\
\hline
\end{tabular}

rotation $\mathbf{5}$
\begin{tabular}{|c|c|c|}
\hline $\mathbf{f 6}, \mathbf{g} \mathbf{3}$ & $\mathbf{I}$ & $\mathbf{h} \mathbf{1 , \mathbf { a } 2}$ \\
\hline 45 & 46 & 47 \\
\hline stat & stat & stat \\
\hline stat & stat & d \\
\hline $300-309$ & $310-317$ & $318-334$ \\
\hline 10 & 8 & 17 \\
\hline
\end{tabular}

cadenza
\begin{tabular}{|c|}
\hline b6 \\
\hline 52 \\
\hline stat \\
\hline$d$ \\
\hline $415-469$ \\
\hline 55 \\
\hline
\end{tabular}

transition

\begin{tabular}{|c|}
\hline tr \\
\hline 53 \\
\hline$d$ \\
\hline$d$ \\
\hline $470-495$ \\
\hline 26 \\
\hline
\end{tabular}


The spawning of stratification chains $\mathrm{G}$ and $\mathrm{H}$ in the development from $\mathrm{D} 1$ in the exposition is not only formally integrating in a general sense, it also helps to preserve the sonata form outline, since it is the only content in the exposition that is developed in the development section. In addition, $\mathrm{G}$ is reiterated in the recapitulation, thus essentially completing the cycle of exposition, development, and recapitulation for this particular theme.

The genealogy of theme $\mathrm{G}$ is traced in Examples 30-34; all of these exemplars show the piano part without accompanying instruments (except for Example 34):

Example 30 shows D1, the progenitor of $\mathrm{G}$, as it appears in the exposition.

Example 31 shows G1, as it appears in rotation 1 of the development.

It is characterized by groups of three descending pitches.

Example 32 shows G2, as it appears in rotations 2 and 3 of the development.

It is characterized by groups of three ascending pitches, an inversion of G1.

Example 33 shows G3, as it appears in rotation 5 of the development.

It is a synthesis of G1 and G2, consisting of both ascending and descending pitches, in groups of three and four.

Example 34 shows G4, as it appears in the recapitulation.

Example 30. Adams, Century Rolls, First Movement, D1, Block 5, mm. 68-69

(without accompanying parts).

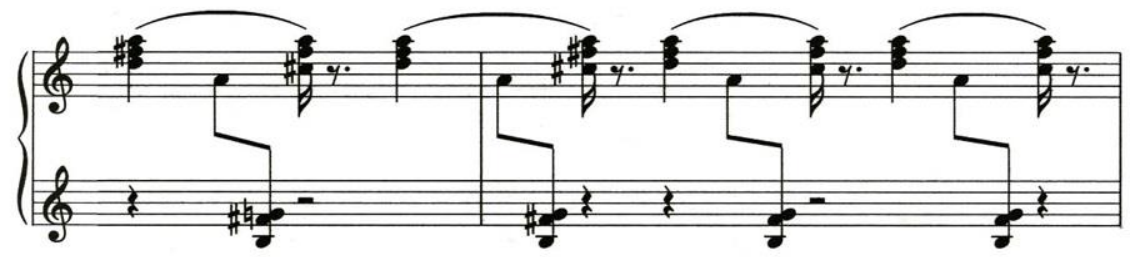


Example 31. Adams, Century Rolls, First Movement, G1, Block 19, mm. 117-119.

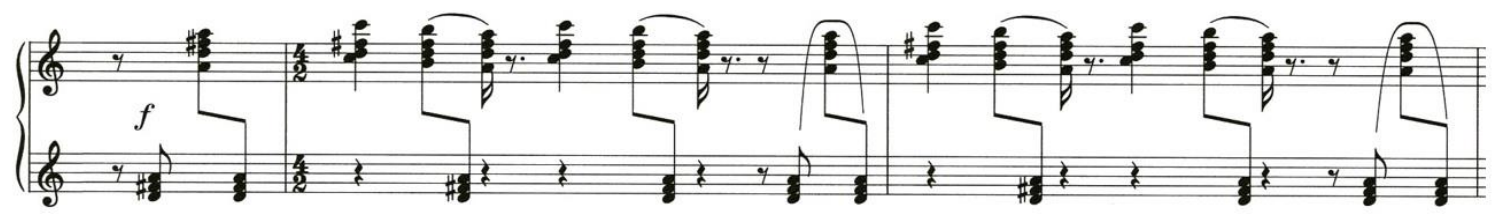

Example 32. Adams, Century Rolls, First Movement, G2, Block 32, mm. 205-208. (G2 also recurs in Block 35, mm. 230-237.)
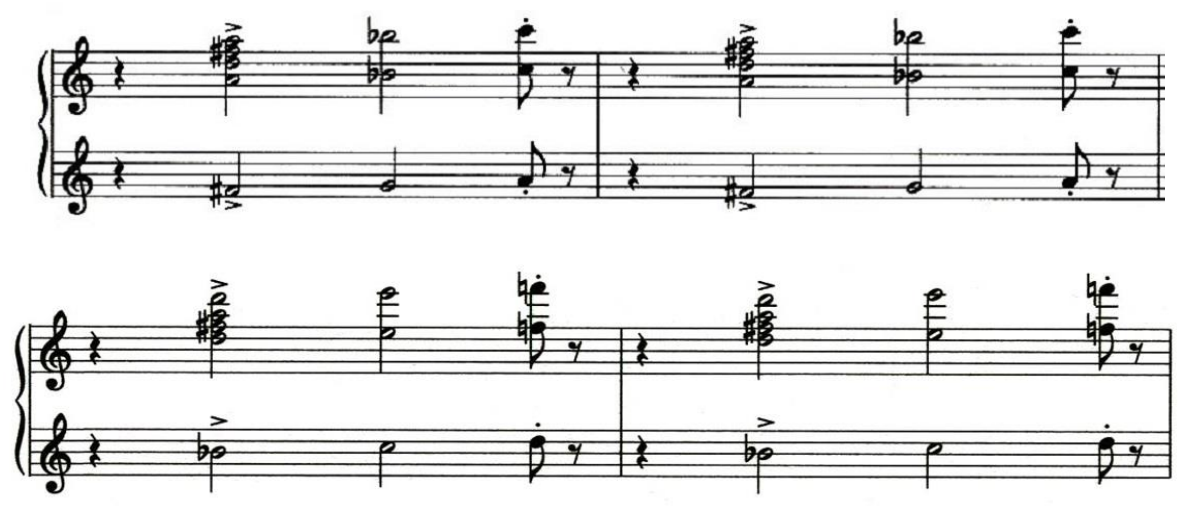

Example 33. Adams, Century Rolls, First Movement, G3, Block 45, mm. 300-303.
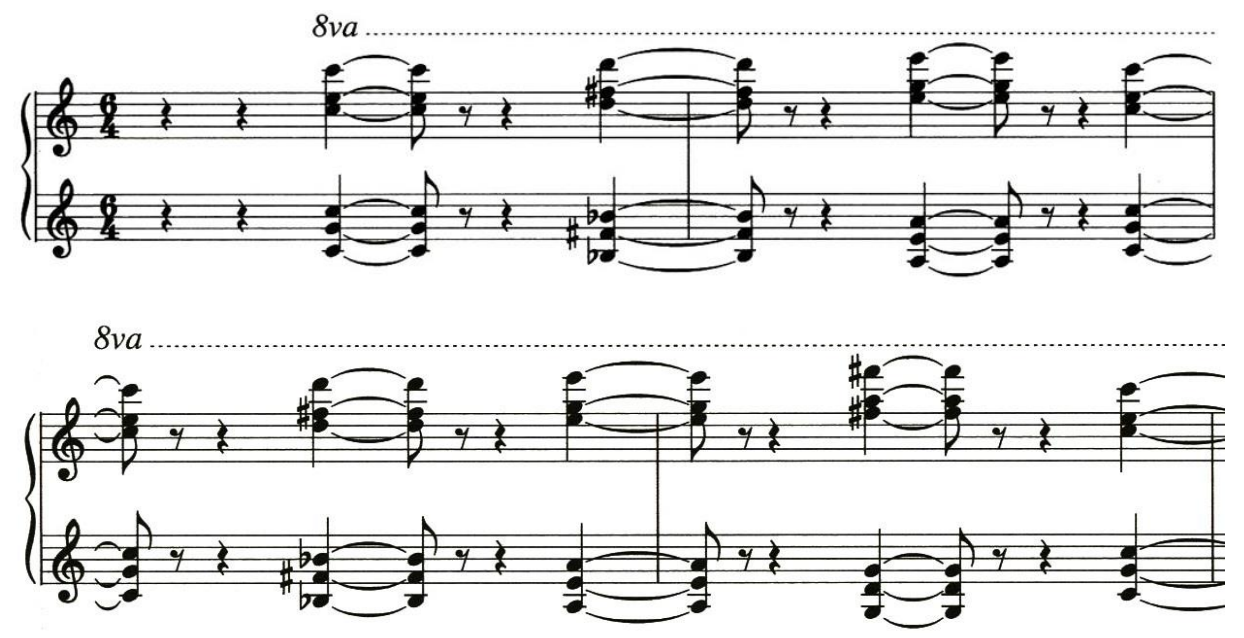
Example 34. Adams, Century Rolls, First Movement, G4, Block 50, mm. 365-366.

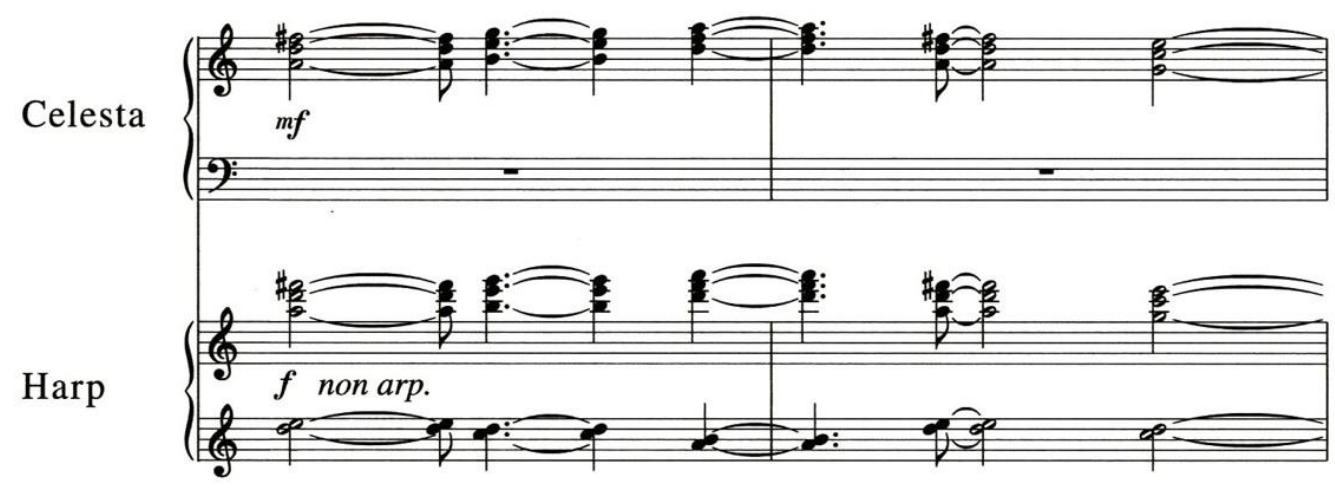

The genealogy of theme $\mathrm{H}$ is traced in Examples 35-39; unlike G, occurrences of $\mathrm{H}$ are confined to rotations 1 and 5 of development, thus framing this section (H1 in rotation 5 is not shown in the sequence of Examples); all of these exemplars show the piano part without accompanying instruments:

Example 35 shows $\mathrm{D} 1$, the progenitor of $\mathrm{H}$, as it appears in the exposition.

Example 36 shows $\mathrm{H} 1$, as it appears in rotation 1 of the development.

It is characterized by a melody that oscillates between two pitches.

Example 37 shows $\mathrm{H} 2$, as it appears in rotation 1 of the development.

It is characterized by the same two pitch melody, but now in hemiola.

Example 38 shows $\mathrm{H} 2$, as it appears in rotation 1 of the development.

It consists of the same hemiola figure, but now with a $\mathrm{C}$ in the bass that anticipates $\mathrm{H} 3$.

Example 39 shows $\mathrm{H} 3$, as it appears in rotation 1 of the development.

Example 35. Adams, Century Rolls, First Movement, D1, Block 5, mm. 68-69

(without accompanying parts).

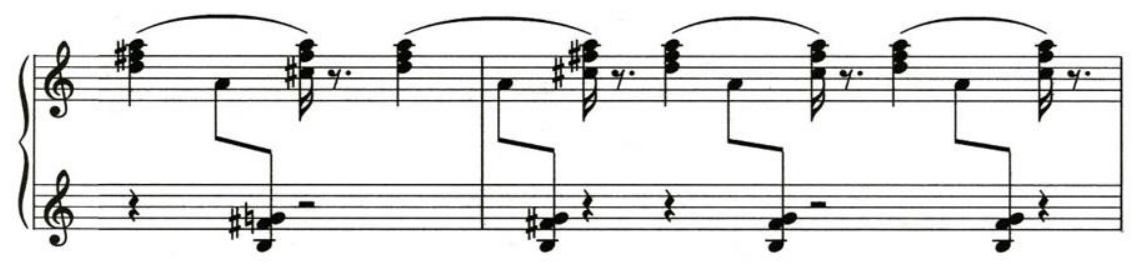


Example 36. Adams, Century Rolls, First Movement, H1, Block 20, mm. 121-124.

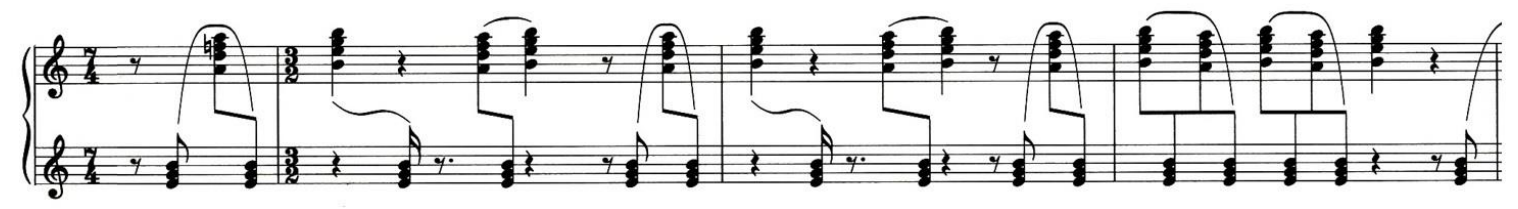

Example 37. Adams, Century Rolls, First Movement, H2, Block 21, mm. 135-136.

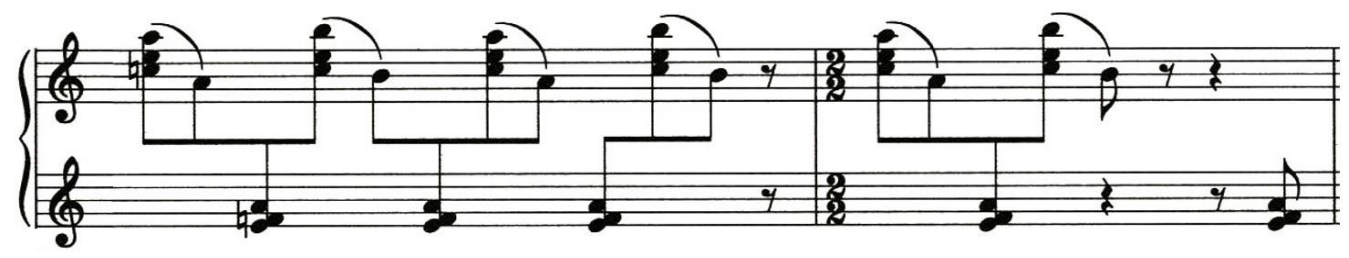

Example 38. Adams, Century Rolls, First Movement, H2, Block 25, m. 152.

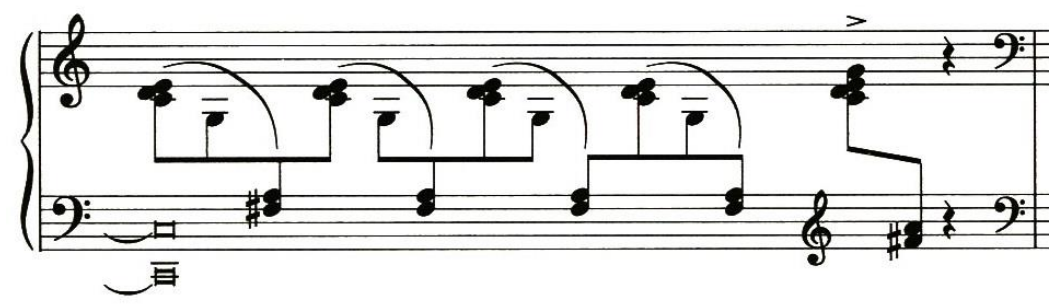

Example 39. Adams, Century Rolls, First Movement, H3, Block 28, mm. 163-165.

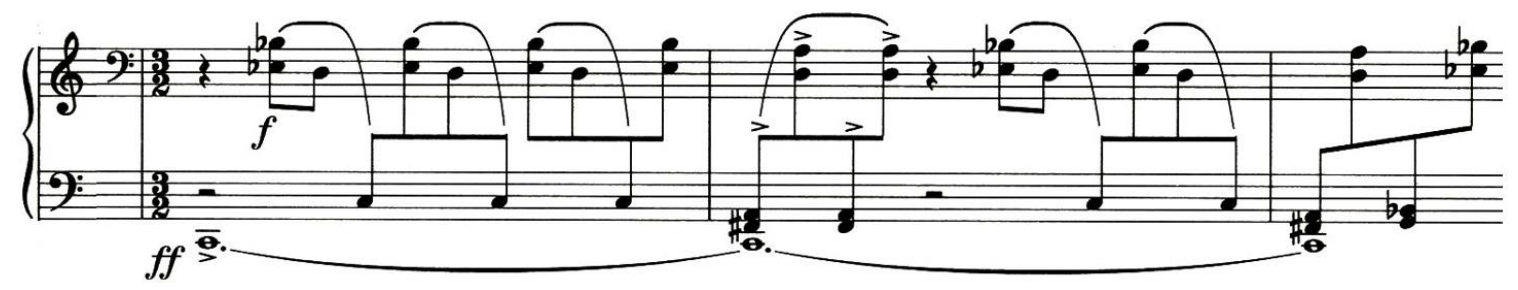

In contrast, the first movement of Son of Chamber Symphony does not feature extensive chains of stratification, as documented by Table 9. Recurrence is comparatively limited. A1 and A3 recur without modification, except for an octave transposition of A1 that transforms it from a bass to treble voice; A2 recurs once in the recapitulation; B returns once in the recapitulation, largely intact; D returns once, largely unmodified. $\mathrm{K}$ and $\mathrm{L}$ are a special case. They recur together once to form a local three part form with the 
recapitulation at the center, as documented by Table 10. $\mathrm{K}$ also appears before and after the three part form. Beyond this, C, E, F, G, H, and I are each stated once.

Therefore, while connection between separated sections in Century Rolls is promoted by shared content, enabling the creation of chains of stratification, connection between separated sections in Son of Chamber Symphony is comparatively limited as a consequence of the extent of unshared, autonomous content.

\subsubsection{Century Rolls, First Movement: Additional Considerations}

This section will briefly discuss a harmonic event of interest in the exposition of the first movement of Century Rolls, and local ternary structures.

Although my analyses have focused on thematic events, a momentary harmonic event in the exposition nevertheless merits attention. Within the prevailing harmonic field of the exposition, B Aeolian, the piano in mm. 50-51 introduces pitch class C (see Example 40). Its appearance in the bass raises the profile of this foreign element.

Example 40. Adams, Century Rolls, First Movement, Block 2, mm. 50-51 (without accompanying parts).

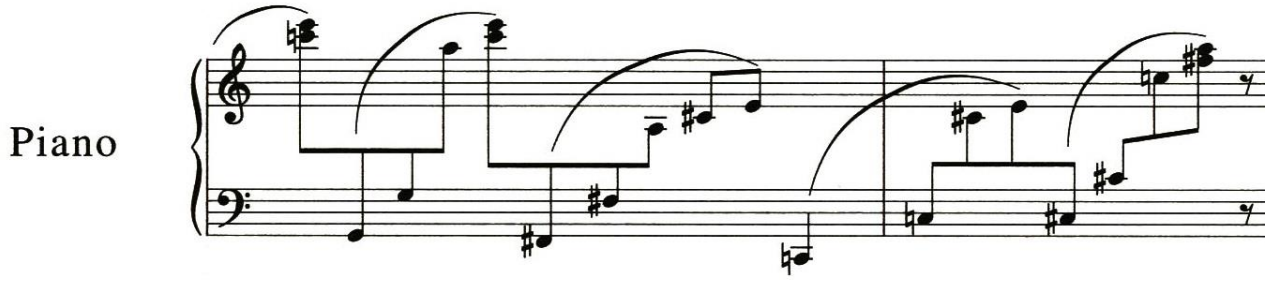

Like a pebble dropped into a pond, this event appears to trigger detectable rippling effects in harmonic content. Later in the exposition, for example, theme D2 in blocks 13 and 17 manifests a C-Major triad (in alternation with a D-Major triad, mm. 94-97, and mm. 106109); and in the development, theme $\mathrm{H} 3$ in block 28 is centered in a $\mathrm{C}$ tonality (mm. 163176). Its appearance in rotation 5 of the development (mm. 300-307), the last rotation before the recapitulation, is most significant. While rotations 1-4 are all initiated by a B- 
Minor sonority with B in the bass, rotation 5 is initiated by a D-Major sonority with $\mathrm{C}$ in the bass. In addition, this surprising harmonic event intersects with the culminating event in the $G$ stratification chain, the appearance of G3, which synthesizes G1 and G2. Together, these events appear calculated to signal the end of the development and the approach of recapitulation. Since my analyses in this paper privilege thematic content, my comments on harmony are therefore incomplete, and can only focus on the most salient of features.

Another device of interest involves what could be described as local ternary structures. This simply involves recurrence of an idea immediately after a single, perhaps two, contrasting idea(s). For the first movement of Century Rolls, these structures are indicated in Table 12 with outlines, and include blocks 8-10, 12-17, 24-26, and 27-29; for the first movement of Son of Chamber Symphony, they are indicated in Table 9, and include blocks 6-8 and 17-26. ${ }^{193}$

These structures introduce formal functions of both contrast and recurrence, and therefore promote a balance between unity and variety, and help integrate content through repetition. Consistent with the conservative and radical approaches to block form shown to be in evidence in Century Rolls and Son of Chamber Symphony respectively, the former work makes greater use of this device than the latter.

\subsubsection{Century Rolls, First Movement: Summary}

The thematic content of this movement is substantially integrated, and is therefore congruent to one of the major values of the sonata form process that it simulates. A major exception is the absence of themes A and B in the development, but at least stratification from theme $\mathrm{D}$ to themes $\mathrm{G}$ and $\mathrm{H}$ link the exposition to the development, and $\mathrm{A}, \mathrm{B}$, and $\mathrm{G}$ appear in the recapitulation, thus adhering to the sonata form process. These aspects of the form are largely traditional.

\footnotetext{
${ }^{193}$ Section 3.3 of this paper included a discussion of the special formal function of the ternary form featured in blocks 17-26.
} 
Much of the thematic, as well as harmonic, content of the movement is static and deployed in blocks, and is therefore modernist. This modernism, however, is tempered by enough repetition and recurrence of themes that blocks or moments in the form are largely integrated, rather than autonomous, events. The potential for rhetorical discontinuity between blocks of content is subverted through a steady sense of pulse and shared harmonic content, though this isn't always the case. In addition, juxtaposed blocks are sometimes seamlessly linked to support a traditional musical discourse, such as occurs in rotations 3 and 4 of the development which are united by an uninterrupted stream of scales and arpeggios. These scales and arpeggios provide momentum toward rotation 5 and recapitulation. So even though the block aspects of the form are modernist, the thematic content nevertheless largely adheres to traditional sonata form values in terms of its formal integration and rhetoric, and therefore belies the modernism implicit in the movement's block structures.

Unlike movement one of Son of Chamber Symphony, movement one of Century Rolls demonstrates in aggregate a traditional emphasis on unity in terms of its thematic content. It also demonstrates something similar to harmonic unity in the way that the music cycles back to a B-Minor sonority, which is in evidence throughout the exposition, at the beginning of rotations 1-4 in the development, and at the beginning of the recapitulation. These harmonic events could be said to be linked by association, but not prolongation. Overall, this movement is fascinating in the way that its essential traditionalism is expressed through a filter of modernism.

\subsection{Disunity and Analysis: Summary}

The content of chapter 3 in this paper, which includes an outline of a method for analyzing non-formalist, discontinuous music, and two analyses based on the method, is a culmination of the ideas in chapter 2 , so this summary will review both chapters.

Since the evidence suggests that music by Adams composed after Phrygian Gates (19771978) does not conform to formalist values (at least some of it), the problem emerges of 
how to analyze and understand such works, since non-formalist music is disunified, at least as understood in the traditional context of musical formalism. To address this problem, a systematic survey of tonal practices in three typologies (tonal formalism, post-tonal formalism, and post-tonal non-formalism) was conducted in chapter 2 to understand how closure and hierarchy are operative in each. Since comprehensive closure and hierarchy are indicators of formalism, the identification of how and where these indicators are disrupted in the course of the survey should bring into focus the challenges involved with analyzing post-tonal non-formalist music, and lead to an understanding of what analytical goals are appropriate for its elucidation.

It was discovered that in post-tonal non-formalist music a comprehensive teleology of closure and a comprehensive tonal hierarchy, or prolongation, are untenable and have to be abandoned.

Based on analytical work by Jonathan Cross outlined in section 2.3.4, in the absence of a process of closure, an analysis of a disunified piece can instead focus on assessing the balance among integrative and disintegrative elements. Integrative features of music tend to repeat and recur, and are dependent; disintegrative elements tend to not repeat, and are autonomous. An analytical strategy devised by Edward T. Cone, that he labeled "stratification," is applied by Cross to show how it can demonstrate the integration of chronologically non-contiguous, or discontinuous content.

Based on analytical work by Joseph Straus outlined in section 2.4.4, in the absence of a hierarchy, we cannot make claims of prolongation, only ones of association. By confronting the necessity to scale back claims of prolongation to association, we are also compelled to confront a type of analysis that engages with musical disunity, since unity requires prolongation in order to rationalize how the variety of musical content on the surface of a work is an organic manifestation of a single idea.

Based on the findings in this paper, an analysis of a non-formalist work will therefore identify sections based on content arranged in a flat, non-hierarchical sequence, detect 
where and how content recurs through association and stratification, and assess the balance between integrative and disintegrative elements. Balance assessment of this kind occurs between reciprocals of unity and disunity on a continuum, rather than in polarity. An important analytical question to answer regarding a piece is not whether it is unified or disunified, but rather what is the balance between unity and disunity. In the first case, a traditional approach, analytical questions tend to cease once the threshold from unity to disunity is crossed; in the latter case, they are only beginning.

Sections 2.6.1 through 2.6.4 provide a historical context for disunified music in practice and theory through introducing moment form theory, and also demonstrate the utility moment form theory has had for analyzing the music of Debussy, and how it could be similarly adapted for the music of Adams.

Finally, in chapter 3 I outlined a method for conducting analyses of non-formalist music based on the results of the survey in chapter 2 (summarized in 2.5.1, "Principles of Disunity") and on the principles of moment form theory; the method was then applied to two works by John Adams, including the first movements of Son of Chamber Symphony (2007) and Century Rolls (1996). Assessing the balance of thematic integration or disintegration proved to be a key part of the analytical method I created, helping me arrive at conclusions regarding their formal structure. This assessment was also informed by expectations engendered by the sonata form process that both movements participate in. In the end, the analytical process enabled me to explore and describe with specificity the balance between unity and disunity in these works, and to explain their distinguishing characteristics, including the radical discontinuity and pluralistic logic of Son of Chamber Symphony, and the more traditional thematic integration of Century Rolls. These results are included in the summary statements of sections 3.3.2 and 3.4.7 respectively. 


\section{Bibliography}

"BSO Hangout with Marin Alsop, John Adams and Tim McAllister." YouTube, posted 21 September 2013, accessed 18 June 2014, https://www.youtube.com/watch?v=eDlYWjCgq2M.

"Lecture 1 [PARTE 1/4] Stockhausen Karlheinz - English Lectures (1972)." YouTube, posted 25 January 2013, accessed 4 February 2016, https://www.youtube.com/watch?v=1YmMXB0e17E.

Adams, John. Century Rolls. New York: Hendon Music, 1997, 2006.

Adams, John. Hallelujah Junction: Composing an American Life. New York: Farrar, Straus \& Giroux, 2008.

Adams, John. Liner notes to John Adams: Son of Chamber Symphony, String Quartet. Nonesuch 523014-2. CD. 2011.

Adams, John. Phrygian Gates. New York: Associated Music Publishers, 1983.

Adams, John. Son of Chamber Symphony. New York: Hendon Music, 2007.

Albaugh, Michael D. "Musical Form and Joseph Schwantner's Aftertones of Infinity." DMA, West Virginia University, 2004.

Aldwell, Edward, Allen Cadwallader, and Carl Schachter. "Diatonic Sequences." In Harmony and Voice Leading, 301-329. Boston: Schirmer, 2011.

Babbbitt, Milton. Milton Babbitt: Words About Music. Edited by Stephen Dembski and Joseph N. Straus. Madison: University of Wisconsin Press, 1987.

Bailey, Robert, ed. Prelude and Transfiguration from Tristan and Isolde. New York: Norton, 1985.

Bailey, Robert. "The Structure of the 'Ring' and Its Evolution." 19th-Century Music, vol. 1, no. 1 (July 1977): 48-61.

Bernard, Jonathan W. "Theory, Analysis, and the 'Problem' of Minimal Music." In Concert Music, Rock, and Jazz since 1945: Essays and Analytical Studies, edited by Elizabeth West Marvin and Richard Hermann, 259-284. Rochester: University of Rochester Press, 1995.

Boss, Jack F. "'Away with Motivic Working?' Not So Fast: Motivic Processes in Schoenberg's op. 11, no. 3." Music Theory Online, vol. 21, no. 3 (September 2015). 
Brinkmann, Reinhold. Arnold Schönberg: Drei Klavierstücke Op. 11: Studien zur frühen Atonalität bei Schönberg. Beihefte zum Archiv für Musikwissenschaft, vol. 7. Wiesbaden: Franz Steiner Verlag, 1969.

Buchanan, Herbert H. "A Key to Schoenberg's 'Erwartung' (Op. 17)," Journal of the American Musicological Society, 20, no. 3 (1967): 434-449.

Cahill, Sarah. "Century Rolls." In The John Adams reader: Essential writings on an American composer, edited by Thomas May, 160-162. Pompton Plains, NJ: Amadeus Press, 2006.

Christensen, Thomas and and Graham Sadler. "Rameau, Jean-Philippe." Grove Music Online. Accessed September 15, 2016. http://www.oxfordmusiconline.com

Cone, Edward T. "Stravinsky: The Progress of a Method." Perspectives of New Music, vol. 1, no. 1 (Autumn 1962): 18-26.

Cone, Edward T. "The Uses of Convention: Stravinsky and His Models." The Musical Quarterly, vol. 48 (July, 1962): 287-299.

Cook, Nicholas. A Guide to Musical Analysis. New York: Norton, 1987.

Cross, Jonathan. The Stravinsky Legacy. New York: Cambridge University Press, 2005.

Dahlhaus, Carl. "Issues in Composition." In Between Romanticism and Modernism, translated by Mary Whitall, 40-78. Berkeley and Los Angeles: University of California Press, 1989.

Darcy, Warren. "Die Zeit ist da: Rotational Form and Hexatonic Magic in Act 2 Scene 1." In A Companion to Wagner's Parsifal, 215-241. Rochester, NY: Camden House, 2005.

Fink, Robert. "Going Flat: Post-Hierarchical Music Theory and the Musical Surface." In Rethinking Music, ed. Nicholas Cook and Mark Everist, 102-137. New York: Oxford University Press, 2001.

Friedheim, Philip. "Rhythmic Structure in Schoenberg's Atonal Compositions," Journal of the American Musicological Society, 19, no. 1 (1966): 59-72.

Fyr, Kyle. "Proportion, Temporality, and Performance Issues in Piano Works of John Adams." PhD diss., Indiana University, 2011.

Haimo, Ethan. Schoenberg's Transformation of Musical Language. New York: Cambridge University Press, 2006. 
Hamm, Charles. "Privileging the Moment: Cage, Jung, Synchronicity, Postmodernism." The Journal of Musicology, vol. 15, no. 2 (Spring 1997): 278-289.

Hepokoski, James, and Warren Darcy. Elements of Sonata Theory: Norms, Types, and Deformations in the Late-Eighteenth-Century Sonata. New York: Oxford University Press, 2006.

Hepokoski, James. "Musical Process and Architecture: A Proposed Overview." In Sibelius: Symphony No. 5, 58-84. New York: Cambridge University Press, 1993.

Hopkins, Robert G. Closure and Mahler's Music: The Role of Secondary Parameters. Philadelphia: University of Pennsylvania Press, 1990.

Horlacher, Gretchen G. Building Blocks: Repetition and Continuity in the Music of Stravinsky. New York: Oxford University Press, 2011.

Jemian, Rebecca, and Anne Marie De Zeeuw. "An Interview With John Adams." Perspectives of New Music, vol. 34, no. 2 (June 1, 1996): 88-104.

Kinderman, William, and Harald Krebs, eds. The Second Practice of Nineteenth-Century Tonality. Lincoln: University of Nebraska Press, 1996.

Kramer, Jonathan D. "Moment Form in Twentieth Century Music." The Musical Quarterly, vol. 64, no. 2 (April 1978): 177-194.

Kramer, Jonathan. The Time of Music: New Meanings, New Temporalities, New Listening Strategies. New York: Schirmer Books, 1988.

Krebs, Harald. "Tonal Structure in Nielsen's Symphonies: Some Addenda to Robert Simpson's Analyses." In The Nielsen Companion, edited by Mina Miller, 208-249. Portland, Oregon: Amadeus Press, 1994.

Lankov, Jeff. "The Solo Piano Compositions of John Adams: Style, Analysis, and Performance." PhD diss., New York University, 2014.

Lewis, Christopher O. Tonal Coherence in Mahler's Ninth Symphony. Ann Arbor, Michigan: UMI Research Press, 1984.

McConville, Brendan. "A 'Simple Composition' of Charles Wuorinen: Isomorphism, Self-Similarity, and Nesting in Cello Variations." Theory and Practice, vol. 36 (October 2011): 151-177.

Mead, Andrew. "Large-Scale Strategy in Arnold Schoenberg's Twelve-Tone Music." Perspectives of New Music, vol. 24, no. 1 (Autumn-Winter, 1985): 120-157.

Newlin, Dika. Bruckner, Mahler, Schoenberg. New York: W. W. Norton, 1978. 
Opper, Jacob. "Musical Classicism Reflected in Enlightenment Mentality." In Science and the Arts: A Study in Relationships from 1600-1900, 88-125. Cranbury, New Jersey: Associated University Presses, 1973.

Paddison, Max. Adorno's Aesthetics of Music. Cambridge: Cambridge University Press, 1993.

Pellegrino, Catherine Ann. "Formalist Analysis in the Context of Postmodern Aesthetics: The Music of John Adams as a Case Study." PhD diss., Yale University, 1999.

Pellegrino, Catherine. "Aspects of Closure in the Music of John Adams." Perspectives of New Music, vol. 40, no. 1 (January 1, 2002): 147-175.

Pomeroy, Boyd. "Tales of Two Tonics: Directional Tonality in Debussy's Orchestral Music." Music Theory Spectrum, vol. 26, no. 1 (2004): 87-118.

Potter, Keith Potter. Four Musical Minimalists: La Monte Young, Terry Riley, Steve Reich, Philip Glass. New York: Cambridge University Press, 2000.

Randel, Don, ed. The New Harvard Dictionary of Music. Tenth ed. Cambridge, Massachusetts: Belknap, 2001.

Reich, Steve. "Music as a Gradual Process." In Perceptible Processes: Minimalism and the Baroque, ed. Claudia Swan, 56. New York: Eos Music, 1997.

Reich, Steve. Interview by Jonathan Cott. Liner notes to Steve Reich: Works 1965-1995. Nonesuch 79451-2. CD. 1997.

Rothstein, William and Donald Martino. "Linear Structure in the Twelve-Tone System: An Analysis of Donald Martino's 'Pianississimo'." Journal of Music Theory, vol. 24, no. 2 (Autumn 1980): 129-165.

Schoenberg, Arnold. "Composition With Twelve Tones (2)." In Style and Idea, ed. Leonard Stein, 245-249. Berkeley and Los Angeles: University of California Press, 1984.

Schoenberg, Arnold. Theory of Harmony. Trans. by Roy E. Carter. Los Angeles and Berkeley: University of California Press, 1983.

Schwarz, K. Robert. "Process vs. Intuition in the Recent Works of Steve Reich and John Adams." American Music, vol. 8, no. 3 (September 1, 1990): 245-273.

Shultis, Christopher. "Silencing the Sounded Self: John Cage and the Intentionality of Nonintention." Musical Quarterly, vol. 79, no. 2 (Summer 1995): 312-350. 
Smith, Barbara Herrnstein. Poetic Closure: A Study of How Poems End. Chicago: University of Chicago Press, 1968.

Solie, Ruth A. "The Living Work: Organicism and Musical Analysis." 19th Century Music, vol. 4, no. 2 (Autumn, 1980): 147-156.

Stockhausen, Karlheinz, and Jerome Kohl, "Stockhausen on Opera," Perspectives of New Music, 23, no. 2 (1985), 25.

Stockhausen, Karlheinz. "Momentform: Neue Zusammenhange zwischen Aufführungsdauer, Werkdauer und Moment." In Texte zur elektronischen undinstrumentalen Musik, Vol. 1, 189-210. Cologne: DuMont, 1963.

Straus, Joseph. "A Principle of Voice Leading in the Music of Stravinsky." Music Theory Spectrum, vol. 4 (Spring 1982): 106-124.

Straus, Joseph. "Atonal Composing-Out." In Order and Disorder: Music-Theoretical Strategies in 20th-Century Music, 31-51. Leuven, Flanders: Leuven University Press, 2004.

Straus, Joseph. "Centricity, Referential Collections, and Triadic Post-Tonality." In Introduction to Post-Tonal Theory, 130-181. Upper Saddle River, New Jersey: Pearson Education, 2005.

Straus, Joseph. "Middleground Misreadings." In Remaking the Past: Musical Modernism and the Influence of the Tonal Tradition, 169-185. Cambridge: Harvard University Press, 1990.

Straus, Joseph. "The Problem of Prolongation in Post-Tonal Music." Journal of Music Theory, vol. 31, no. 1 (Spring 1987): 1-21.

Straus, Joseph. Remaking the Past: Musical Modernism and the Influence of the Tonal Tradition. Cambridge: Harvard University Press, 1990.

Stuckenschmidt, H.H. Arnold Schoenberg. Translated by Edith Temple Roberts and Humphrey Searle. New York: J. Calder, 1959.

Van Den Toorn, Pieter C. Music, Politics, and the Academy. Berkeley and Los Angeles: University of California Press, 1995.

van Geest, William. "The Concept of Unity in Musical Analysis: Some Ontological Issues." Paper presented at the 5th International Conference of Students of Systematic Musicology, Montreal, Canada, May 24-26, 2012. 
Wadsworth, Benjamin Kay. "Directional Tonality in Schumann's Early Works." Music Theory Online, vol. 18, no. 4 (December 2012): 1-15. Accessed March 24, 2015. http://www.mtosmt.org/issues/mto.12.18.4/mto.12.18.4.wadsworth.php

Walker, Alan. "Chopin and Musical Structure: An Analytical Approach." In The Chopin Companion: Profiles of the Man and Musician, edited by Alan Walker, 227-257. New York: W.W. Norton, 1973.

Wheeldon, Marianne. "Interpreting Discontinuity in the Late Works of Debussy." Current Musicology, no. 77 (Spring 2004): 97-115. 